\title{
Caustic-Side Solvent Extraction: Chemical and Physical Properties of the Optimized Solvent
}

October 2002

Prepared by

Lætitia H. Delmau

Joseph F. Birdwell, Jr.

Peter V. Bonnesen

Linda J. Foote

Tamara J. Haverlock

Leon N. Klatt

Douglas D. Lee

Ralph A. Leonard

Tatiana G. Levitskaia

Michael P. Maskarinec

Bruce A. Moyer

Frederick V. Sloop, Jr.

Bruce A. Tomkins 


\title{
DOCUMENT AVAILABILITY
}

Reports produced after January 1, 1996, are generally available free via the U.S. Department of Energy (DOE) Information Bridge:

Web site: http://www.osti.gov/bridge

Reports produced before January 1,1996, may be purchased by members of the public from the following source:

\author{
National Technical Information Service \\ 5285 Port Royal Road \\ Springfield, VA 22161 \\ Telephone: 703-605-6000 (1-800-553-6847) \\ TDD: $703-487-4639$ \\ Fax: 703-605-6900 \\ E-mail: info@ntis.fedworld.gov \\ Web site: http://www.ntis.gov/support/ordernowabout.htm
}

Reports are available to DOE employees, DOE contractors, Energy Technology Data Exchange (ETDE) representatives, and International Nuclear Information System (INIS) representatives from the following source:

Office of Scientific and Technical Information

P.O. Box 62

Oak Ridge, TN 37831

Telephone: 865-576-8401

Fax: 865-576-5728

E-mail: reports@adonis.osti.gov

Web site: http://www.osti.gov/contact.html

\begin{abstract}
This report was prepared as an account of work sponsored by an agency of the United States Government. Neither the United States government nor any agency thereof, nor any of their employees, makes any warranty, express or implied, or assumes any legal liability or responsibility for the accuracy, completeness, or usefulness of any information, apparatus, product, or process disclosed, or represents that its use would not infringe privately owned rights. Reference herein to any specific commercial product, process, or service by trade name, trademark, manufacturer, or otherwise, does not necessarily constitute or imply its endorsement, recommendation, or favoring by the United States Government or any agency thereof. The views and opinions of authors expressed herein do not necessarily state or reflect those of the United States Government or any agency thereof.
\end{abstract}


ORNL/TM-2002/190

\title{
CAUSTIC-SIDE SOLVENT EXTRACTION : CHEMICAL AND PHYSICAL PROPERTIES OF THE OPTIMIZED SOLVENT
}

Lætitia H. Delmau, Joseph F. Birdwell, Jr., Peter V. Bonnesen, Linda J. Foote, Tamara J. Haverlock, Leon N. Klatt, Douglas D. Lee, Ralph A. Leonard, Tatiana G. Levitskaia, Michael P. Maskarinec, Bruce A. Moyer, Frederick V. Sloop, Jr., and Bruce A. Tomkins

Date Published: October 2002

\author{
Prepared by \\ OAK RIDGE NATIONAL LABORATORY \\ P.O. Box 2008 \\ Oak Ridge, Tennessee 37831-6285 \\ managed by \\ UT-Battelle, LLC \\ for the \\ U.S. DEPARTMENT OF ENERGY \\ under contract DE-AC05-00OR22725
}





\section{CONTENTS}

\section{Page}

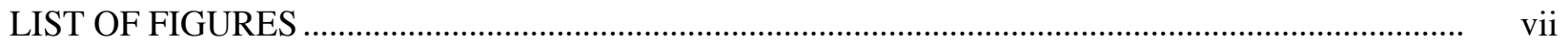

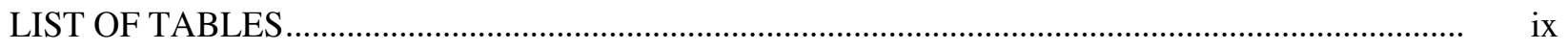

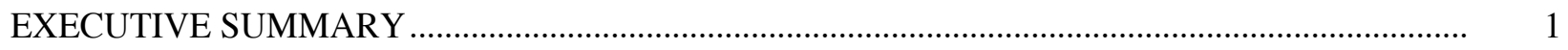

ABSTRACT

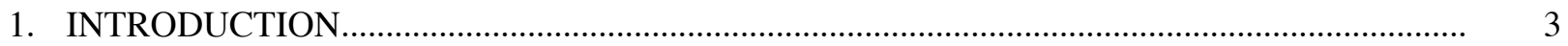

2. CAUSTIC-SIDE SOLVENT EXTRACTION SOLVENT COMPOSITION

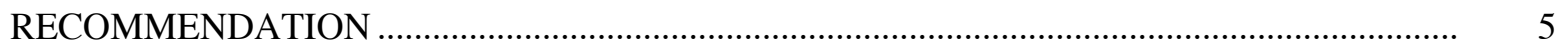

2.1 BASIS FOR TASK AND SUMMARY RECOMMENDATION ............................................. 5

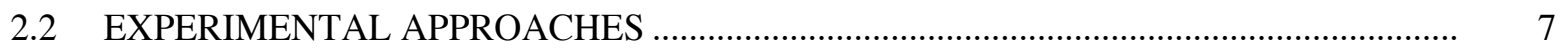

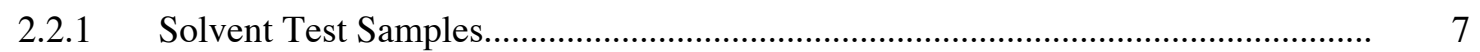

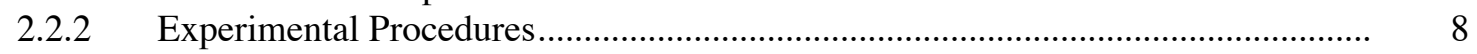

2.2.2.1 BOBCalixC6 solubility studies .............................................................. 8

2.2.2.2 Extraction, scrub, and strip protocol...................................................... 8

2.2.2.3 Third-phase determination ................................................................. 9

2.2.2.4 Dispersion-number measurement ......................................................... 9

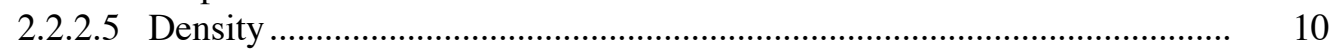

2.2.2.6 Viscosity ........................................................................................ 10

2.2.2.7 Surface tension and interfacial tension ...................................................... 11

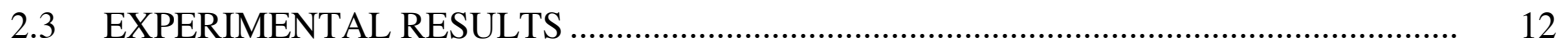

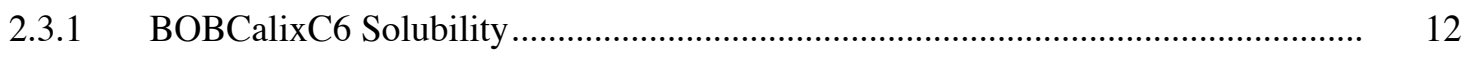

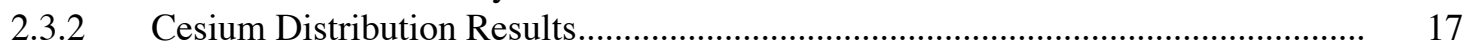

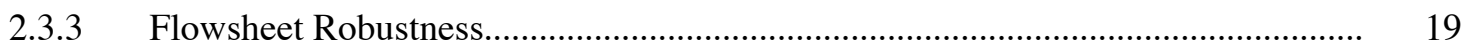

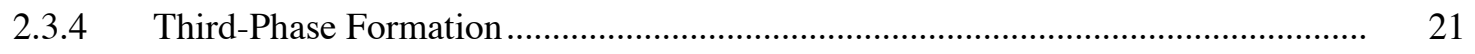

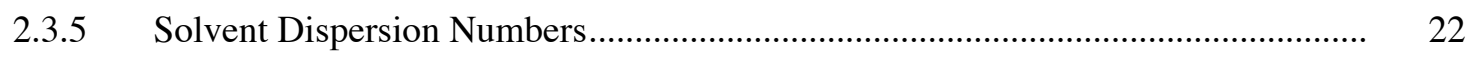

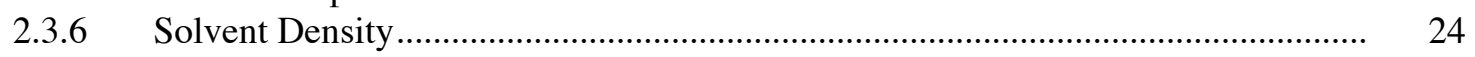

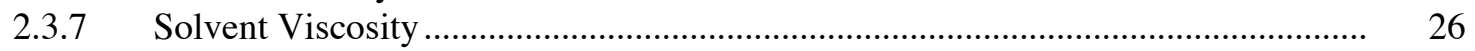

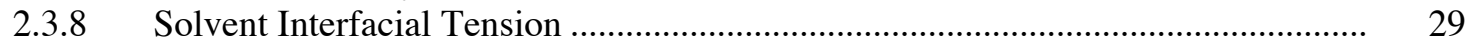

2.4 SOLVENT-COMPOSITION RECOMMENDATION PROCESS ….................................. 32

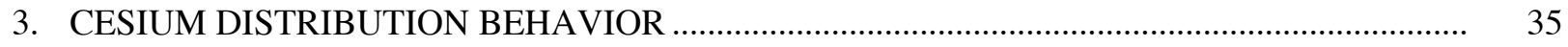

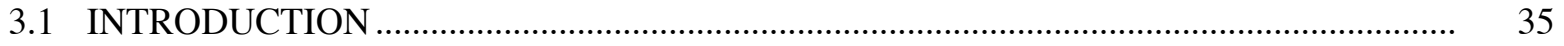

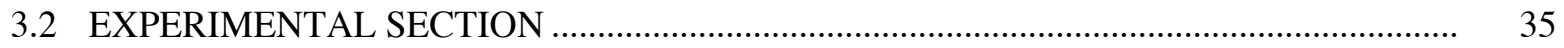

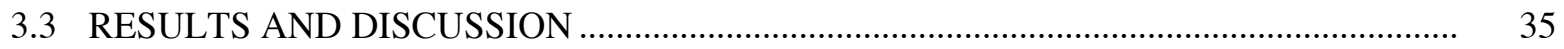

3.3.1 Extraction, Scrub, and Strip Performance .................................................................. 35

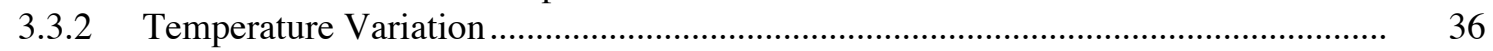

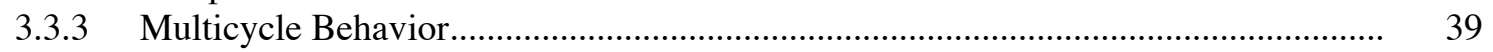

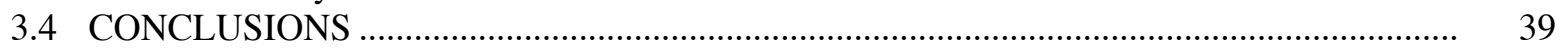

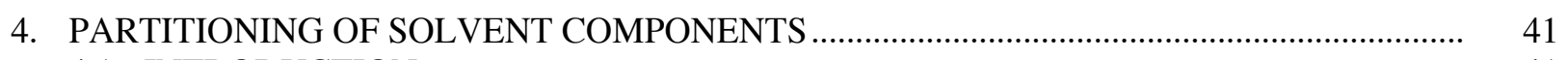

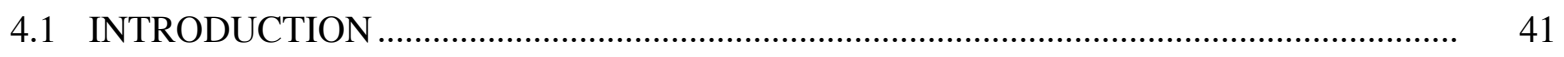

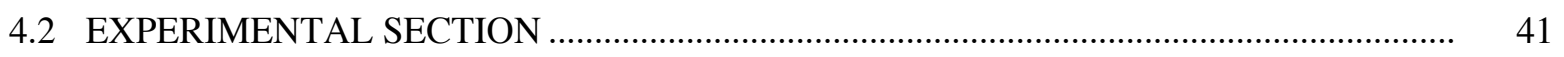




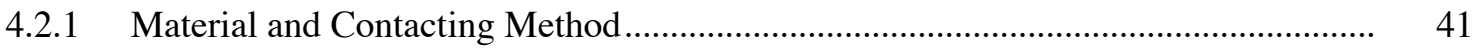

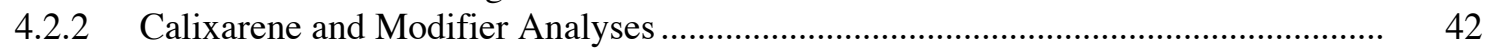

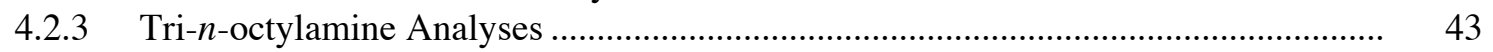

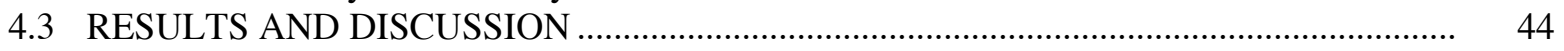

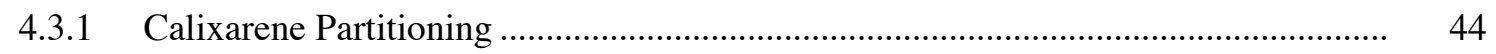

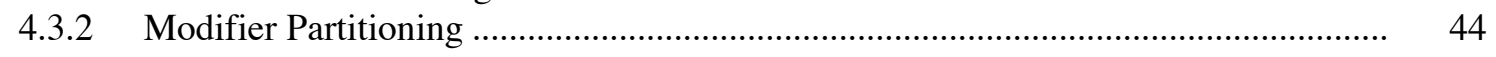

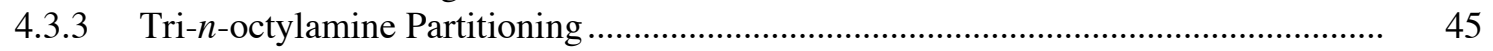

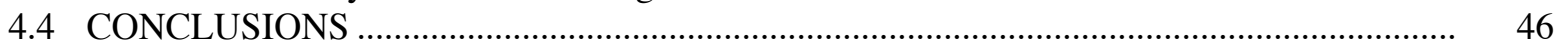

5. DISTRIBUTION OF MINOR ORGANIC AND INORGANIC COMPONENTS......................... 49

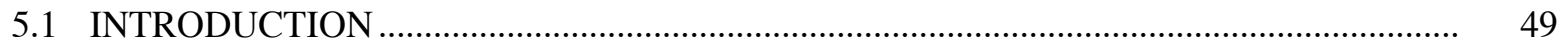

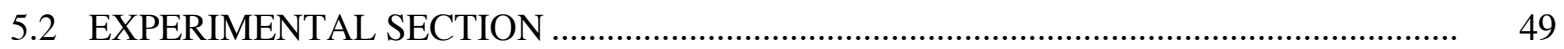

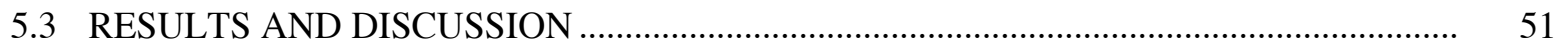

5.3.1 Distribution of Dibutylphosphate …..................................................................... 51

5.3.2 Distribution of Other Metals and Selected Radionuclides ........................................ 51

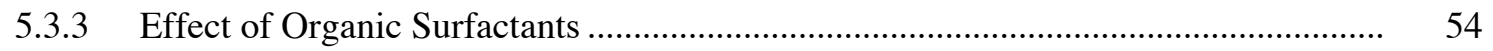

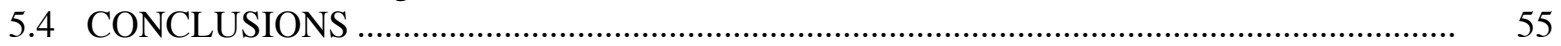

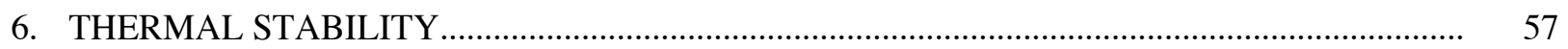

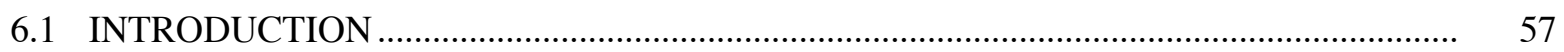

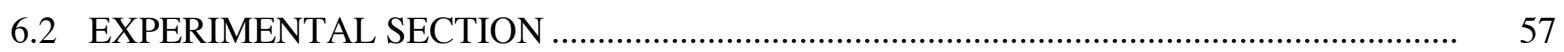

6.2.1 Materials, Equipment, and Contacting Method ..................................................... 57

6.2.2 ESS Analyses of Phase-Stability Samples ............................................................ 58

6.2.3 HPLC Analyses of Phase-Stability Samples ............................................................ 59

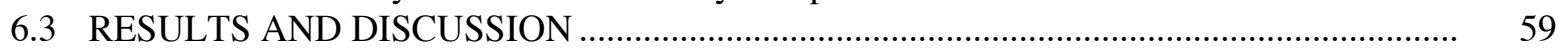

6.3.1 Phase Stability at Low Temperature....................................................................... 59

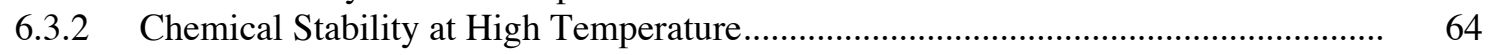

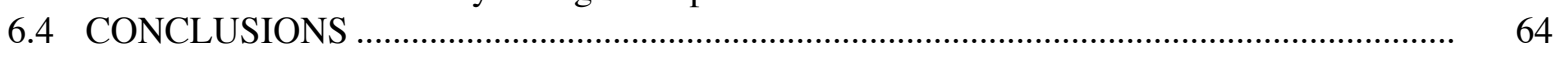

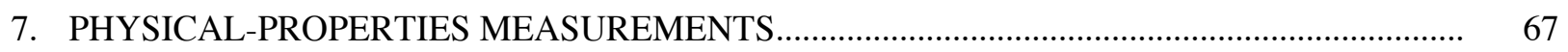

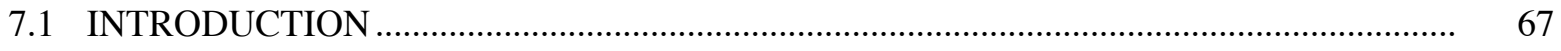

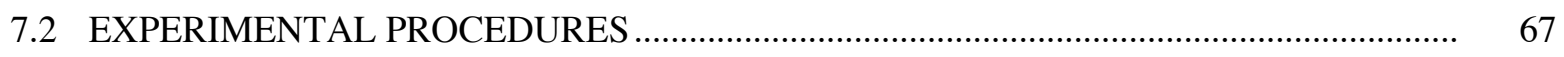

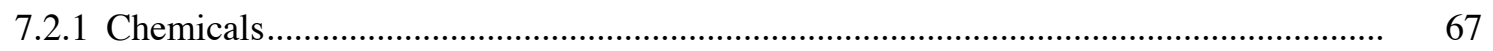

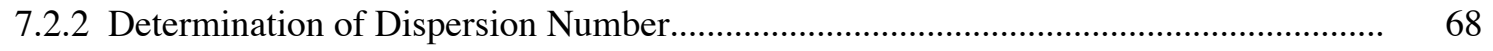

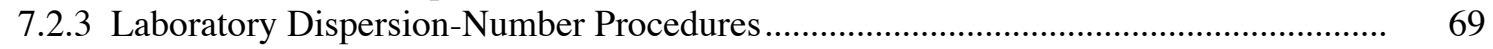

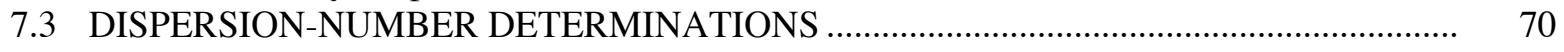

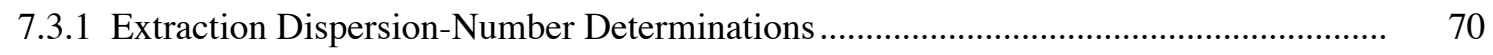

7.3.2 Scrubbing-Condition Dispersion-Number Determinations .......................................... 71

7.3.3 Stripping-Condition Dispersion-Number Determinations ............................................... 74

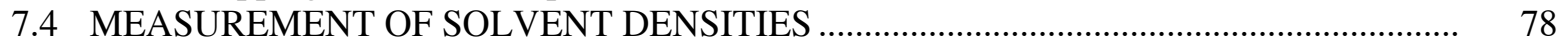

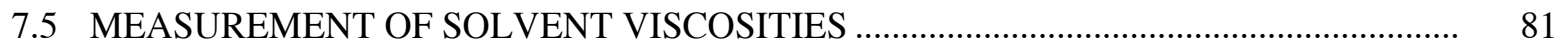

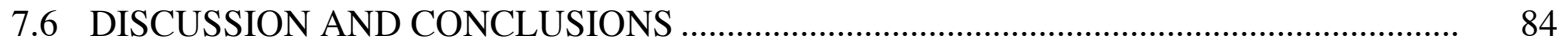

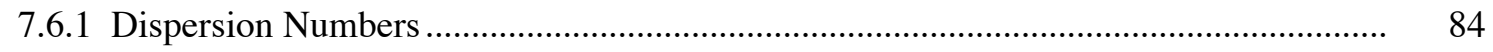

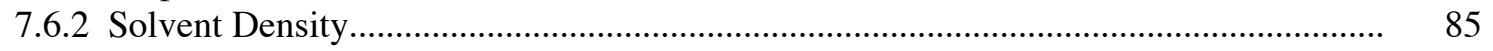

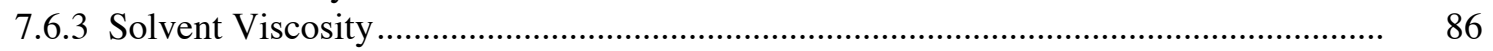

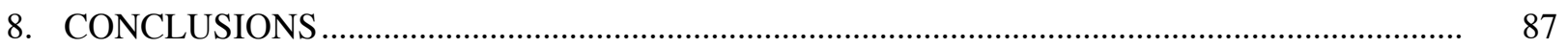

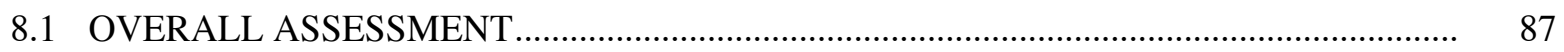

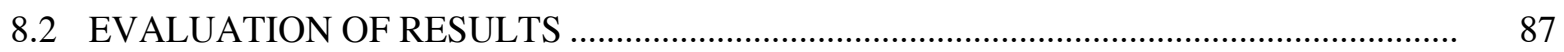

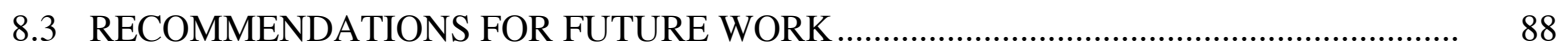

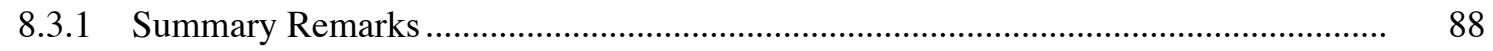




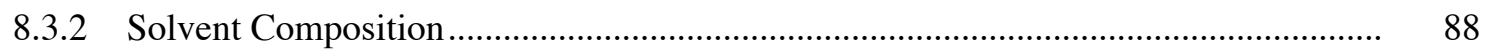

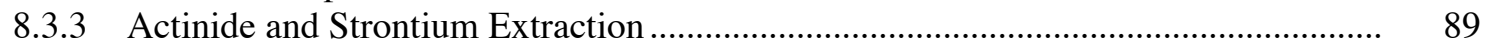

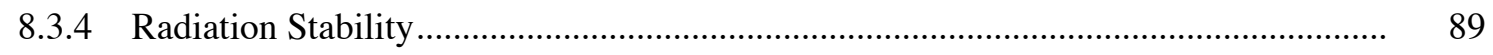

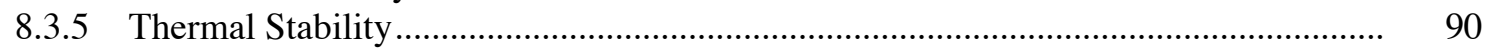

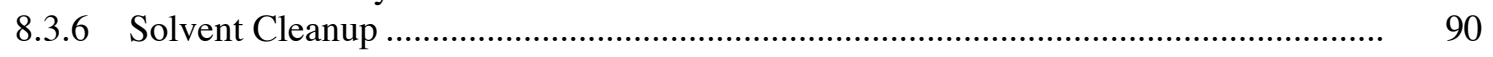

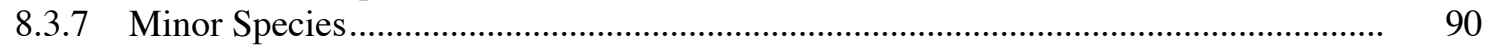

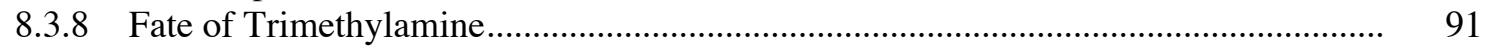

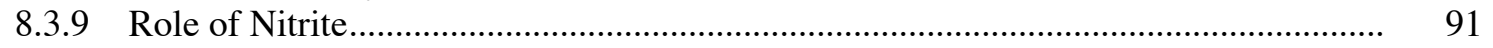

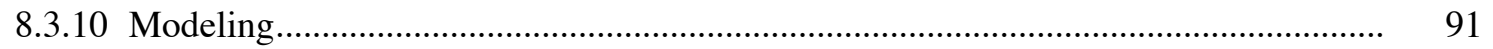

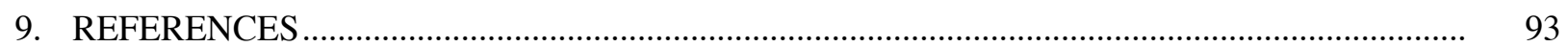

APPENDIX A. PREDICTED $D_{\mathrm{Cs}}$ VALUES USING THE log VERSUS log RELATIONSHIPS BETWEEN $D_{\mathrm{Cs}}$ VALUES AND BOBCALIXC6 AND Cs-7SB MODIFIER CONCENTRATIONS.... 99 



\section{LIST OF FIGURES}

Figure

Page

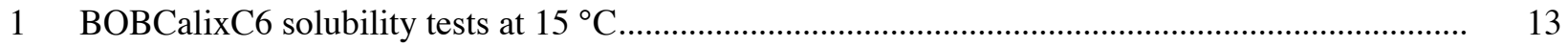

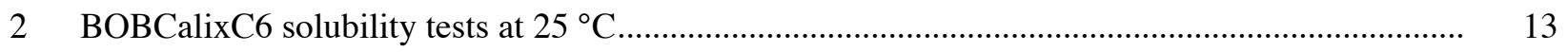

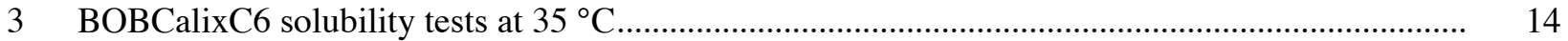

4 Comparison of BOBCalixC6 solubility data ................................................................................ 15

5 CSSX solvent dispersion numbers for extraction, scrub, and strip conditions at baseline O:A ratios 23

6 CSSX solvent dispersion numbers for solvent wash with dilute $\mathrm{NaOH}$............................................ 23

7 CSSX solvent dispersion numbers for solvent washing as a function of $\mathrm{NaOH}$ concentration ........ 24

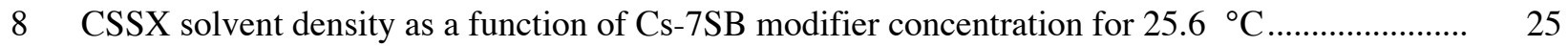

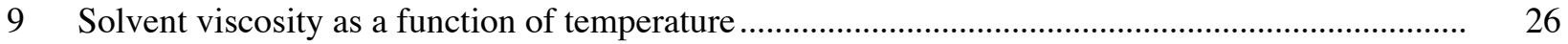

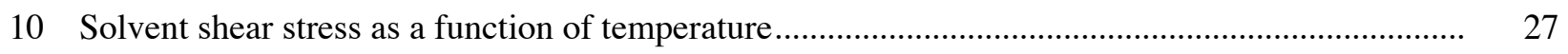

11 Solvent and process solution surface tension ............................................................................

12 Solvent interfacial tension in extraction, scrub, and strip contacts .............................................. 32

13 ESS tests at three different temperatures ...................................................................................

14 ESS protocol for optimized solvent phase-stability test.............................................................. 58

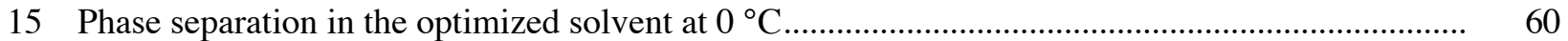

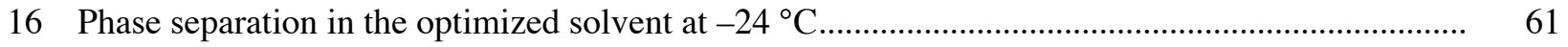

17 Gel-like material formed during dispersion-number determinations...............................................

18 Graph of CSSX solvent extraction equilibration dispersion numbers ...........................................

19 Graph of CSSX solvent scrub equilibration dispersion numbers ..................................................... 76

20 Graph of CSSX solvent strip equilibration dispersion numbers ......................................................

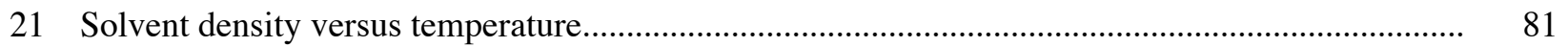

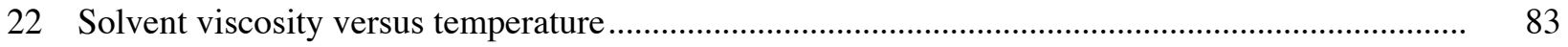

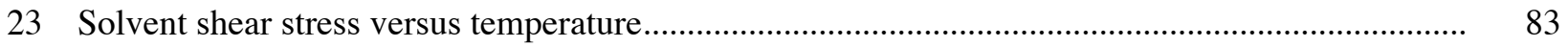





\section{LIST OF TABLES}

Table

Page

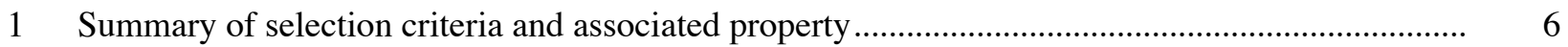

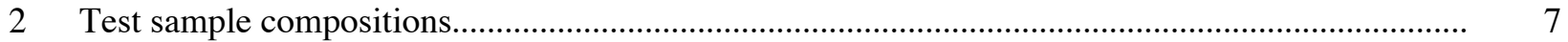

3 Validation data for the modified ESS protocol.............................................................................

$4 \quad$ BOBCalixC6 solubility data from FY 2001 study ....................................................................... 15

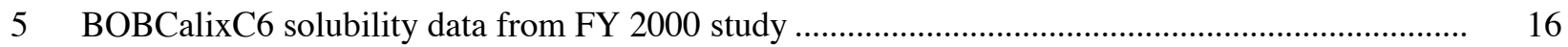

$6 \quad$ ESS results obtained with constant TOA concentration ............................................................... 18

$7 \quad$ ESS results obtained with two selected solvents with variable TOA concentrations ....................... 19

8 Calculated robustness for various CSSX solvent compositions .................................................... 20

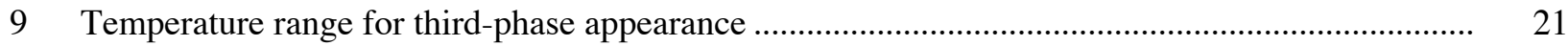

10 Dispersion numbers for extraction, scrub, and stripping of CSSX solvents ................................... 22

11 Dispersion numbers for washing of CSSX solvents B001107-3-4 and B001107-3-5 .................... 24

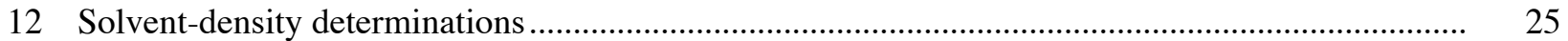

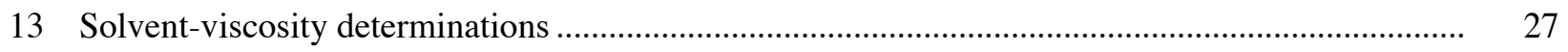

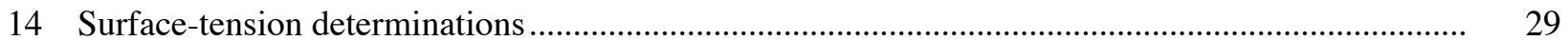

15 Interfacial tension versus simulant..........................................................................................

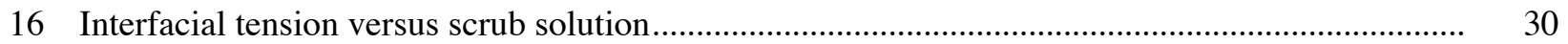

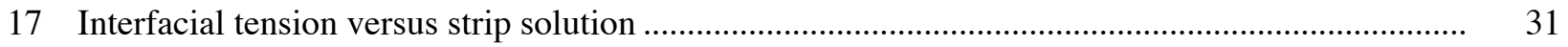

18 Cesium batch ESS performance for previous-baseline and optimized solvents ............................ 36

19 ESS results for three different temperatures .................................................................................. 37

20 Apparent enthalpy changes for each ESS stage ...............................................................................

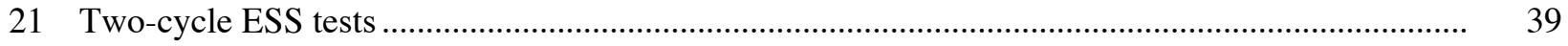

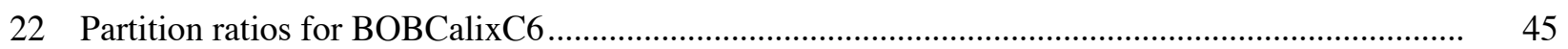

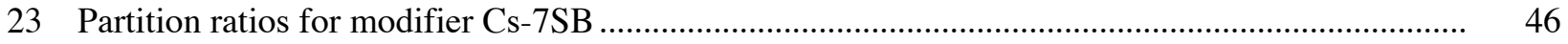

24 Partitioning of dibutylphosphate …………............................................................................. 51

25 Detection limits of non-extractable metals ............................................................................... 52 
26 Concentrations of metals present in the solvent after extraction ................................................. 52

27 Concentrations of anions present in the solvent at each stage ….................................................. 53

28 Concentrations of strontium in the aqueous phase at each stage ….................................................

29 Distribution ratios of technetium obtained in ESS tests .................................................................

30 Effect of dodecanoate on cesium extraction in ESS tests ........................................................... 55

31 Phase separation at $0{ }^{\circ} \mathrm{C}$ for the previous-baseline and the optimized solvents............................... 60

32 Phase compositions at $0{ }^{\circ} \mathrm{C}$ for the previous-baseline and the optimized solvents.......................... 61

33 Phase separation at $-24{ }^{\circ} \mathrm{C}$ for the previous-baseline and the optimized solvents........................... 62

34 Phase compositions at $-24{ }^{\circ} \mathrm{C}$ for the previous-baseline and the optimized solvents....................... 62

35 Solvent compositions at $0{ }^{\circ} \mathrm{C}$ for the previous-baseline and the optimized solvents....................... 62

36 Solvent compositions at $-24{ }^{\circ} \mathrm{C}$ for the previous-baseline and the optimized solvents................... 63

37 ESS tests at $25{ }^{\circ} \mathrm{C}$ using the low temperature-conditioned previous baseline solvent..................... 63

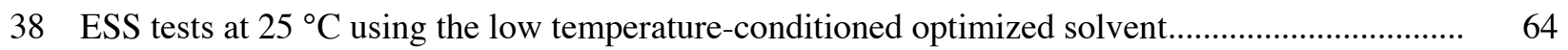

39 ESS tests at $25^{\circ} \mathrm{C}$ using the high temperature-stressed optimized solvent....................................... 65

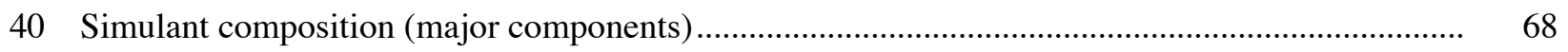

41 Materials for full simulant (added trace metals and organic species) ............................................... 69

42 Dispersion numbers for extraction with optimized CSSX solvent ................................................. 73

43 Dispersion numbers for scrub with optimized CSSX solvent.........................................................

44 Dispersion numbers for strip with optimized CSSX solvent …..................................................... 78

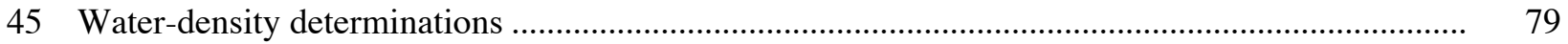

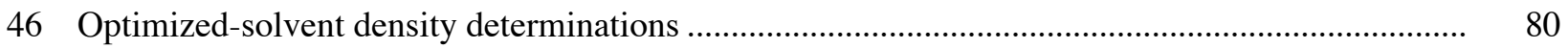

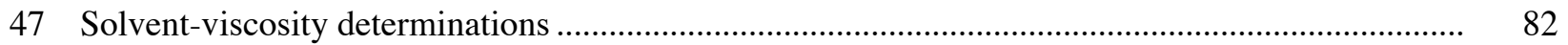

48 Dispersion numbers for CSSX solvent extraction, scrub, and stripping ...................................... 84

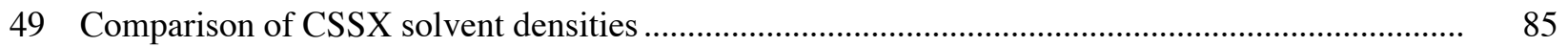

$50 \quad$ Comparison of solvent viscosities........................................................................................... 86

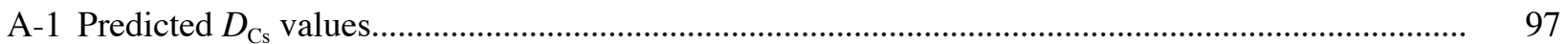




\section{EXECUTIVE SUMMARY}

The present work was undertaken to optimize the solvent used in the Caustic Side Solvent Extraction (CSSX) process and to measure key chemical and physical properties related to its performance. The CSSX process was selected by the USDOE in FY 2001 as the preferred technology for removal of cesium from the alkaline high-level salt waste stored in tanks at the Savannah River Site. This decision had been made with the understanding that the component concentrations of the baseline solvent employed till then would have to be adjusted to avoid supersaturation with respect to the extractant. Taking into consideration bounding requirements, an optimization of the solvent composition was performed, resulting in the following recommended component concentrations in Isopar ${ }^{\circledR}$ L diluent: $0.007 \mathrm{M}$ calix[4]arene-bis(tert-octylbenzo-crown-6) (BOBCalixC6) extractant, 0.75 M 1-(2,2,3,3tetrafluoropropoxy)-3-(4-sec-butylphenoxy)-2-propanol (Cs-7SB) phase modifier, and $0.003 \mathrm{M}$ tri- $n$ octylamine (TOA) stripping aid. Criteria for this selection included BOBCalixC6 solubility, batch cesium distribution ratios $\left(D_{\mathrm{Cs}}\right)$, calculated flowsheet robustness, third-phase formation, dispersion numbers, and density. Although some minor compromises within acceptable limits were made in flowsheet robustness and solvent density, significant benefits from solvent optimization were gained in lower risk of thirdphase formation (operation to as low as $11{ }^{\circ} \mathrm{C}$ at high cesium and potassium loading versus $20^{\circ} \mathrm{C}$ using the previous solvent) and lower solvent cost. The solubility of BOBCalixC6 in Isopar ${ }^{\circledR} \mathrm{L}$ containing 0.5-1.0 M Cs-7SB at $15-35{ }^{\circ} \mathrm{C}$ was examined by monitoring the concentration of BOBCalixC6 as it precipitated from supersaturated solutions over a period of approximately 9 months. Its solubility at 0.75 M Cs-7SB was found to be $7.7 \mathrm{mM}$ at $25^{\circ} \mathrm{C}$. Extract/scrub/strip (ESS) tests showed that the optimized solvent performs acceptably; the extraction strength from baseline waste simulant is lower by $20 \%$, but this is compensated partially by $5-14 \%$ improved stripping. When the optimized solvent was washed with an aqueous solution of $10 \mathrm{mM}$ sodium hydroxide following an ESS test, identical $D_{\mathrm{Cs}}$ values were obtained on a second ESS test with fresh aqueous phases. The temperature dependence of $D_{\mathrm{Cs}}$ values in ESS testing was found to be similar to that of the former baseline solvent, and parameters are reported for the estimation of $D_{\mathrm{Cs}}$ values for ESS contacts in the range $15-35^{\circ} \mathrm{C}$. Measurements of the partition ratios of BOBCalixC6, Cs-7SB, and TOA between the optimized solvent and aqueous process solutions indicate that the losses of these solvent components by partitioning to the aqueous process solutions will be negligible to minor. Respective fractional replacements of the three components due solely to partitioning losses over the course of one year are estimated to be $4 \%, 27 \%$, and $9 \%$ respectively. The partitioning behavior of selected organic anions examined in studies of the previous baseline solvent were repeated with the optimized solvent with no change in behavior found. For example, dibutylphosphate, present in the waste in trace amounts, will partition weakly into the solvent on extraction, and the fraction that is extracted will remain in the solvent to be washed out efficiently by the $\mathrm{NaOH}$ wash stage. Similarly, trace metal distribution was not significantly changed. Trace $\mathrm{Ag}, \mathrm{Cr}, \mathrm{Cu}, \mathrm{Hg}, \mathrm{Mn}, \mathrm{Mo}, \mathrm{Pb}, \mathrm{Pd}$, $\mathrm{Rh}, \mathrm{Ru}, \mathrm{Sn}$, and $\mathrm{Zn}$ were not extracted; traces of $\mathrm{Al}, \mathrm{Ca}, \mathrm{Sr}$, and Fe were detected in the optimized solvent after extraction but are scrubbed out. The bulk metals $\mathrm{Na}$ and $\mathrm{K}$ are also extracted as expected, and these are also scrubbed out. Technetium in the form of pertechnetate anion is extracted very weakly from the simulant $\left(D_{\mathrm{Tc}}=0.038\right.$ or $1 \%$ extracted $)$ and, like dibutylphosphate, remains in the solvent in the acidic scrub and strip stages, subsequently to be washed out in the $\mathrm{NaOH}$ wash stage. On storage at or below 0 ${ }^{\circ} \mathrm{C}$, both the previous and optimized solvents exhibit phase splitting in which the more dense of two phases is concentrated in $\mathrm{BOBCalixC6}$ and $\mathrm{Cs}-7 \mathrm{SB}$. On warming to room temperature and remixing, the solvents are restored to their original composition and ESS performance. A 43-day test of the solvent stability to elevated temperatures, 35 and $60{ }^{\circ} \mathrm{C}$, showed no evidence of degraded ESS performance. The physical properties density, viscosity, and dispersion number for the solvent against full simulant, scrub, and strip solutions at $15-35{ }^{\circ} \mathrm{C}$ were measured and found to be adequate for contactor operation. Dispersion numbers $\left(N_{\mathrm{Di}}\right)$ under all conditions met the criterion $N_{\mathrm{Di}}>4 \square 10^{-4}$; the solvent density and viscosity at $25^{\circ} \mathrm{C}$ were respectively $0.8516 \pm 0.0001$ and $3.51 \pm 0.1 \mathrm{cP}$. Overall, optimization and testing of the CSSX solvent has reduced the technical risk of the CSSX process by resolving previously identified issues and raising no new issues. 


\begin{abstract}
This work was undertaken to optimize the solvent used in the Caustic Side Solvent Extraction (CSSX) process and to measure key chemical and physical properties related to its performance in the removal of cesium from the alkaline high-level salt waste stored in tanks at the Savannah River Site. The need to adjust the solvent composition arose from the prior discovery that the previous baseline solvent was supersaturated with respect to the calixarene extractant. The following solvent-component concentrations in Isopar $^{\circledR} \mathrm{L}$ diluent are recommended: $0.007 \mathrm{M}$ calix[4]arene-bis(tert-octylbenzo-crown-6) (BOBCalixC6) extractant, 0.75 M 1-(2,2,3,3-tetrafluoropropoxy)-3-(4-secbutylphenoxy)-2-propanol (Cs-7SB) phase modifier, and $0.003 \mathrm{M}$ tri- $n$-octylamine (TOA) stripping aid. Criteria for this selection included BOBCalixC6 solubility, batch cesium distribution ratios $\left(D_{\mathrm{Cs}}\right)$, calculated flowsheet robustness, third-phase formation, coalescence rate (dispersion numbers), and solvent density. Although minor compromises within acceptable limits were made in flowsheet robustness and solvent density, significant benefits were gained in lower risk of third-phase formation and lower solvent cost. Data are also reported for the optimized solvent regarding the temperature dependence of $D_{\mathrm{Cs}}$ in extraction, scrubbing, and stripping (ESS); ESS performance on recycle; partitioning of $\mathrm{BOBCalixC6}$, Cs-7SB, and TOA to aqueous process solutions; partitioning of organic anions; distribution of metals; solvent phase separation at low temperatures; solvent stability to elevated temperatures; and solvent density and viscosity. Overall, the technical risk of the CSSX process has been reduced by resolving previously identified issues and raising no new issues.
\end{abstract}

\title{
1. INTRODUCTION
}

The Caustic-Side Solvent-Extraction (CSSX) process [1,2] for cesium removal from alkaline highlevel waste has been developed for application at the United States Department of Energy (USDOE) Savannah River Site (SRS) [3]. In 2001 the USDOE selected the CSSX process flowsheet as the preferred technology for this application [4,5] following an evaluation of alternative technologies [6-10]. This selection was largely founded on extensive testing and demonstration data that successfully addressed four high technology risks, including chemical stability [11], radiation stability [11-15], proofof-concept demonstration with waste simulant [15], and demonstration with actual SRS high-level waste [16]. All criteria were met or even exceeded. The contactor tests using simulated- and actual-waste feeds met their goals for decontamination factor $(\mathrm{DF} \geq 40,000)$ and concentration factor $(\mathrm{CF} \geq 15)[15,16]$. The stability of solvent to chemical, thermal, and radiation stresses was shown to be high, indicating a solvent lifetime significantly greater than one year [11-15]. Extensive data characterizing the distribution behavior of major and minor system components in extraction, scrubbing, and stripping (ESS) were collected, and effective means for solvent cleanup were described [11]. As work for technology selection drew to a close in April 2001, issues for continued research and development (R\&D) were identified [7,11], ultimately leading to renewed effort through the end of FY 2002 [18]. The most important issue regarding chemical and physical properties was the probable supersaturation of the solvent. Namely, the solubility of the calixarene in the solvent comprising the modifier and tri- $n$-octylamine in Isopar ${ }^{\circledR} \mathrm{L}$ 
appeared to be lower than the $10 \mathrm{mM}$ used in the baseline solvent. Since the calixarene solubility increased with increasing concentration of modifier, the issue of supersaturation was apparently resolvable with little risk by an adjustment of the concentrations of the solvent components. Hence, technology selection proceeded with the understanding that such an adjustment would be necessary early in the subsequent R\&D phase.

Following the selection of the CSSX technology, systematic measurements were performed in late FY 2001 and early FY 2002 toward selection of the new optimized concentrations of the three solvent components. In addition to BOBCalixC6 solubility, the dependence of cesium ESS behavior, flowsheet robustness, coalescence, third-phase formation, and solvent density also were factored into the optimization. The conclusions of this initial phase of the work reported herein form the basis of the selection of the optimum solvent composition described in Chapter 2. In the course of the solventoptimization effort and subsequent experiments, the flowsheet and its requirements were assumed to be unchanged. Hence, the compositions of the aqueous waste simulant, scrub solution, and strip solution remained the same. The reader is referred to a prior report for a complete description of the baseline simulant [11]; its composition may be found in Chapter 7 of the present report.

The changed solvent composition necessitated further characterization of the properties of the optimized solvent, as reflected in program plans [18]. Since rather minor changes were expected in the behavior of the optimized solvent as compared with the previous baseline solvent, a less ambitious testing regimen was undertaken. Chapter 3 describes the cesium distribution behavior in batch ESS tests, its temperature dependence, and a confirmation of the recyclability of the solvent. Chapter 4 re-examines the question of partitioning of the solvent components between the solvent and aqueous process solutions, affording an opportunity to reduce the uncertainties in evaluating loss rates of the solvent components. Chapter 5 focuses on how other system constituents, including both organic and inorganic species, distribute under process conditions. Chapter 6 confirms the chemical and thermal stability of the solvent under process conditions. Finally, Chapter 7 provides data on solvent density and viscosity, as well as its dispersion numbers in contact with process solutions. Overall, the experiments conducted on the optimized solvent were intended to reduce the risk that the changed composition would lead to an unacceptable change in process performance. In reporting results toward reducing this risk, this document not only establishes the properties of the optimized solvent, but it also serves as a companion to the previous inclusive report on the previous baseline solvent [11]. 


\section{CAUSTIC-SIDE SOLVENT EXTRACTION SOLVENT-COMPOSITION RECOMMENDATION}

\subsection{BASIS FOR TASK AND SUMMARY RECOMMENDATION}

The purpose of this chapter is to provide the experimental information that forms the basis for a recommended change in the baseline composition of the caustic-side solvent extraction (CSSX) solvent. In the year and a half prior to technology selection in May 2001, the baseline CSSX solvent composition was $0.010 \mathrm{M}$ calix[4]arene-bis(tert-octylbenzo-crown-6), known as BOBCalixC6; $0.5 \mathrm{M} \mathrm{1-(2,2,3,3-}$ tetrafluoropropoxy)-3-(4-sec-butylphenoxy)-2-propanol, known as Cs-7SB modifier; and 0.001 M tri- $n$ octylamine (TOA) in the diluent Isopar $^{\circledR}$ L [3]. Data for the solubility of BOBCalixC6 acquired and reported for the Salt Processing Program (SPP) alternative technology down-select decision showed the above composition is supersaturated with respect to BOBCalixC6 [11]. Although samples of the baseline solvent have been observed for approximately one year without any solids formation, the CSSX technical team recommended a solvent-composition optimization task be undertaken to address the BOBCalixC6 solubility and other issues [19] such as third-phase formation, as a function of the plant operating temperature.

To accomplish the task of recommending a new baseline solvent composition, the CSSX technical team, the Tanks Focus Area (TFA), and SPP management team, in cooperation with the U.S. Department of Energy-Savannah River, developed an experimental program designed to provide the required information. Part of this effort included the development of the solvent-composition selection criteria [20].

The recommendation for the new solvent composition is a consensus opinion of the CSSX technical team. Based on the results to follow in this chapter, the recommended composition is as follows:

- 0.007 M BOBCalixC6 extractant,

- 0.75 M Cs-7SB modifier,

- $0.003 \mathrm{M}$ TOA stripping aid (sometimes referred to as a suppressor), and

- Isopar $^{\circledR} \mathrm{L}$ diluent.

Table 1 contains a summary of the bounding and goal-selection criteria and the value of the experimental property for the respective criterion for the recommended solvent composition. 
Table 1. Summary of selection criteria and associated properties

\begin{tabular}{|c|c|c|c|}
\hline Criterion & Bounding condition & Goal condition & Value of property \\
\hline BOBCalixC6 solubility & $\begin{array}{l}\text { Thermodynamically } \\
\text { stable }\end{array}$ & $\begin{array}{l}\text { Thermodynamically } \\
\text { stable }\end{array}$ & $\geq 7.55 \mathrm{mM} @ 25^{\circ} \mathrm{C}$ \\
\hline$D_{\mathrm{Cs}}$ values & $\begin{array}{l}\text { Extraction } D_{\mathrm{Cs}}>8 \\
\text { Scrub } D_{\mathrm{Cs}}>0.6 \\
\text { Strip } D_{\mathrm{Cs}}<0.16\end{array}$ & $\begin{array}{l}\text { Extraction } D_{\mathrm{Cs}}>17.8 \\
\text { Scrub } D_{\mathrm{Cs}}>1.6 \\
\text { Strip } D_{\mathrm{Cs}}<0.15\end{array}$ & $\begin{array}{l}\text { Extraction } D_{\mathrm{Cs}}=14.1 \\
\text { Scrub } D_{\mathrm{Cs}}=1.3 \\
\text { Strip } D_{\mathrm{Cs}}=0.10\end{array}$ \\
\hline Flowsheet robustness & 1.0 & 3.0 & $>8.0$ \\
\hline Third-phase formation & $\begin{array}{l}15 \square \mathrm{T} \square 35^{\circ} \mathrm{C} \\
\text { at }\left[\mathrm{K}^{+}\right]=0.05 \mathrm{M}\end{array}$ & $\begin{array}{l}15 \square \mathrm{T} \square 35^{\circ} \mathrm{C} \\
\text { at }\left[\mathrm{K}^{+}\right]=0.05 \mathrm{M}\end{array}$ & $\begin{array}{l}<10^{\circ} \mathrm{C} \\
\text { at }\left[\mathrm{K}^{+}\right]=0.05 \mathrm{M}\end{array}$ \\
\hline $\begin{array}{l}\text { Dispersion number } \\
\text { against simulant, scrub, } \\
\text { and strip solutions }\end{array}$ & $>4.0 \square 10^{-4}$ & $>4.0 \square 10^{-4}$ & $>5.0 \square 10^{-4}$ \\
\hline $\begin{array}{l}\text { Dispersion number } \\
\text { against } \mathrm{NaOH} \text { wash } \\
\text { solution }\end{array}$ & $>4.0 \square 10^{-4}$ & $>4.0 \square 10^{-4}$ & $\begin{array}{l}>4.5 \square 10^{-4} \\
\text { at } 0.3 \mathrm{M} \mathrm{NaOH}\end{array}$ \\
\hline Solvent density & $\square 0.90 \mathrm{~g} / \mathrm{mL}$ at $25^{\circ} \mathrm{C}$ & $\square 0.86 \mathrm{~g} / \mathrm{mL}$ at $25^{\circ} \mathrm{C}$ & $0.85 \mathrm{~g} / \mathrm{mL}$ at $25.6^{\circ} \mathrm{C}$ \\
\hline
\end{tabular}

It should be noted that the criteria dealing with the change in the cesium distribution ratio $D_{\mathrm{Cs}}$ values as a function of solvent composition (i.e., solvent robustness) and the cost of solvent components did not enter into the decision process. These two criteria were intended to be used if the other criteria identified multiple acceptable compositions.

The results presented in the chapter were first documented in a report [21] of limited availability for use by the CSSX technical team in planning and initiating tasks in FY 2002. This document was later converted to an Oak Ridge National Laboratory (ORNL) report whose format is prescribed by the USDOE Office of Scientific and Technical Information (OSTI) [22]. In that the results are, for practical purposes, inseparable from the other results presented herein, the information is again reported in the form of the present chapter. In addition to minor editing, the only technical change of significance made in duplicating this material is the inclusion of the BOBCalixC6 solubility data collected at longer times. Hence, the present report represents the most comprehensive source of information to date on CSSX chemical and physical properties. 


\subsection{EXPERIMENTAL APPROACHES}

\subsubsection{Solvent Test Samples}

A total of 13 test samples of solvent were prepared for this study. The compositions of these samples are given in Table 2. A sample of the baseline solvent was included for reference purposes. Single lots of modifier (Lot No. PVB B000894-48P) and BOBCalixC6 (Lot No. IBC 000714HMKC-0004) were used to prepare all of the test samples. Solvents containing 3 and $10 \mathrm{mM}$ TOA were prepared by adding a measured amount of $0.2 \mathrm{M}$ TOA in Isopar ${ }^{\circledR} \mathrm{L}$ to the solvents originally prepared with $1 \mathrm{mM}$ TOA. All solvents were washed twice with $0.1 \mathrm{M} \mathrm{NaOH}$, twice with $0.05 \mathrm{M} \mathrm{HNO}_{3}$, three times with deionized water, and allowed to stand overnight before being decanted into clean containers. Scrub $\left(0.05 \mathrm{M} \mathrm{HNO}_{3}\right)$ and strip $\left(0.001 \mathrm{M} \mathrm{HNO}_{3}\right)$ solutions were prepared by diluting commercially available stock solutions with deionized water. Sodium hydroxide solutions were prepared by diluting a commercially available standard solution. Savannah River Site (SRS) waste supernatant simulant was formulated according to the SRS procedure [23]. The nominal cesium concentration in all simulant batches used in the testing was 0.00014 M. Aliquots of the solvent were transferred to the Nuclear Sciences and Technology Division (NSTD) at Oak Ridge National Laboratory (ORNL) for measurements of dispersion number, viscosity, density, surface tension, and interfacial tension. Other measurements, plus the initial solvent preparation, were carried out in the ORNL Chemical Sciences Division (CSD).

Table 2. Test sample compositions

\begin{tabular}{ccccc}
\hline Solvent identification & Test no. & $\begin{array}{c}\text { [BOBCalixC6] } \\
(\mathrm{mM})\end{array}$ & $\begin{array}{c}{[\text { Cs-7SB }} \\
(\mathrm{M})\end{array}$ & $\begin{array}{c}{[\mathrm{TOA}]} \\
(\mathrm{mM})\end{array}$ \\
\hline Previous baseline & & 10 & 0.50 & 1 \\
B001107-3-1 & 1 & 10 & 0.65 & 1 \\
B001107-3-2 & 2 & 8 & 0.65 & 1 \\
B001107-3-3 & 3 & 10 & 0.75 & 1 \\
B001107-3-4 & 4 & 8 & 0.75 & 1 \\
B001107-3-5 & 5 & 6 & 0.75 & 1 \\
B001107-3-6 & 6 & 8 & 0.85 & 1 \\
B001107-3-7 & 7 & 6 & 0.85 & 1 \\
B001107-3-8 & 8 & 8 & 1.00 & 1 \\
B001107-3-9 & 9 & 6 & 1.00 & 1 \\
B001107-3-2A & 10 & 8 & 0.65 & 3 \\
B001107-3-2B & 11 & 8 & 0.65 & 3 \\
B001107-3-4C & 12 & 8 & 0.75 & 10 \\
B001107-3-4D & 13 & 8 & 0.75 & \\
\hline
\end{tabular}




\subsubsection{Experimental Procedures}

\subsubsection{BOBCalixC6 solubility studies}

A series of solvents were prepared from five different pristine nonwashed solutions of Cs-7SB modifier in Isopar ${ }^{\circledR} \mathrm{L}(0.5,0.65,0.75,0.85$, and $1.0 \mathrm{M})$ containing $1 \mathrm{mM}$ TOA as follows. Three and one-half grams of BOBCalixC6 (Lot 000714 HMKC-0004) was dissolved in $50 \mathrm{~mL}$ of modifier solution in Isopar ${ }^{\circledR} \mathrm{L}$ by applying sonication and heating to about $50{ }^{\circ} \mathrm{C}$, cooling to room temperature, and then seeding with about $2 \mathrm{mg}$ of recrystallized BOBCalixC6. BOBCalixC6 was used as received from IBC Advanced Technologies, Inc. The modifier solutions in Isopar ${ }^{\circledR} \mathrm{L}$ were washed following the standard washing protocol. The samples were then shaken and divided into six samples of equal volume. Samples in duplicate were placed in a water bath at $15^{\circ} \mathrm{C}$, an air box at $25{ }^{\circ} \mathrm{C}$, and an incubator at $35^{\circ} \mathrm{C}$. Agitation was effected by shaking in the water bath and wheel rotation in the air box and incubator. The initial concentration of BOBCalixC6 in each sample was $59 \mathrm{mM}$. After a given time interval, the samples were allowed to settle for 30 to $60 \mathrm{~min}$, whereupon an aliquot of the supernatant solution was withdrawn, filtered through No. 40 filter paper, diluted with chloroform, and submitted for high-performance liquid chromatography (HPLC) analysis. Samples archived from the solubility study initiated approximately 1

year ago [11] were also analyzed. A new calibration curve was prepared with fresh calixarene solutions for each analysis series.

\subsubsection{Extraction, scrub and strip protocol}

Extraction, scrub, and strip (ESS) tests were performed on all of the samples listed in Table 2. The experiments were conducted following the protocol defined in Ref. 11 using organic:aqueous (O:A) volume ratios of 1:3 on extraction and 5:1 on scrubs and strips. An extra scrub step was added to the previous protocol [11] to more realistically approximate the flowsheet. It should be noted that the solvent weakly extracts sodium and potassium, and the second scrub step more completely removes these metals from the solvent prior to stripping. With only one scrub, the first strip step is expected to exhibit slightly higher values of $D_{\mathrm{Cs}}$, because the incomplete scrubbing of sodium and potassium results in these metal nitrates reporting to the aqueous phase of the first strip step, thereby increasing the aqueous-phase nitrate concentration. The data validating the modified ESS protocol are given in Table 3. The data confirm that addition of the second scrub improves stripping performance as expected. The $D_{\mathrm{Cs}}$ values are slightly dependent on the O:A ratios employed, with better performance occurring when the strip O:A ratio is lower. All stripping $D_{\mathrm{Cs}}$ values converge to the same value upon successive stripping. In the solventoptimization tests, an increase in modifier concentration is expected to increase sodium and potassium extraction [11]. However, the consequent negative impact on stripping is expected to be essentially eliminated by the second scrub and thus appropriately rendered an insignificant factor in solvent selection. 


\subsubsection{Third-phase determination}

Third-phase formation experiments involved the 10 solvents containing $1 \mathrm{mM}$ of TOA and three different simulants: baseline simulant $\left(\left[\mathrm{Cs}^{+}\right]=0.14 \mathrm{mM},\left[\mathrm{K}^{+}\right]=0.02 \mathrm{M}\right)$, high-potassium simulant $\left(\left[\mathrm{Cs}^{+}\right]^{\prime}=0.14 \mathrm{mM},\left[\mathrm{K}^{+}\right]=0.05 \mathrm{M}\right)$; and high-potassium, high-cesium simulant $\left(\left[\mathrm{Cs}^{+}\right]=0.44 \mathrm{mM}\right.$, $\left.\left[\mathrm{K}^{+}\right]^{\prime \prime}=' 0.05 \mathrm{M}\right)$. These conditions encompass those that could be potentially encountered with real wastes [3]. After two repeated contacts with the simulants $(\mathrm{O}: \mathrm{A}=1: 3)$ at $25^{\circ} \mathrm{C}$, the solvent samples were cooled in a water bath and shaken periodically. The presence or absence of a third phase was determined by independent visual examination by two researchers.

Table 3. Validation data for the modified ESS protocol

\begin{tabular}{lcccc}
\hline & \multicolumn{4}{c}{ Value of $D_{\mathrm{Cs}}$ by O:A ratios ${ }^{a}$} \\
\cline { 2 - 5 } Step & $1: 3(\mathrm{E})$ & $1: 5(\mathrm{E})$ & $1: 3(\mathrm{E})$ & $1: 5(\mathrm{E})$ \\
& $5: 1(\mathrm{SS})$ & $3: 1(\mathrm{SS})$ & $5: 1(\mathrm{SS})$ & $3: 1(\mathrm{SS})$ \\
\hline Extraction & 17.6 & 17.1 & 16.6 & 17.3 \\
Scrub no. 1 & 1.55 & 1.57 & 1.56 & 1.57 \\
Scrub no. 2 & $\mathrm{NA}$ & $\mathrm{NA}$ & 1.56 & 1.57 \\
Strip no. 1 & 0.137 & 0.130 & 0.120 & 0.116 \\
Strip no. 2 & 0.080 & 0.075 & 0.078 & 0.071 \\
Strip no. 3 & 0.064 & 0.064 & 0.062 & 0.062 \\
Strip no. 4 & 0.052 & 0.054 & 0.052 & 0.054 \\
\hline
\end{tabular}

${ }^{a}$ The letter "E" denotes O:A ratio for extraction; "SS" denotes O:A ratio for scrub and strip. NA denotes "not applicable," as the second scrub was intentionally omitted in the corresponding sequence.

\subsubsection{Dispersion-number measurement}

Dispersion numbers were determined under extraction, scrubbing, and stripping conditions in the presence of cesium. Prior to use, all new or previously used glassware and plastic vessels were washed by rinsing with tap water three times, rinsing with deionized water three times, rinsing with ethanol two times, and rinsing with acetone two times. The equipment was allowed to air dry or was dried with a stream of dry nitrogen or argon before use. In all tests, phase volumes proportional to the flow rates of the solvent, scrub, and strip solutions in the CSSX baseline flowsheet were placed into a 100-mL graduated Pyrex ${ }^{\circledR}$ cylinder. The position of the interface was recorded. The cylinder was capped with a ground-glass stopper, the solutions were agitated at ambient laboratory temperature for $20 \mathrm{~s}$. Agitation was suspended for $10 \mathrm{~s}$ and then resumed for an additional $20 \mathrm{~s}$. At the end of the second agitation, a stopwatch was started and the time required for the interface to return to its original position was 
recorded. In these tests, the "original" position was assumed to be that within 1-2 mm of the interface prior to the agitation and when all indications of dispersed phases at the interface had disappeared. The total height of the dispersion within the cylinder was measured. Each determination was repeated three times. Dimensionless dispersion numbers were calculated according to the expression [24]:

$$
N_{D i}=\frac{1}{t_{b}} \sqrt{\frac{z}{g_{c}}}
$$

where $t_{b}$ is the break time in seconds, $z$ is the dispersion band height in centimeters, and $g_{c}$ is the gravitational force of $981 \mathrm{~cm} / \mathrm{s}^{2}$.

\subsubsection{Density}

The solvent densities were measured using procedures based on ASTM D891 [25] and ASTM D1429, [25] using new 50-mL class A borosilicate glass volumetric flasks with ground-glass stoppers. Calibration of the volumetric flasks for density measurements was performed based on ASTM E542 [27]. A Mettler AE260 analytical balance (S/N J19097) capable of measuring to $0.1 \mathrm{mg}$ was used to weigh the flasks. National Institute of Standards and Technology (NIST)-based test weights were used to check the balance calibration. A thermometer accurate to $0.1{ }^{\circ} \mathrm{C}$ (LaPine 398-12-53) was used to measure the temperature of the liquid in the flasks. The flasks were cleaned and dried before each use as described above, using tap water, deionized water, ethanol, and acetone, followed by drying with argon gas. Each flask was filled using a $10-\mathrm{mL}$ transfer pipette to just below the line and then adjusted to the line with a small transfer pipette. The actual volume of each flask was calculated from the weight of the water contained.

\subsubsection{Viscosity}

The viscosities of each of the nine candidate solvents and the previous baseline solvent were measured at 20, 25, 30, 35, and $40{ }^{\circ} \mathrm{C}$ using procedures adapted from ASTM D2196 [28] and the Brookfield viscometer operating instructions [29]. The determinations were made using a Brookfield rotational viscometer model LVTDV-II, serial number D15869, with a UL adapter. The water jacket on the UL adapter was heated and cooled by a VWR model 13270-615 circulation bath, with 190-Ws cooling, and operated at a coolant recirculation rate of $\square 2 \mathrm{~L} / \mathrm{min}$. It contained a 50/50 mixture of ethylene glycol and water, which was circulated by the water bath circulation pump. The thermometer used, the LaPine 398-12-53, was immersed in the water bath for the temperature measurement. (There is no room in the UL adapter for a thermometer.) The spindle speed was set to give a torque percent reading in the middle or upper portion of the scale. The UL adapter (a large-diameter spindle in a cylindrical container just slightly larger in diameter than the spindle) is used for measuring low-viscosity liquids (liquids with viscosities between 1 and $20 \mathrm{cP}$ ). The UL adapter with spindle holds $16 \mathrm{~mL}$ of sample for measurement. 
Each test was begun by adding the test solvent to the UL adapter, installing it on the viscometer, starting the spindle rotation at $60 \mathrm{rpm}$, and then setting the temperature bath to $20{ }^{\circ} \mathrm{C}$. After the temperature had stabilized for several minutes, the viscosity of the sample was measured. The temperature bath was then adjusted to the next temperature and the system temperature allowed to stabilize before the next reading was taken.

\subsubsection{Surface tension and interfacial tension}

The surface tension of each of the nine candidate solvents, the previous baseline solvent, simulant, strip solution, and scrub solution were measured at $\sim 25^{\circ} \mathrm{C}$ using a CSC Du Nouy tensiometer (serial no. 013457) with a 6-cm-circumference ring. The experimental procedures were adapted from ASTM D971 [30] and ASTM D1331 [31]. The tensiometer was calibrated against known weights and its zero point adjusted according to the procedure of the manufacturer. Interfacial tension was determined by measuring the force necessary to detach a planar ring of platinum wire from the surface of the liquid of higher surface tension, that is, upward from the aqueous-organic interface. To calculate the interfacial tension, the force so measured was corrected by an empirically determined factor that depends upon the force applied, the densities of both organic and aqueous layers, and the dimensions of the ring. Measurements are made under rigidly standardized nonequilibrium conditions in which the measurement is completed within $60 \mathrm{~s}$ after formation of the interface. The surface tension of deionized water was measured to determine that the apparatus was functioning correctly. A value of $71-73 \mathrm{dyn} / \mathrm{cm}$ must be obtained; the literature value at $25^{\circ} \mathrm{C}$ is $72.0 \mathrm{dyn} / \mathrm{cm}$ [32].

A Teflon ${ }^{\circledR}$ sample container having a minimum diameter of $45 \mathrm{~mm}$ was used. The container was cleaned as described above (with tap water, deionized water, ethanol, and acetone) between each solvent/aqueous determination. The ring was then flamed in a blue gas flame, using spinning to obtain rapid, uniform heating. The ring should barely glow orange and should be heated for no more than $5 \mathrm{~s}$.

Interfacial tension measurements were made by carefully placing a layer of the organic on the surface of the aqueous layer (the aqueous layer was placed in the container first and the ring submerged in this layer) until a depth of at least $10 \mathrm{~mm}$ was reached using a pipette. This procedure was used to ensure that minimum mixing occurred and that the organic did not touch the surface of the submerged ring. The organic-aqueous interface was allowed to age for $30 \pm 1 \mathrm{~s}$ after the last of the organic had been layered onto the water. The platform was lowered and the value at rupture recorded. The measurement was timed so that, as nearly as possible, $30 \mathrm{~s}$ were required to draw the ring through the interface. The entire operation, from the time of pouring the organic onto the aqueous until the interface ruptured, was completed in about $60 \pm 10 \mathrm{~s}$. Each solvent was tested in duplicate, with the cup and the ring cleaned between the two readings.

The interfacial tension of the sample was calculated by means of the following equation:

$$
\text { Interfacial tension, } \mathrm{dyn} / \mathrm{cm}=P_{\text {interface }} \square F
$$


where $P_{\text {interface }}$ is the scale reading when the film ruptures (in dynes per centimeter) and $F$ is the factor converting the scale reading (in dynes per centimeter) to interfacial tension, as obtained from Eq. (3). The value of the diameter ratio, $R / r$, for the ring, as specified by the manufacturer, is 53.6. The value of $F$ is obtained as follows:

$$
F=0.7250+\left[0.01452 P_{\text {interface }} / C^{2}\left(\square_{\text {aq }}-\square_{\text {org }}\right)+0.04534-1.679 /\left(r_{\text {ring }} / r_{\text {wire }}\right)\right]^{1 / 2}
$$

where $C$ is the circumference of the ring $(5.992 \mathrm{~cm}), \square_{\text {aq }}$ is the density of the aqueous layer at $25{ }^{\circ} \mathrm{C}$, in grams per milliliter; $\square_{\text {org }}$ is the density of the organic layer for interfacial testing at $25^{\circ} \mathrm{C}$, in grams per

milliliter; $r_{\text {ring }}$ is the radius of the ring, in centimeters; and $r_{\text {wire }}$ is the radius of the wire of the ring, in centimeters.

\subsection{EXPERIMENTAL RESULTS}

\subsubsection{BOBCalixC6 Solubility}

The data on the BOBCalixC6 are a combination of information acquired from the experiments conducted in the latter portion of FY 2001 (see Experimental Section) and from the previous experiments [11]. This summary of the experimental results is necessary because of the long periods of time required for the BOBCalixC6 to achieve the solubility equilibrium condition. Table 4 summarizes the data obtained from the most recent solubility study.

The time-trend analysis of the data shows that after eight weeks, solubility equilibrium has not been achieved. Nevertheless, the data imply the supersaturation of the baseline solvent. After 36 weeks, the change in the calixarene content is fairly minor, as can be seen in Figs. 1-3, where the temperatures were chosen to represent respectively the minimum, medium, and maximum temperatures encountered in the process. (Note that the results after 36 weeks were not available when the composition of the optimized solvent was chosen [21]). 


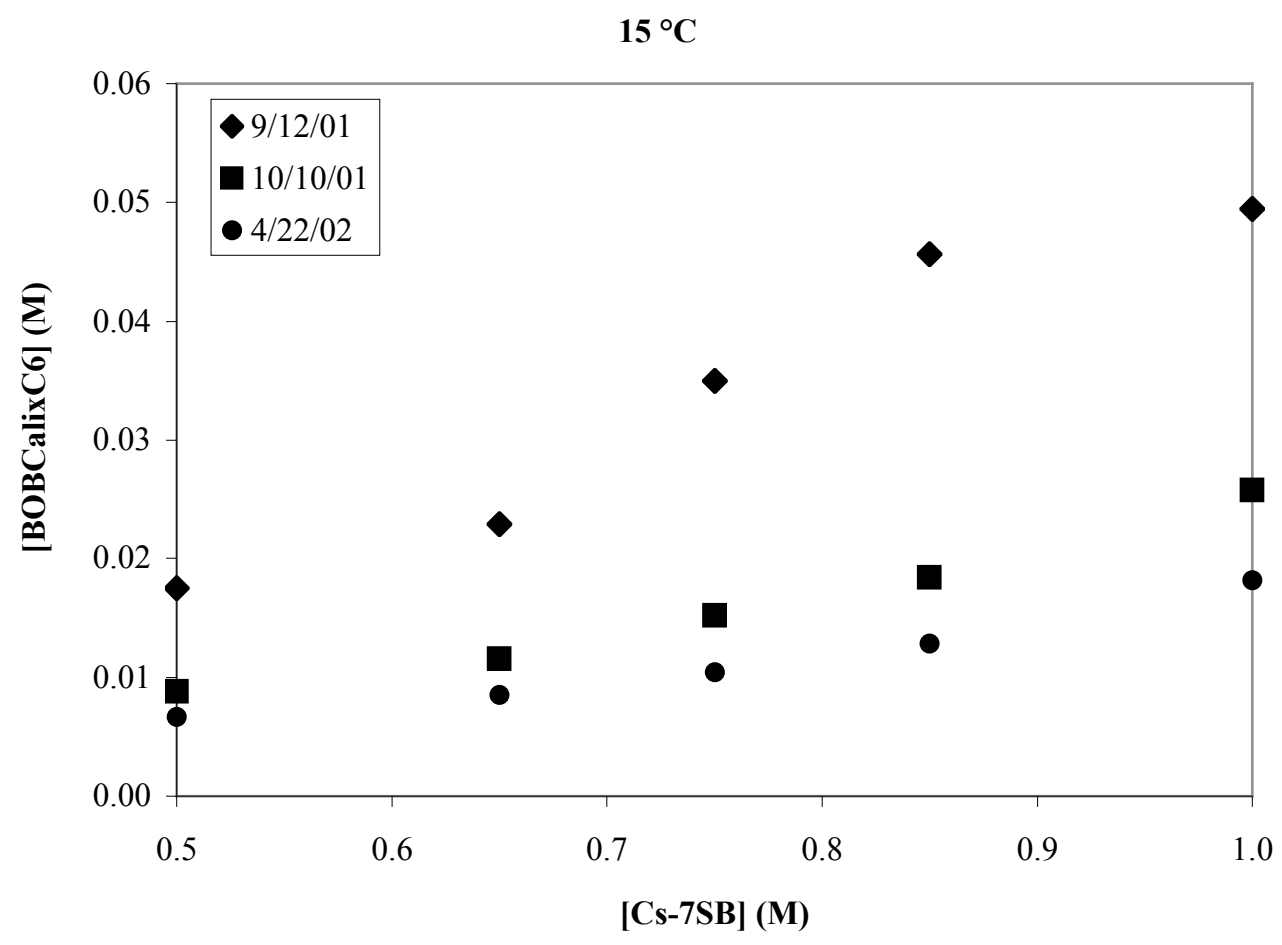

Fig. 1. BOBCalixC6 solubility tests at $15^{\circ} \mathrm{C}$.

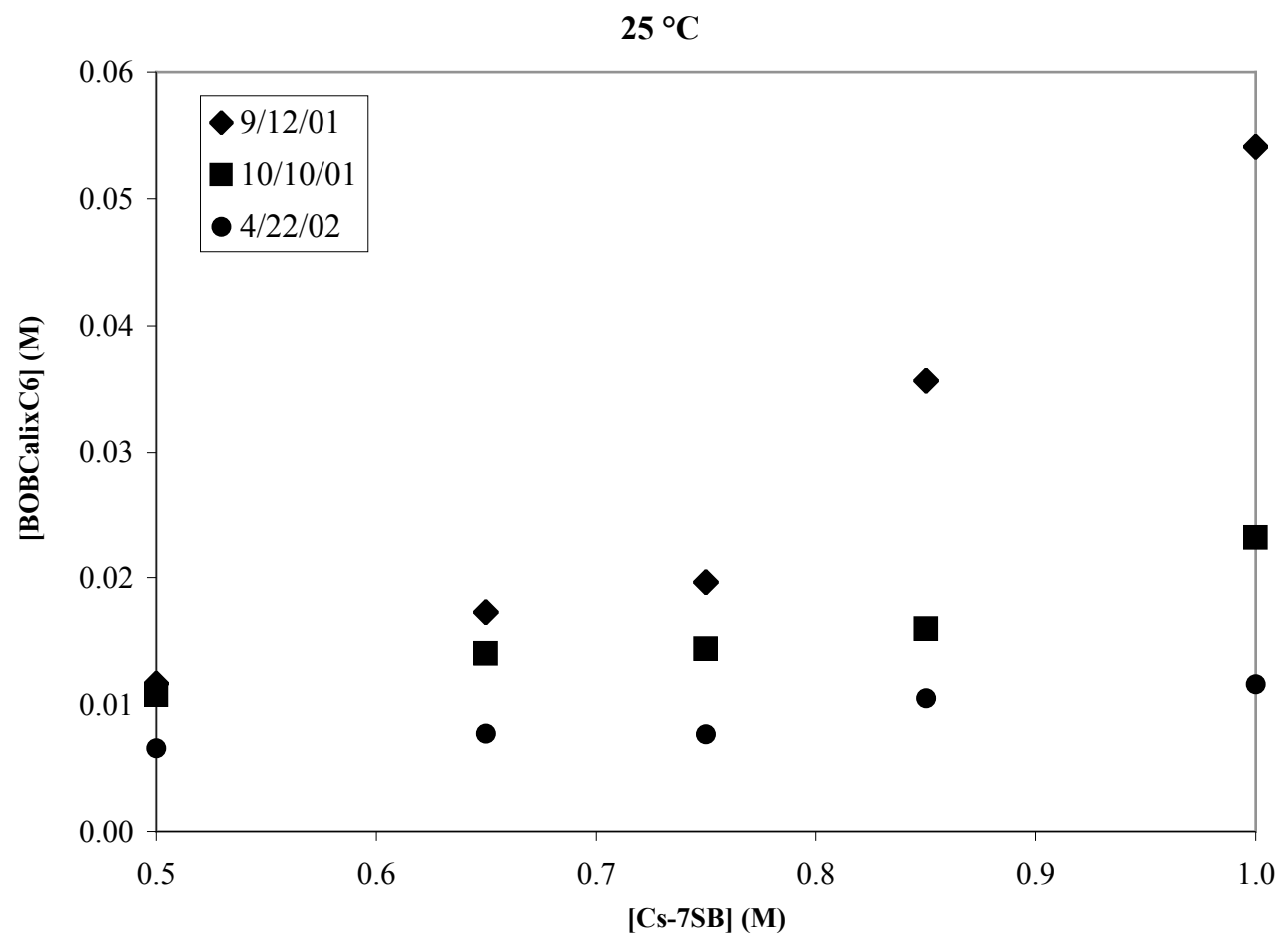

Fig. 2. BOBCalixC6 solubility tests at $25^{\circ} \mathrm{C}$. 


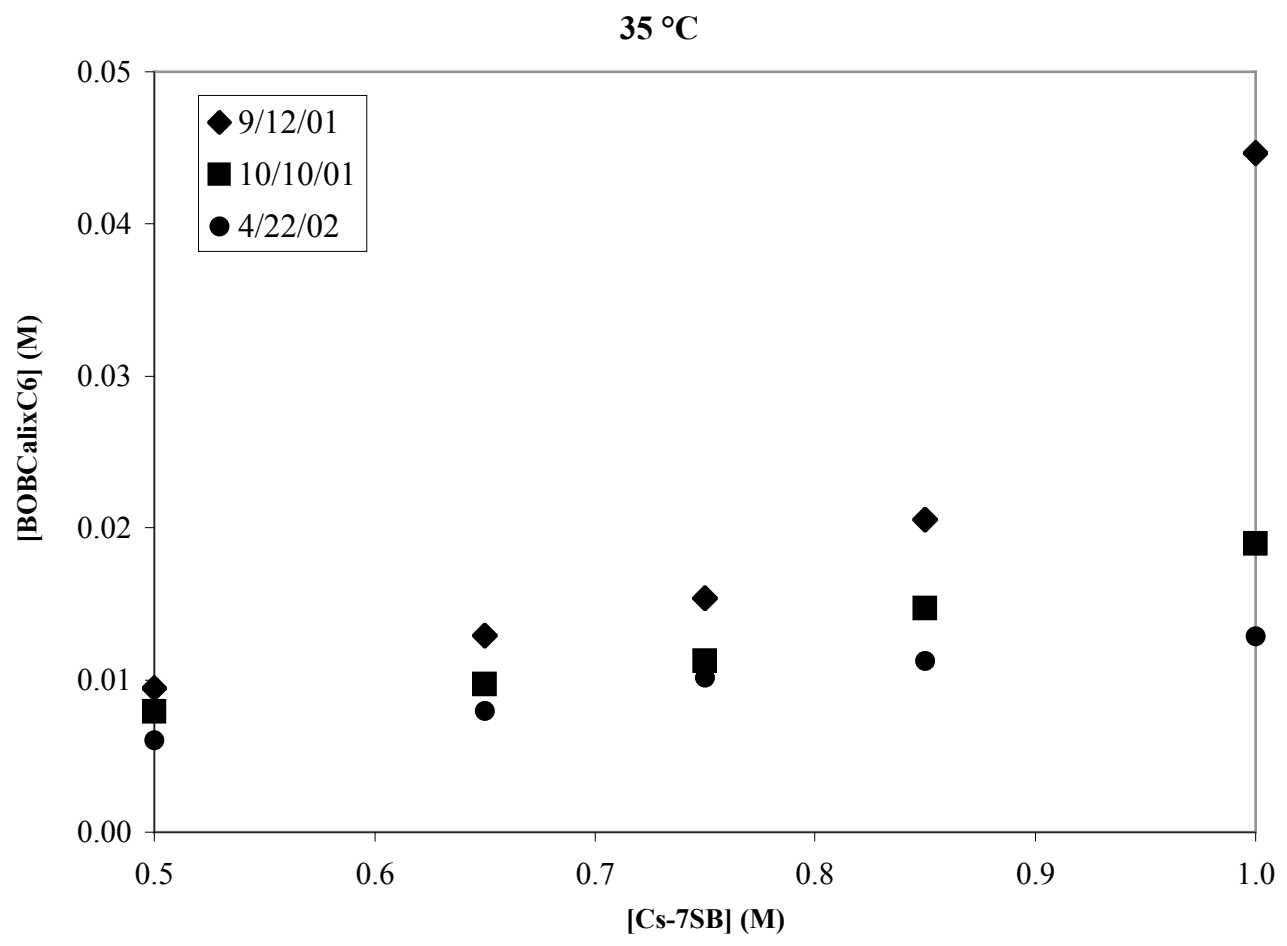

Fig. 3. BOBCalixC6 solubility tests at $35^{\circ} \mathrm{C}$.

The experiment carried out at $35^{\circ} \mathrm{C}$ indicates that the solubility of calixarene in a solvent containing the chosen concentration of modifier for the optimized solvent $(0.75 \mathrm{M})$ varied minimally in 6 months, and the concentration of soluble calixarene is still greater than $7 \mathrm{mM}$. For the two other temperatures, the gap between the measurements performed in October 2001 and in April 2002 is larger, but BOBCalixC6 is still at a concentration greater than $7 \mathrm{mM}$ in both cases for a concentration of modifier of $0.75 \mathrm{M}$.

A conservative estimate of the lower bound of the BOBCalixC6 solubility at $25^{\circ} \mathrm{C}$ was obtained by reanalysis of samples from the solubility study that was initiated approximately 1 year ago [11]. These samples had been stored at the original experimental temperatures with intermittent agitation. Selected results are summarized in Fig. 4. As indicated in the legend, data are shown for both as-received and recrystallized BOBCalixC6 and for equilibrium approached from the direction of both dissolution (solid BOBCalixC6 present at start) and precipitation (starting with supersaturated BOBCalixC6 upon sonication and then seeding). In each case, no TOA or water is present in the solvent; that is, solid BOBCalixC6 is suspended in Cs-7SB at the indicated concentration in Isopar $^{\circledR}$ L only. A tabulation of the data after 1 year, including systems containing TOA and water, is given in Table 5. Except for the single data point at $0.25 \mathrm{M} \mathrm{Cs}-7 \mathrm{SB}$, which shows a deviation of $\pm 26 \%$, the average analytical deviation among duplicate samples is $\pm 3.5 \%$. The data show that TOA and water have little or no effect on BOBCalixC6 solubility. 
Table 4. BOBCalixC6 solubility data from FY 2001 study $^{a}$

\begin{tabular}{|c|c|c|c|c|c|c|c|c|c|c|}
\hline \multirow{3}{*}{$\begin{array}{c}{[\mathrm{Cs}-7 \mathrm{SB}]} \\
(\mathrm{M})\end{array}$} & \multicolumn{10}{|c|}{ [BOBCalixC6] (mM) } \\
\hline & \multirow[b]{2}{*}{ Initial } & \multicolumn{3}{|c|}{$15^{\circ} \mathrm{C}$} & \multicolumn{3}{|c|}{$25^{\circ} \mathrm{C}$} & \multicolumn{3}{|c|}{$35^{\circ} \mathrm{C}$} \\
\hline & & 4 wks & 8 wks & 36 wks & 4 wks & 8 wks & 36 wks & 4 wks & 8 wks & 36 wks \\
\hline 0.50 & 59 & 17.5 & 8.80 & 6.70 & 11.7 & 10.7 & 6.59 & 9.50 & 7.94 & 6.04 \\
\hline 0.65 & 59 & 22.9 & 11.5 & 8.54 & 17.3 & 14.0 & 7.72 & 12.9 & 9.72 & 7.98 \\
\hline 0.75 & 59 & 35.0 & 15.2 & 10.4 & 19.7 & 13.1 & 7.69 & 15.4 & 11.2 & 10.1 \\
\hline 0.85 & 59 & 45.6 & 18.3 & 12.9 & 35.7 & 15.9 & 10.5 & 20.5 & 14.7 & 11.3 \\
\hline 1.0 & 59 & 49.5 & 25.7 & 18.1 & 54.1 & 23.1 & 11.6 & 44.7 & 19.0 & 12.9 \\
\hline
\end{tabular}

${ }^{a}$ Each value is the average of an analysis of each of duplicate solubility samples.

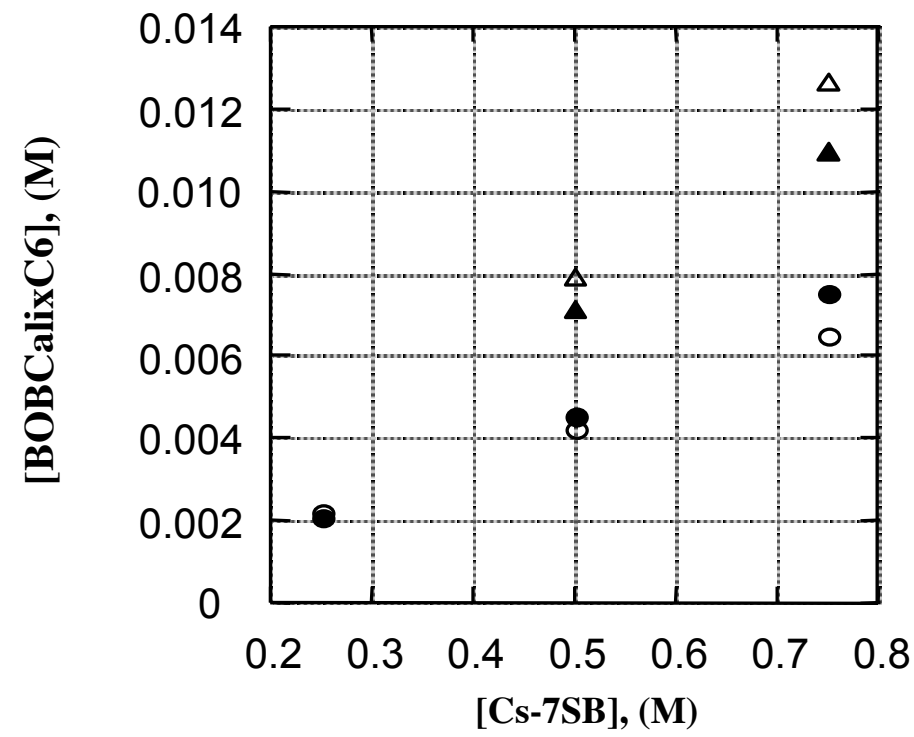

- Recrystallized BOBCalixC6, dissolution, equilibrated for 52 days

- Recrystallized BOBCalixC6, dissolution, equilibrated for 410 days

$\Delta \quad$ As-received BOBCalixC6, precipitation, equilibrated for 38 days

- As-received BOBCalixC6, precipitation, equilibrated for 395 days

Fig. 4. Comparison of BOBCalixC6 solubility data. The circles correspond to solubility tests performed by dissolution with recrystallized calixarene; the triangles correspond to solubility tests performed by precipitation with calixarene used asreceived. 
Conservatively, the lower bound of the BOBCalixC6 thermodynamic solubility corresponds to the recrystallized $\mathrm{BOBCalixC6}$ that had been dissolving over the course of 13 months. At $0.75 \mathrm{M} \mathrm{Cs}-7 \mathrm{SB}$, the lower bound at $25{ }^{\circ} \mathrm{C}$ is $7.55 \mathrm{mM}$. Although the solubility of BOBCalixC6 generally increases with increasing Cs-7SB concentration, a gap exists between the data for the recrystallized BOBCalixC6 that is dissolving and the as-received BOBCalixC6 that is precipitating.

Table 5. BOBCalixC6 solubility data from FY 2000 study $^{a}$

\begin{tabular}{|c|c|c|c|c|c|c|c|}
\hline $\begin{array}{c}\text { Sample } \\
\text { no. }\end{array}$ & $\begin{array}{c}{[\mathrm{Cs}-7 \mathrm{SB}]} \\
(\mathrm{M})\end{array}$ & $\begin{array}{c}{[\mathrm{TOA}]} \\
(\mathrm{mM})\end{array}$ & $\begin{array}{c}\text { Solvent } \\
\text { washed? }\end{array}$ & $\begin{array}{l}\text { Dissolution } \\
\text { method }\end{array}$ & $\begin{array}{c}\text { [BOBCalixC6] } \\
\text { purification }\end{array}$ & $\begin{array}{c}\text { [BOBCalixC6] } \\
(\mathrm{mM})\end{array}$ & $\begin{array}{c}\text { [BOBCalixC6] } \\
\text { average }(\mathrm{mM})\end{array}$ \\
\hline & & & & & Recrystallized & & \\
\hline $5-\mathrm{A}$ & 0.25 & 0 & No & Dissolve & & 2.62 & \\
\hline $5-\mathrm{B}$ & 0.25 & 0 & No & Dissolve & Recrystallized & 1.55 & 2.08 \\
\hline $6-A$ & 0.50 & 0 & No & Dissolve & Recrystallized & 4.31 & \\
\hline $6-B$ & 0.50 & 0 & No & Dissolve & Recrystallized & 4.76 & 4.54 \\
\hline 7-A & 0.75 & 0 & No & Dissolve & Recrystallized & 6.98 & \\
\hline 7-B & 0.75 & 0 & No & Dissolve & Recrystallized & 8.12 & 7.55 \\
\hline 8-A & 0.50 & 1 & No & Dissolve & Recrystallized & 4.38 & \\
\hline $8-\mathrm{B}$ & 0.50 & 1 & No & Dissolve & Recrystallized & 4.48 & 4.43 \\
\hline $9-\mathrm{A}$ & 0.50 & 1 & Yes & Dissolve & Recrystallized & 4.26 & \\
\hline $9-B$ & 0.50 & 1 & Yes & Dissolve & Recrystallized & 4.64 & 4.45 \\
\hline $10-\mathrm{A}$ & 0.50 & 1 & No & Precipitate & Recrystallized & 6.18 & \\
\hline $10-\mathrm{B}$ & 0.50 & 1 & No & Precipitate & Recrystallized & 6.68 & 6.43 \\
\hline $11-\mathrm{A}$ & 0.50 & 0 & No & Precipitate & As Received & 7.26 & \\
\hline $11-\mathrm{B}$ & 0.50 & 0 & No & Precipitate & As Received & 7.05 & 7.15 \\
\hline $12-\mathrm{A}$ & 0.75 & 0 & No & Precipitate & As Received & 11.1 & \\
\hline $12-\mathrm{B}$ & 0.75 & 0 & No & Precipitate & As Received & 10.8 & 10.95 \\
\hline $13-\mathrm{A}$ & 0.50 & 0 & Yes & Precipitate & As Received & 5.11 & \\
\hline $13-\mathrm{B}$ & 0.50 & 0 & Yes & Precipitate & As Received & & \\
\hline
\end{tabular}

${ }^{a} \mathrm{HPLC}$ analysis of samples held at $25^{\circ} \mathrm{C}$ for approximately 13 months. 
From the data shown in Fig. 1, one may conclude that the true solubility of BOBCalixC6 in Isopar ${ }^{\circledR} \mathrm{L}$ that contains only Cs-7SB at $25{ }^{\circ} \mathrm{C}$ lies within this gap. Both sets of data show a very slow convergence over the course of the past year. The increases in solubility upon dissolution were $8.4 \%$ and $16.5 \%$ for 0.5 and $0.75 \mathrm{M}$ Cs-7SB, respectively. The comparable decreases upon precipitation were $9.7 \%$ and $13.4 \%$ for 0.5 and $0.75 \mathrm{M} \mathrm{Cs}-7 \mathrm{SB}$, respectively. At this time, it is impossible to determine conclusively whether the upper set differs from the lower set because of the purity of BOBCalixC6 or because of the direction from which equilibrium is being approached. However, we believe that the latter cause is more probable, because the high concentration of Cs-7SB likely negates any effects on solubility of minor impurities in the as-received BOBCalixC6. As discussed earlier [11], these impurities apparently have an effect on the rate of dissolution of BOBCalixC6. Whereas recrystallized BOBCalixC6 can be dissolved very slowly (even with prolonged sonication and warming), the as-received material, nominally $97 \%$ pure, quickly dissolves to concentrations as high as $50 \mathrm{mM}$. For this reason, it has been impractical to experimentally approach equilibrium by precipitation of recrystallized BOBCalixC6. It is clear, then, that the lower bound of $7.55 \mathrm{mM}$ BOBCalixC6 at $0.75 \mathrm{M} \mathrm{Cs}-7 \mathrm{SB}$ is a conservative estimate for the BOBCalixC6 solubility. Not only is the final plateau concentration of BOBCalixC6 likely to be higher, but the most realistic condition in a plant environment is for equilibrium to be approached by precipitation of the as-received material.

\subsubsection{Cesium Distribution Results}

The cesium distribution data obtained with the ESS tests are summarized in Tables 6 and 7. The data in Table 6 are for the series of test samples containing $1 \mathrm{mM}$ TOA, and the results in Table 7 are for the series of test samples containing varying amounts of TOA and modifier with fixed BOBCalixC6 concentration. 
Table 6. ESS results obtained with constant TOA concentration ${ }^{a}$

\begin{tabular}{ccccccccc}
\hline $\begin{array}{c}{[\text { BOBCalixC6 }]} \\
(\mathrm{mM})\end{array}$ & $\begin{array}{c}{[\text { Cs-7SB }]} \\
(\mathrm{M})\end{array}$ & Extract & $\begin{array}{c}\text { Scrub } \\
\# 1\end{array}$ & $\begin{array}{c}\text { Scrub } \\
\# 2\end{array}$ & $\begin{array}{c}\text { Strip } \\
\# 1\end{array}$ & $\begin{array}{c}\text { Strip } \\
\# 2\end{array}$ & $\begin{array}{c}\text { Strip } \\
\# 3\end{array}$ & $\begin{array}{c}\text { Strip } \\
\# 4\end{array}$ \\
\hline 10 & 0.50 & 17.2 & 1.52 & 1.52 & 0.114 & 0.070 & 0.055 & 0.051 \\
10 & 0.65 & 19.6 & 1.75 & 1.79 & 0.136 & 0.084 & 0.066 & 0.057 \\
10 & 0.75 & 20.7 & 1.91 & 1.91 & 0.152 & 0.092 & 0.072 & 0.062 \\
& & & & & & & & \\
8 & 0.65 & 15.4 & 1.38 & 1.44 & 0.109 & 0.066 & 0.053 & 0.045 \\
8 & 0.75 & 16.1 & 1.52 & 1.54 & 0.120 & 0.075 & 0.056 & 0.050 \\
8 & 0.85 & 17.2 & 1.68 & 1.66 & 0.134 & 0.077 & 0.062 & 0.053 \\
8 & 1.00 & 17.7 & 1.87 & 1.78 & 0.145 & 0.086 & 0.069 & 0.060 \\
& & & & & & & & \\
6 & 0.75 & 12.2 & 1.12 & 1.16 & 0.089 & 0.051 & 0.042 & 0.036 \\
6 & 0.85 & 12.3 & 1.23 & 1.25 & 0.095 & 0.055 & 0.044 & 0.040 \\
6 & 1.00 & 13.6 & 1.39 & 1.39 & 0.112 & 0.065 & 0.051 & 0.046 \\
\hline
\end{tabular}

${ }^{a}$ Temperature $=25^{\circ} \mathrm{C} .[\mathrm{TOA}]=1 \mathrm{mM}$.

Interest in increasing the TOA concentration is twofold. First, as the TOA concentration increases, the CSSX process becomes more resistant to anionic impurities. Second, thermal [11] and radiolytic $[12,14]$ stability test results showed that TOA is the solvent component most susceptible to decomposition. However, the concentration cannot be increased excessively, because the organic-phase concentration of nitrate in the scrub stage will increase by the protonation of TOA. This extracted nitrate will be partially released in the first strip stage, causing the value of $D_{\mathrm{Cs}}$ for the first strip stage to increase, which could ultimately limit stripping efficiency. Assuming an O:A ratio of 5:1 in the strip section, stripping becomes ineffective (because of "pinching") when the first strip $D_{\mathrm{Cs}}$ value becomes equal to or greater than 0.2. The data show that stripping will not be so affected at TOA concentrations as high as $10 \mathrm{mM}$.

The results show that values of $D_{\mathrm{Cs}}$ for the two scrubs decrease as the concentration of TOA increases. This behavior is expected, because more nitrate is extracted, which both decreases the aqueous nitrate concentration and decreases the effective concentration of modifier, as more modifier molecules are tied up in solvating the nitrate. The $D_{\mathrm{Cs}}$ values in the initial strip stages also increase. Again, this result is expected, because greater nitrate extraction in scrubbing implies greater release of nitrate from the solvent into the strip aqueous phase. As a result of this higher nitrate concentration in the first strip stage and resultant higher $D_{\mathrm{Cs}}$, more stages are required for the $D_{\mathrm{Cs}}$ value to converge to the limiting value. This limiting value should, in principle, be the same for all TOA concentrations. It also appears that the extraction $D_{\mathrm{Cs}}$ values decrease with increasing TOA concentrations. Assuming this slight decrease is real, it may reflect more modifier molecules being tied up in solvating the TOA. 
Table 7. ESS results obtained with two selected solvents with variable TOA concentrations ${ }^{a}$

\begin{tabular}{|c|c|c|c|c|c|c|c|}
\hline \multirow[b]{2}{*}[\mathrm{TOA}]{,$(\mathrm{mM})$} & \multicolumn{7}{|c|}{$D_{\mathrm{Cs}}$} \\
\hline & Extract & $\begin{array}{c}\text { Scrub } \\
\text { no. } 1\end{array}$ & $\begin{array}{l}\text { Scrub } \\
\text { no. } 2\end{array}$ & $\begin{array}{l}\text { Strip } \\
\text { no. } 1\end{array}$ & $\begin{array}{l}\text { Strip } \\
\text { no. } 2\end{array}$ & $\begin{array}{l}\text { Strip } \\
\text { no. } 3\end{array}$ & $\begin{array}{l}\text { Strip } \\
\text { no. } 4\end{array}$ \\
\hline \multicolumn{8}{|c|}{$[$ BOBCalixC6 $]=8 \mathrm{mM},[\mathrm{Cs}-7 \mathrm{SB}]=0.65 \mathrm{M}$} \\
\hline 1 & 15.4 & 1.38 & 1.44 & 0.109 & 0.066 & 0.053 & 0.045 \\
\hline 3 & 14.9 & 1.08 & 1.39 & 0.116 & 0.081 & 0.069 & 0.056 \\
\hline 10 & 14.7 & 1.00 & 0.76 & 0.134 & 0.104 & 0.090 & 0.076 \\
\hline \multicolumn{8}{|c|}{$[\mathrm{BOBCalixC6}]=8 \mathrm{mM},[\mathrm{Cs}-7 \mathrm{SB}]=0.75 \mathrm{M}$} \\
\hline 1 & 16.4 & 1.54 & 1.55 & 0.121 & 0.073 & 0.059 & 0.052 \\
\hline 3 & 15.5 & 1.26 & 1.49 & 0.124 & 0.083 & 0.075 & 0.059 \\
\hline 10 & 15.2 & 1.20 & 0.70 & 0.137 & 0.101 & 0.091 & 0.078 \\
\hline
\end{tabular}

${ }^{a}$ Temperature $=25^{\circ} \mathrm{C}$.

Based on the cesium distribution ratio $\left(D_{\mathrm{Cs}}\right)$ data contained in Tables 6 and 7, all of the tested solvent compositions meet the $D_{\mathrm{Cs}}$ acceptance criterion. The $D_{\mathrm{Cs}}$ values in Tables 6 and 7 , when analyzed as $\log$ $D_{\mathrm{Cs}}$ versus $\log$ (BOBCalixC6 concentration) and $\log D_{\mathrm{Cs}}$ versus $\log$ (Cs-7SB modifier concentration), are linear with slopes approximately equal to one. Using these relationships, a simple set of equations can be used to predict the $D_{\mathrm{Cs}}$ values as a function of the BOBCalixC6 and Cs-7SB modifier concentrations. The results of the prediction for BOBCalixC6 and modifier concentrations about the recommended solvent composition are given in Appendix A, Table"A.1.

\subsubsection{Flowsheet Robustness}

A series of Spreadsheet Algorithms for Stagewise Solvent Extraction (SASSE) [33] calculations were performed using the $D_{\mathrm{Cs}}$ values contained in Tables 6 and 7. The assumptions used in these calculations include the following: (1) the extraction and scrub $D_{\mathrm{Cs}}$ values are proportional to the concentration of free BOBCalixC6 in the organic phase; (2) the BOBCalixC6 is loaded with only one cesium ion; (3) the $D_{\mathrm{Cs}}$ value for the strip is proportional to the concentration of nitrate in the aqueous phase; (4) the total cesium concentration of the waste feed is $0.00014 \mathrm{M}$; (5) the temperature of the entire contactor cascade is $25^{\circ} \mathrm{C}$; (6) the stage efficiency is $80 \%$; (7) $0.1 \%$ other-phase carryover occurs between stages; (8) there are 15 "extraction stages, 2 scrub stages, and 15 strip stages; (9) there are $20.1 \mathrm{gal} / \mathrm{min}$ of waste feed and $1.33 \mathrm{gal} / \mathrm{min}$ of strip feed, and (10) the O:A in the scrub section is 5.0.

The results of the calculations are given in Table 8 . The robustness number $(\mathrm{Rb})$ is defined as the ratio of the decontamination factor for a given set of flowsheet conditions to the process-required bounding decontamination factor of 40,000. The baseline flowsheet specifies a solvent flow rate of 
$6.6 \mathrm{gal} / \mathrm{min}$ [3]. The maximum robustness was obtained by varying the solvent flow rate, which is shown in the fourth column of Table 8 .

All of the solvent compositions tested meet the bounding criterion for robustness at the baseline solvent flow rate; however, the two solvent compositions containing $10 \mathrm{mM}$ TOA do not meet the "goal" (i.e., the target criterion) for robustness. When the solvent flow rate is adjusted to achieve the maximum robustness, all of the solvent compositions meet the goal for robustness.

Table 8. Calculated robustness for various CSSX solvent compositions

\begin{tabular}{lccc}
\hline Solvent identification $^{a}$ & $\begin{array}{c}\mathrm{Rb} \text { at } 6.6 \mathrm{gal} / \mathrm{min} \\
\text { waste feed }\end{array}$ & $\mathrm{Rb}_{\max }$ & $\begin{array}{c}\text { Optimum flow rate } \\
\text { (Flow rate at } \mathrm{Rb}_{\text {max }}, \text { gal/min) }\end{array}$ \\
\hline Previous baseline $^{\text {B }}$ & 21.9 & 25.3 & 6.1 \\
B001107-3-1 & 11.9 & 26.4 & 5.3 \\
B001107-3-2 & 25.0 & 25.3 & 6.7 \\
B001107-3-3 & 6.6 & 23.6 & 4.9 \\
B001107-3-4 & 19.3 & 20.7 & 6.2 \\
B001107-3-5 & 8.8 & 24.3 & 8.5 \\
B001107-3-6 & 15.7 & 21.2 & 5.8 \\
B001107-3-7 & 9.1 & 17.8 & 8.0 \\
B001107-3-8 & 7.3 & 15.4 & 5.4 \\
B001107-3-9 & 14.3 & 15.6 & 7.0 \\
B001107-3-2A & 8.8 & 10.1 & 6.1 \\
B001107-3-2B & 1.1 & 3.0 & 5.3 \\
B001107-3-4C & 6.9 & 9.7 & 5.8 \\
B001107-3-4D & 1.0 & 3.2 & 5.1 \\
\hline
\end{tabular}

${ }^{a}$ See Table 2 for the composition of the specified solvent.

It should be noted that the SASSE calculations are considered to be conservative, since they assume a constant process temperature and a stage efficiency of $80 \%$. In the actual process, the extraction section will be kept cooler than the strip section, thereby improving the process robustness. For example, if the extraction section were at $25{ }^{\circ} \mathrm{C}$, the scrub section at $29{ }^{\circ} \mathrm{C}$, and the strip section at $33{ }^{\circ} \mathrm{C}$, the robustness for the baseline solvent at a flow rate of $6.6 \mathrm{gal} / \mathrm{min}$ increases from 21.9 to 80.7. Thus, process robustness can be increased substantially by means of temperature control.

At the time the calculations were performed, it was believed that while a stage efficiency of $80 \%$ was assumed for the centrifugal contactor, the expected efficiency will be greater than 90\% [34,35]. Assuming a $90 \%$ stage efficiency in the SASSE calculations at $25{ }^{\circ} \mathrm{C}$, the robustness for the baseline 
solvent at a flow rate of $6.6 \mathrm{gal} / \mathrm{min}$ would increase from 21.9 to 599 . Higher stage efficiency, which can be expected with the plant-scale contactors, would increase process robustness. Since then, experiments carried out at INEEL with the baseline solvent in $5.5 \mathrm{~cm}$ contactors (ORNL design) showed a lower efficiency (72-75\% on extraction, 36-60\% on stripping). However, it is expected that process chemistry was not the cause, that an optimized contactor design could solve the low efficiency issue and that the assumptions considered for the SASSE calculations were still valid [36].

\subsubsection{Third-Phase Formation}

One of the major criteria the solvent must meet is the absence of third-phase formation for the expected maximum loading of the solvent at $15{ }^{\circ} \mathrm{C}$, which occurs at the high cesium and potassium concentrations. This requirement was determined in FY 2001 at the time the process temperature range was established [3]. The results of the third-phase evaluations for solvents containing $1 \mathrm{mM}$ TOA are presented in Table 9. Results of these experiments indicate that the use of any solvent containing $10 \mathrm{mM}$ BOBCalixC6 is not recommended at a Cs-7SB modifier concentration less than $0.75 \mathrm{M}$.

Table 9. Temperature range for third-phase appearance

\begin{tabular}{|c|c|c|c|c|}
\hline \multirow{2}{*}{$\begin{array}{c}\text { [BOBCalixC6] } \\
(\mathrm{mM})\end{array}$} & \multirow{2}{*}{$\begin{array}{c}{[\mathrm{Cs}-7 \mathrm{SB}]} \\
(\mathrm{M})\end{array}$} & \multicolumn{3}{|c|}{ Temperature range $\left({ }^{\circ} \mathrm{C}\right)$} \\
\hline & & $\begin{array}{l}\text { Full SRS } \\
\text { simulant }\end{array}$ & $\begin{array}{l}\text { High-potassium } \\
\text { simulant }\end{array}$ & $\begin{array}{l}\text { High-cesium and high- } \\
\text { potassium simulant }\end{array}$ \\
\hline 10 & 0.50 & $15.0-16.5$ & $17.5-20.0$ & $17.5-20.0$ \\
\hline 10 & 0.65 & $12.0-13.0$ & $15.0-16.5$ & $15.0-16.5$ \\
\hline 10 & 0.75 & $10.0-11.0$ & $12.0-13.0$ & $12.0-13.0$ \\
\hline 8 & 0.65 & $10.0-11.0$ & $12.0-13.0$ & $12.0-13.0$ \\
\hline 8 & 0.75 & $8.5-9.0$ & $10.0-11.0$ & $10.0-11.0$ \\
\hline 8 & 0.85 & $7.5-8.0$ & $8.5-9.0$ & $8.5-9.0$ \\
\hline 8 & 1.00 & $6.5-7.0$ & $6.5-7.0$ & $6.5-7.0$ \\
\hline 6 & 0.75 & $6.5-7.0$ & $8.0-8.5$ & $8.5-9.0$ \\
\hline 6 & 0.85 & $5.0-6.5$ & $7.0-7.5$ & $7.0-7.5$ \\
\hline 6 & 1.00 & $\mathrm{~F}^{a}$ & $\mathrm{~F}^{a}$ & $\mathrm{~F}^{a}$ \\
\hline
\end{tabular}

${ }^{a}$ The letter "F" denotes that the solvent did not exhibit a third-phase at $5{ }^{\circ} \mathrm{C}$. However, because of the high concentration of modifier, the solvent viscosity had increased significantly at that temperature, making observation of a third-phase difficult. 


\subsubsection{Solvent Dispersion Numbers}

The results for the dispersion-number determinations are given in Table 10 and shown graphically in Fig. 5. The subset of the solvent test samples contained $1 \mathrm{mM}$ TOA. The data for the baseline solvent are taken from earlier testing [34]. The results show that all nine compositions meet the dispersion-number criterion for extraction, scrub, and strip conditions (cf. Table 1).

Dispersion-number determinations for a selected subset of the samples against $10-\mathrm{mM} \mathrm{NaOH}$ wash solutions are shown in Fig. 6. None of the solvent samples met the $\mathrm{NaOH}$ solvent-wash solution criterion. The 10-mM NaOH concentration was used during the FY 2001 flowsheet tests at Argonne National Laboratory [16], which used simulant as the feed, and tests at Savannah River Technology Center [17], which used real waste as the feed. During these tests, minor emulsion formation was observed. Solvent samples B001107-3-4 and B001107-3-5 were determined to have the most desirable characteristics when compared against all of the selection criteria. These two solvents were selected for dispersion-number determinations as a function of $\mathrm{NaOH}$ concentrations. The results of these tests are given in Table 11 and shown graphically in Fig. 7. When the $\mathrm{NaOH}$ concentration was $300 \mathrm{mM}$, these two solvent compositions met the dispersion-number criterion for solvent washing.

Table 10. Dispersion numbers for extraction, scrub, and stripping of CSSX solvents

\begin{tabular}{ccccc}
\hline & \multicolumn{3}{c}{ Dispersion number } \\
\cline { 2 - 5 } $\begin{array}{c}\text { Solvent } \\
\text { description }^{a}\end{array}$ & Simulant/solvent & Scrub/solvent & Strip/solvent & $\begin{array}{c}\text { Wash/solvent } \\
\text { O.01 M NaOH } \\
\text { (O:A"="5:1) }\end{array}$ \\
\hline Previous baseline & 0.00149 & 0.00096 & 0.00115 & - \\
B001107-3-1 & 0.00075 & 0.00102 & 0.00091 & - \\
B001107-3-2 & 0.00056 & 0.00070 & 0.00078 & 0.00022 \\
B001107-3-3 & 0.00102 & 0.00052 & 0.00088 & - \\
B001107-3-4 & 0.00102 & 0.00053 & 0.00094 & 0.00034 \\
B001107-3-5 & 0.00118 & 0.00050 & 0.00088 & 0.00024 \\
B001107-3-6 & 0.00105 & 0.00059 & 0.00075 & 0.00016 \\
B001107-3-7 & 0.00125 & 0.00058 & 0.00085 & 0.00016 \\
B001107-3-8 & 0.00120 & 0.00062 & 0.00054 & - \\
B001107-3-9 & 0.00141 & 0.00041 & 0.00051 & - \\
\hline
\end{tabular}

${ }^{a}$ See Table 2 for the composition of the specified solvent. 


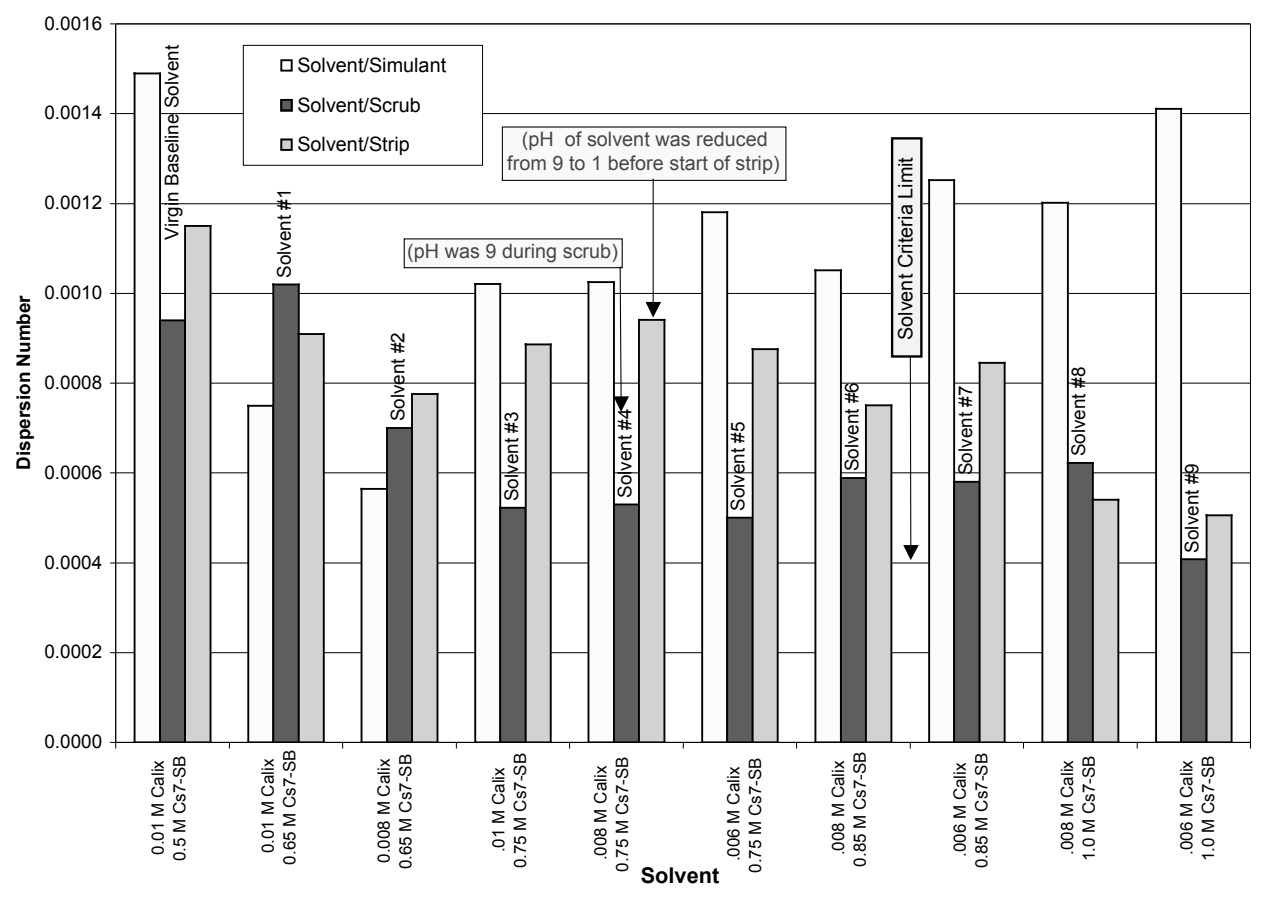

Fig. 5. CSSX solvent dispersion numbers for extraction, scrub, and strip conditions at baseline $O$ :A ratios.

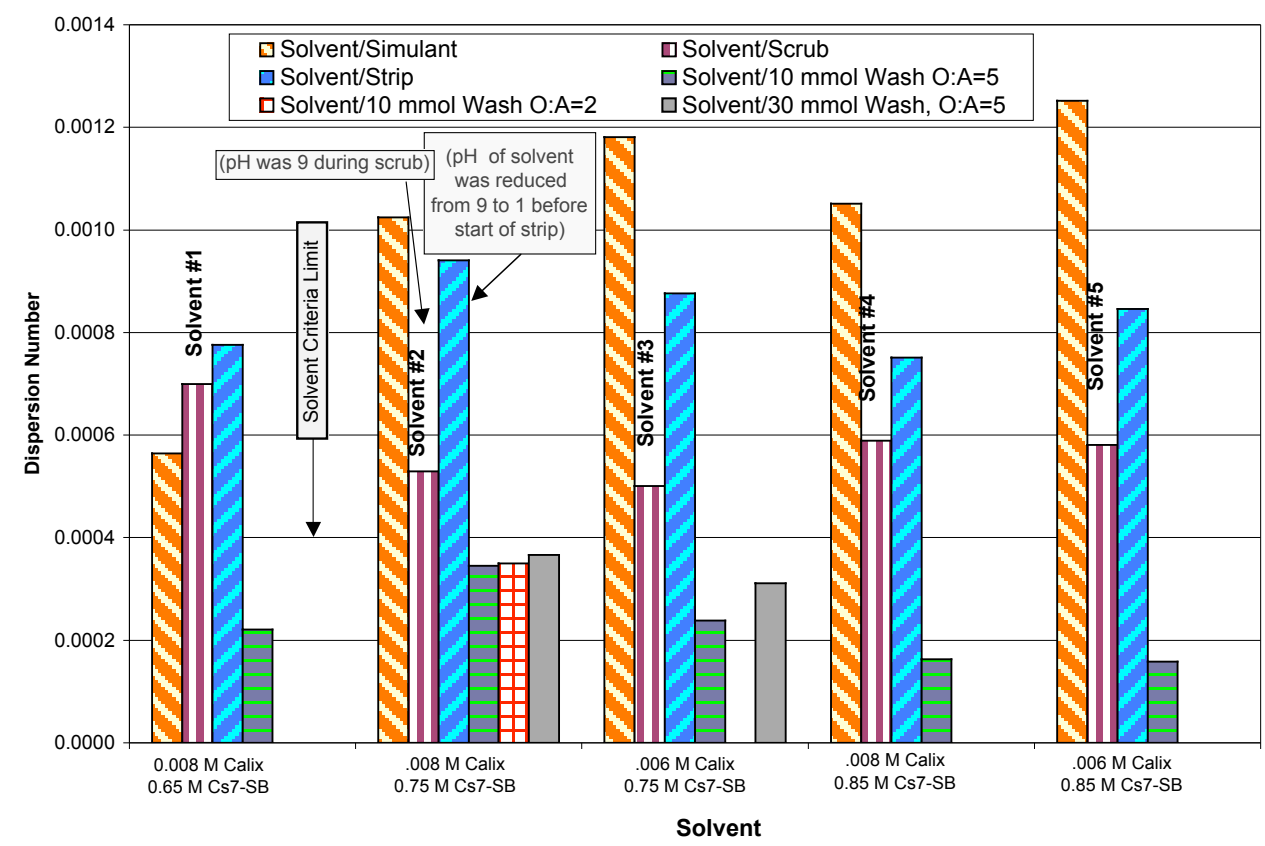

Fig. 6. CSSX solvent dispersion numbers for solvent wash with dilute $\mathrm{NaOH}$. 
Table 11. Dispersion numbers for washing of CSSX solvents B001107-3-4 and B001107-3-5

Solvent/wash dispersion number

\begin{tabular}{ccccc}
$\begin{array}{c}\text { Solvent } \\
\text { descriptor }^{a}\end{array}$ & $0.01 \mathrm{M} \mathrm{NaOH}$ wash & $0.03 \mathrm{M} \mathrm{NaOH}$ wash & $0.1 \mathrm{M} \mathrm{NaOH}$ wash & $0.3 \mathrm{M} \mathrm{NaOH}$ wash \\
\hline B001107-3-4 & 0.00035 & 0.00037 & 0.00037 & 0.00049 \\
B001107-3-5 & 0.00024 & 0.00031 & 0.00024 & 0.00045
\end{tabular}

${ }^{a}$ See Table 2 for the composition of the specified solvent.

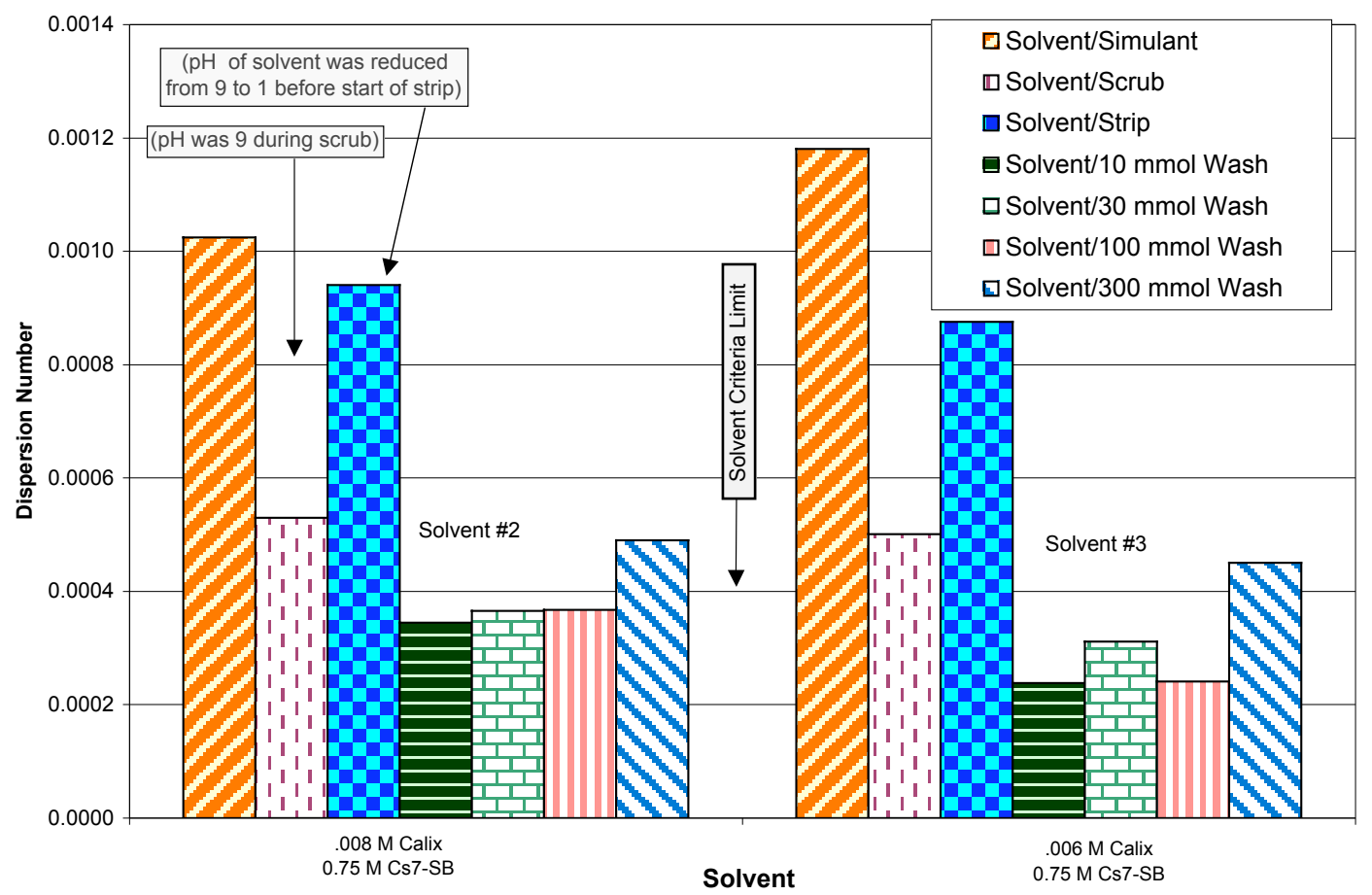

Fig. 7. CSSX solvent dispersion numbers for solvent washing as a function of $\mathrm{NaOH}$ concentration.

\subsubsection{Solvent Density}

The results of the density determinations are presented in Table 12. As expected, solvent density is primarily dependent on the modifier concentration. The relationship between density and modifier concentration is shown in Fig. 8. All the solvent samples that were tested met the bounding criterion for density (cf. Table 1); however, the solvent samples with modifier concentrations equal to or greater than $0.85 \mathrm{M}$ did not meet the goal for density. 
Table 12. Solvent-density determinations

\begin{tabular}{ccccccccc}
\hline $\begin{array}{c}\text { Solvent } \\
\text { identification }^{a}\end{array}$ & $\begin{array}{c}\text { Mass of } \\
\text { solvent } \\
(\mathrm{g})\end{array}$ & $\begin{array}{c}\text { Density }^{b} \\
\left(\mathrm{~g} / \mathrm{cm}^{3}\right)\end{array}$ & $\begin{array}{c}{[\text { Calix }]} \\
(\mathrm{M})\end{array}$ & $\begin{array}{c}\text { [Modifier] } \\
(\mathrm{M})\end{array}$ & $\begin{array}{c}\text { Corrected } \\
\text { volume } \\
(\mathrm{mL})\end{array}$ & $\begin{array}{c}\text { Mass of } \\
\text { water } \\
(\mathrm{g})\end{array}$ & $\begin{array}{c}\text { Specific } \\
\text { gravity }\end{array}$ & $\begin{array}{c}50-\mathrm{mL} \\
\text { vol. } \\
\text { flask }\end{array}$ \\
\hline Baseline $^{c}$ & & 0.810 & & & & & & \\
\hline B001107-3-1 & 41.9085 & 0.8395 & 0.010 & 0.65 & 49.9202 & 49.7819 & 0.99723 & 1 \\
B001107-3-2 & 41.9230 & 0.8395 & 0.008 & 0.65 & 49.9362 & 49.7979 & 0.99723 & 2 \\
B001107-3-3 & 42.5920 & 0.8531 & 0.010 & 0.75 & 49.9242 & 49.7859 & 0.99723 & 3 \\
B001107-3-4 & 42.5149 & 0.8525 & 0.008 & 0.75 & 49.8703 & 49.7322 & 0.99723 & 5 \\
B001107-3-5 & 42.4714 & 0.8516 & 0.006 & 0.75 & 49.8703 & 49.7322 & 0.99723 & 5 \\
B001107-3-6 & 43.0887 & 0.8644 & 0.008 & 0.85 & 49.8480 & 49.7099 & 0.99723 & 6 \\
B001107-3-7 & 43.1036 & 0.8632 & 0.006 & 0.85 & 49.9362 & 49.7979 & 0.99723 & 2 \\
B001107-3-8 & 44.0269 & 0.8819 & 0.008 & 1.00 & 49.9242 & 49.7859 & 0.99723 & 3 \\
B001107-3-9 & 44.6565 & 0.8951 & 0.006 & 1.00 & 49.8925 & 49.7543 & 0.99723 & 4 \\
\hline
\end{tabular}

${ }^{a}$ See Table 2 for the composition of the specified solvent.

${ }^{b}$ Temperature was $25.6^{\circ} \mathrm{C}$.

${ }^{c}$ Measured previously on previous-baseline pristine solvent.

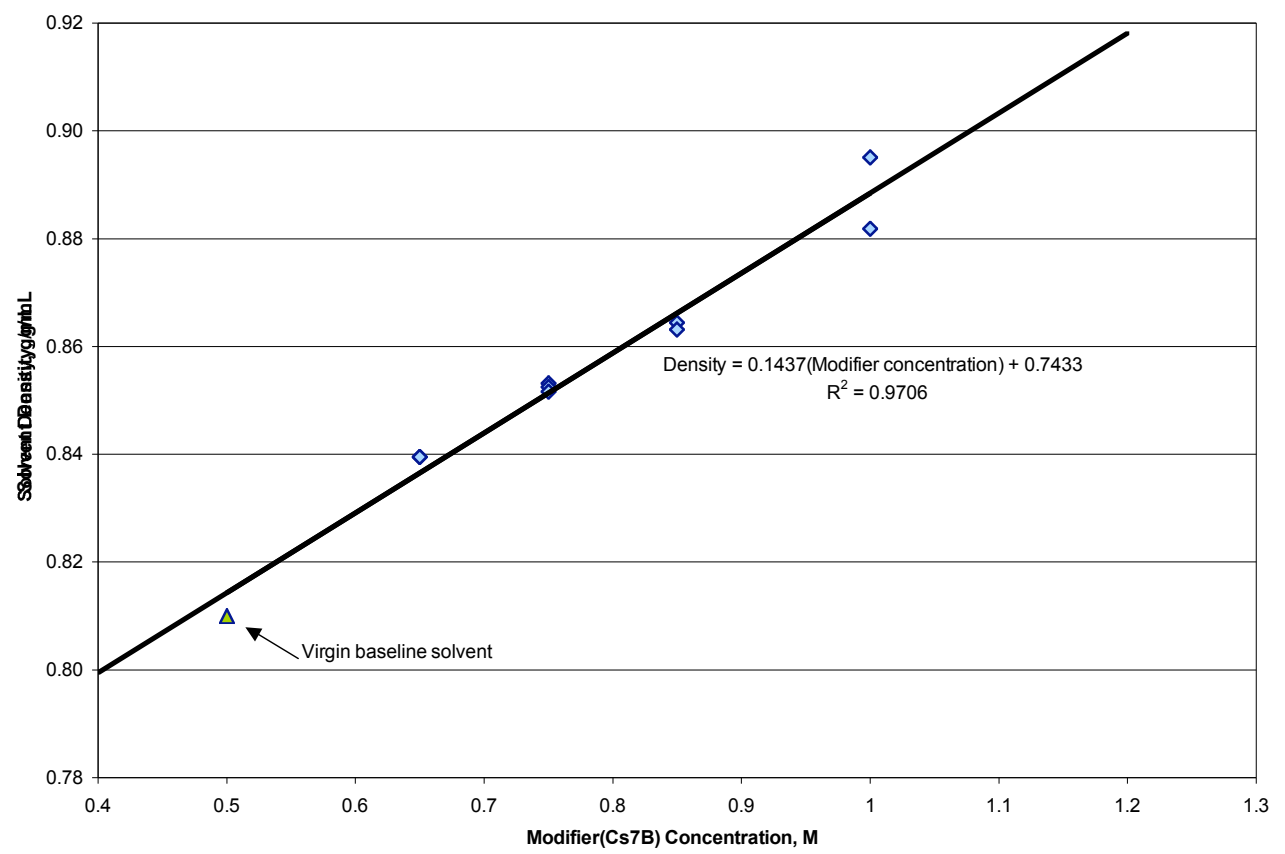

Fig. 8. CSSX solvent density as a function of Cs-7SB modifier concentration for $25.6{ }^{\circ} \mathrm{C}$. 


\subsubsection{Solvent Viscosity}

The results of the solvent-viscosity measurements are shown in Fig. 9, and Fig. 10 shows the shear stress as a function of temperature. The data are presented in tabular form in Table 13. The solvents with the lowest concentration of the Cs-7SB modifier have the lowest viscosity. The BOBCalixC6 concentration has only a minor effect on the viscosity decrease, because its concentration decreases at a given Cs-7SB concentration. The viscosity of all solvent samples decreases with increasing temperature, as expected for this type of liquid.

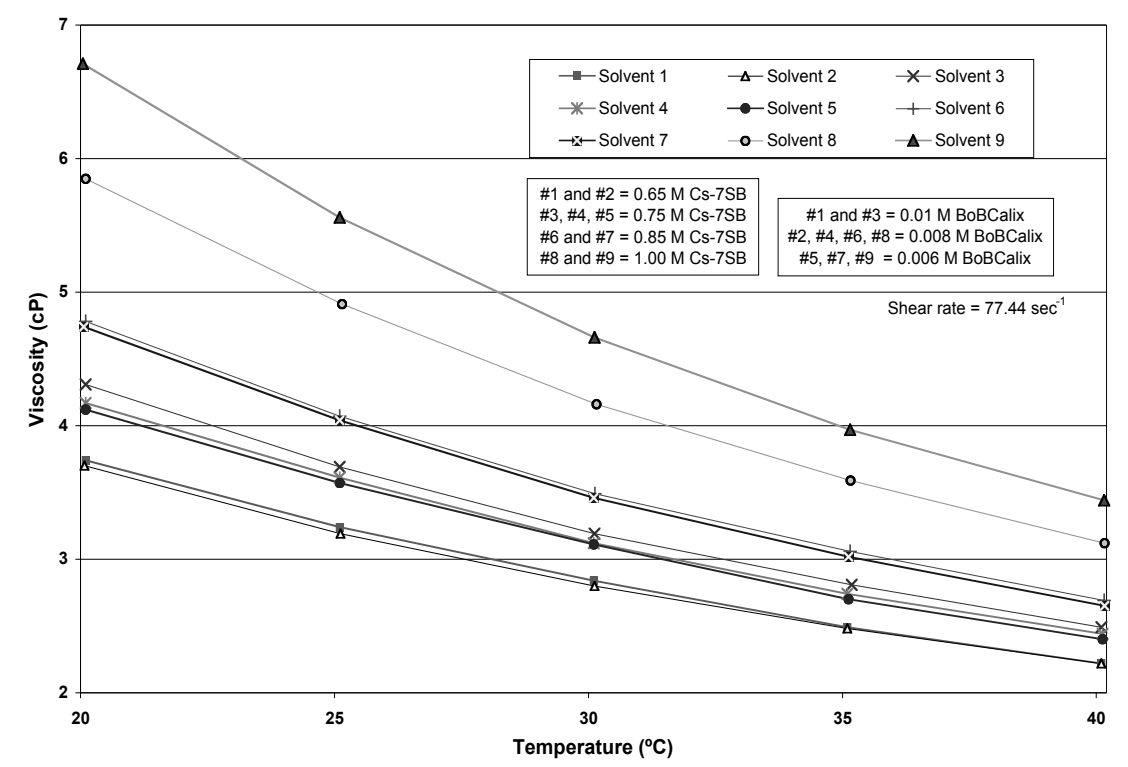

Fig. 9. Solvent viscosity as a function of temperature. The numbers in the legend are the test numbers from Table 2. 


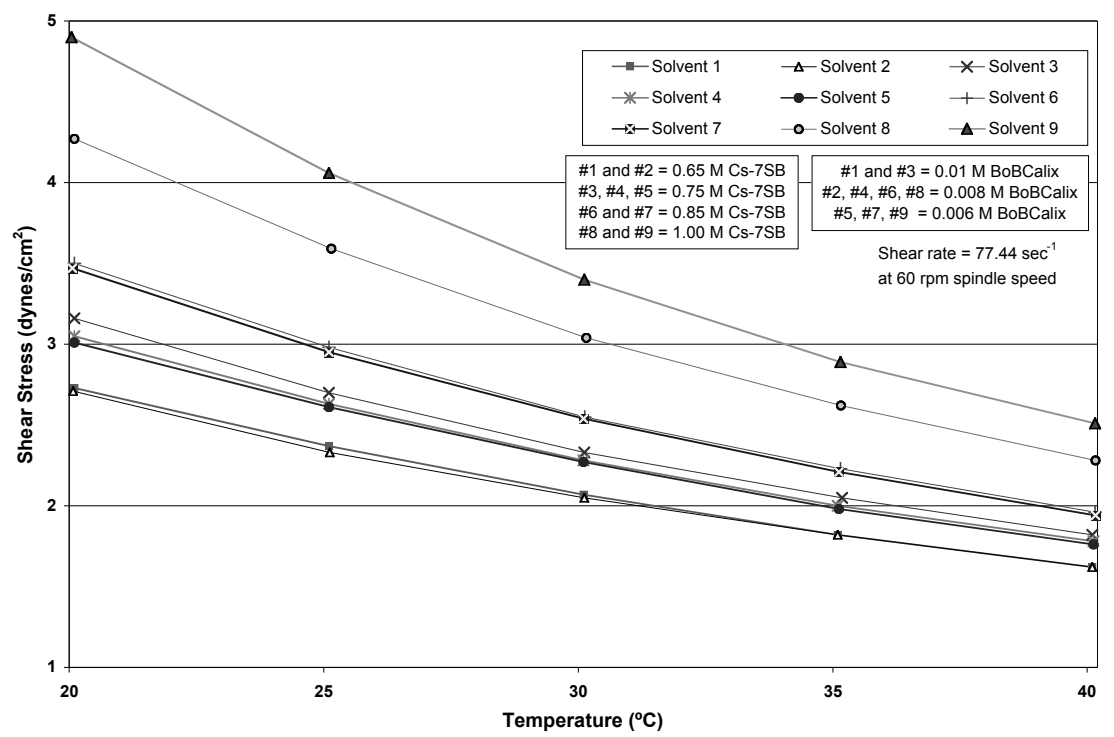

Fig. 10. Solvent shear stress as a function of temperature. The solvent numbers in the legend are the test numbers from Table 2.

Table 13. Solvent-viscosity determinations ${ }^{a}$

\begin{tabular}{ccccc}
\hline Solvent $^{b}$ & $\begin{array}{c}\text { Temperature } \\
\left({ }^{\circ} \mathrm{C}\right)\end{array}$ & $\begin{array}{c}\text { Torque } \\
(\%)\end{array}$ & $\begin{array}{c}\text { Viscosity }^{c} \\
(\mathrm{cP})\end{array}$ & $\begin{array}{c}\text { Shear stress } \\
\left(\mathrm{dyn} / \mathrm{cm}^{2}\right)\end{array}$ \\
\hline B001107-3-1 & 20.00 & 37.3 & 3.74 & 2.73 \\
& 25.00 & 32.3 & 3.24 & 2.37 \\
& 30.00 & 28.2 & 2.84 & 2.07 \\
& 35.00 & 24.9 & 2.49 & 1.82 \\
B001107-3-2 & 40.00 & 22.2 & 2.22 & 1.62 \\
& 19.98 & 36.9 & 3.70 & 2.71 \\
& 25.02 & 31.9 & 3.19 & 2.33 \\
& 30.02 & 28.0 & 2.80 & 2.05 \\
& 35.00 & 24.8 & 2.48 & 1.82 \\
& 40.00 & 22.2 & 2.22 & 1.62 \\
& & & & 3.16 \\
& 20.00 & 43.2 & 4.31 & 2.70 \\
& 25.00 & 36.9 & 3.69 & 2.33 \\
& 30.02 & 31.9 & 3.19 & 2.05 \\
& 35.08 & 28.0 & 2.81 & 1.82 \\
\hline
\end{tabular}


Table 13 - continuation. Solvent-viscosity determinations ${ }^{a}$

\begin{tabular}{|c|c|c|c|c|}
\hline Solvent $^{b}$ & $\begin{array}{c}\text { Temperature } \\
\left({ }^{\circ} \mathrm{C}\right)\end{array}$ & $\begin{array}{l}\text { Torque } \\
(\%)\end{array}$ & $\begin{array}{l}\text { Viscosity }^{c} \\
(\mathrm{cP})\end{array}$ & $\begin{array}{c}\text { Shear stress } \\
\left(\mathrm{dyn} / \mathrm{cm}^{2}\right)\end{array}$ \\
\hline \multirow[t]{6}{*}{ B001107-3-4 } & 20.00 & 41.8 & 4.17 & 3.05 \\
\hline & 25.00 & 36.0 & 3.61 & 2.63 \\
\hline & 25.00 & 36.0 & 3.61 & 2.63 \\
\hline & 30.00 & 31.2 & 3.12 & 2.28 \\
\hline & 35.00 & 27.4 & 2.74 & 2.00 \\
\hline & 40.02 & 24.4 & 2.44 & 1.78 \\
\hline \multirow[t]{5}{*}{ В001107-3-5 } & 20.00 & 41.3 & 4.12 & 3.01 \\
\hline & 25.00 & 35.7 & 3.57 & 2.61 \\
\hline & 30.00 & 31.0 & 3.11 & 2.27 \\
\hline & 35.02 & 27.1 & 2.70 & 1.98 \\
\hline & 40.02 & 24.0 & 2.40 & 1.76 \\
\hline \multirow[t]{5}{*}{ B001107-3-6 } & 20.00 & 47.8 & 4.78 & 3.50 \\
\hline & 25.00 & 40.7 & 4.07 & 2.98 \\
\hline & 30.03 & 34.9 & 3.49 & 2.55 \\
\hline & 35.05 & 30.5 & 3.06 & 2.23 \\
\hline & 40.05 & 26.8 & 2.69 & 1.96 \\
\hline \multirow[t]{5}{*}{ B001107-3-7 } & 19.96 & 47.3 & 4.74 & 3.47 \\
\hline & 25.00 & 40.3 & 4.04 & 2.95 \\
\hline & 30.00 & 34.6 & 3.46 & 2.54 \\
\hline & 35.02 & 30.2 & 3.02 & 2.21 \\
\hline & 40.06 & 26.6 & 2.65 & 1.94 \\
\hline \multirow[t]{5}{*}{ B001107-3-8 } & 20.00 & 58.5 & 5.85 & 4.27 \\
\hline & 25.05 & 49.0 & 4.91 & 3.59 \\
\hline & 30.06 & 41.6 & 4.16 & 3.04 \\
\hline & 35.06 & 35.8 & 3.59 & 2.62 \\
\hline & 40.06 & 31.3 & 3.12 & 2.28 \\
\hline \multirow[t]{5}{*}{ B001107-3-9 } & 19.95 & 67.1 & 6.71 & 4.90 \\
\hline & 25.00 & 55.4 & 5.56 & 4.06 \\
\hline & 30.02 & 46.5 & 4.66 & 3.40 \\
\hline & 35.05 & 39.7 & 3.97 & 2.89 \\
\hline & 40.05 & 34.3 & 3.44 & 2.51 \\
\hline
\end{tabular}

${ }^{a}$ Brookfield LVTDV-II (Serial Number D15869) UL Adapter with heating jacket.

${ }^{b}$ See Table 2 for the composition of the specified solvent.

${ }^{c}$ Standard deviation is estimated to be \pm 0.1 centipoise (cP). 


\subsubsection{Solvent Interfacial Tension}

The results of the measurements are given in Tables 14-17 and are shown graphically in Figs. 11 and"12. The tables contain the data for the four series of tests. Figure 11 shows the surface tension of the solvents and also contains the surface tensions of the aqueous simulant, scrub solution, and strip solution. Figure 12 shows the interfacial tension of the solvents versus simulant, scrub, and strip solutions. The results reveal nothing unusual, and the individual solvents behave similarly with the three aqueous solutions tested.

Table 14. Surface-tension determinations

\begin{tabular}{|c|c|c|c|c|c|c|}
\hline \multirow{2}{*}{$\begin{array}{c}\text { Solution } \\
\text { identification }^{a}\end{array}$} & \multirow{2}{*}{$\begin{array}{l}\text { Density } \\
\left(\mathrm{g} / \mathrm{cm}^{3}\right)\end{array}$} & \multicolumn{2}{|c|}{$\begin{array}{c}\text { Indicated } \\
\text { surface tension } \\
(\mathrm{dyn} / \mathrm{cm}) \\
\end{array}$} & \multirow{2}{*}{$\begin{array}{c}\text { Instrument } \\
\text { reading, } \\
\text { average } \\
\left(P_{\text {interface }}\right)\end{array}$} & \multirow{2}{*}{$\begin{array}{l}\text { Correction } \\
\text { factor }(F) \\
\text { from Eq. } 3\end{array}$} & \multirow{2}{*}{$\begin{array}{c}\text { Actual } \\
\text { surface } \\
\text { tension } \\
(\text { dyn } / \mathrm{cm})\end{array}$} \\
\hline & & Trial 1 & Trial 2 & & & \\
\hline B001107-3-1 & 0.8395 & 26.9 & 26.8 & 26.9 & 0.8896 & 23.9 \\
\hline В001107-3-2 & 0.8395 & 26.8 & 26.8 & 26.8 & 0.8895 & 23.8 \\
\hline В001107-3-3 & 0.8531 & 26.8 & 26.7 & 26.8 & 0.8888 & 23.8 \\
\hline В001107-3-4 & 0.8525 & 26.8 & 26.9 & 26.9 & 0.8890 & 23.9 \\
\hline B001107-3-5 & 0.8516 & 27.0 & 27.1 & 27.1 & 0.8893 & 24.1 \\
\hline В001107-3-6 & 0.8644 & 27.0 & 26.9 & 27.0 & 0.8886 & 23.9 \\
\hline B001107-3-7 & 0.8632 & 26.9 & 27.0 & 27.0 & 0.8886 & 23.9 \\
\hline В001107-3-8 & 0.8819 & 27.0 & 27.1 & 27.1 & 0.8879 & 24.0 \\
\hline В001107-3-9 & 0.8951 & 27.1 & 27.0 & 27.1 & 0.8874 & 24.0 \\
\hline Strip solution & 0.9974 & 41.0 & 40.0 & 40.5 & 0.8999 & 36.4 \\
\hline Scrub solution & 0.9984 & 48.3 & 48.1 & 48.2 & 0.9085 & 43.8 \\
\hline Simulant & 1.2536 & 64.6 & 64.8 & 64.7 & 0.9122 & 59.0 \\
\hline
\end{tabular}

${ }^{a}$ See Table 2 for the composition of the specified solvent. 
Table 15. Interfacial tension versus simulant

\begin{tabular}{|c|c|c|c|c|c|c|}
\hline \multirow{2}{*}{$\begin{array}{c}\text { Solvent } \\
\text { identification }^{a}\end{array}$} & \multirow{2}{*}{$\begin{array}{l}\text { Density } \\
\left(\mathrm{g} / \mathrm{cm}^{3}\right)\end{array}$} & \multicolumn{2}{|c|}{$\begin{array}{c}\text { Indicated } \\
\text { interfacial tension } \\
(\mathrm{dyn} / \mathrm{cm})\end{array}$} & \multirow{2}{*}{$\begin{array}{l}\text { Instrument } \\
\text { reading, } \\
\text { average } \\
\left(P_{\text {interface }}\right)\end{array}$} & \multirow{2}{*}{$\begin{array}{l}\text { Correction } \\
\text { factor } \\
\text { from Eq. } 3\end{array}$} & \multirow{2}{*}{$\begin{array}{c}\text { Actual } \\
\text { interfacial } \\
\text { tension } \\
(\mathrm{dyn} / \mathrm{cm})\end{array}$} \\
\hline & & Trial 1 & Trial 2 & & & \\
\hline B001107-3-1 & 0.8395 & 20.5 & 20.8 & 20.7 & 0.9103 & 18.8 \\
\hline B001107-3-2 & 0.8395 & 20.8 & 20.7 & 20.8 & 0.9106 & 18.9 \\
\hline B001107-3-3 & 0.8531 & 20.9 & 20.8 & 20.9 & 0.9127 & 19.0 \\
\hline B001107-3-4 & 0.8525 & 20.7 & 20.5 & 20.6 & 0.9119 & 18.8 \\
\hline B001107-3-5 & 0.8516 & 20.7 & 20.6 & 20.7 & 0.9119 & 18.8 \\
\hline B001107-3-6 & 0.8644 & 20.3 & 20.4 & 20.4 & 0.9129 & 18.6 \\
\hline B001107-3-7 & 0.8632 & 20.2 & 20.4 & 20.3 & 0.9126 & 18.5 \\
\hline B001107-3-8 & 0.8819 & 20.5 & 20.5 & 20.5 & 0.9160 & 18.8 \\
\hline B001107-3-9 & 0.8951 & 20.1 & 20.3 & 20.2 & 0.9172 & 18.5 \\
\hline
\end{tabular}

${ }^{a}$ See Table 2 for the composition of the specified solvent.

Table 16. Interfacial tension versus scrub solution

\begin{tabular}{ccccccc}
\hline Solvent & \multicolumn{9}{c}{$\begin{array}{c}\text { Indicated } \\
\text { interfacial tension } \\
\text { identification }\end{array}$} & $\begin{array}{c}\text { Density } \\
\left(\mathrm{g} / \mathrm{cm}^{3}\right)\end{array}$ & $\begin{array}{c}\text { Instrument } \\
\text { reading, } \\
\text { Trial 1 }\end{array}$ & Trial 2 & $\begin{array}{c}\text { average } \\
\left(P_{\text {interface })}\right.\end{array}$ & $\begin{array}{c}\text { Correction } \\
\text { factor } \\
\text { from Eq. 3 }\end{array}$ & $\begin{array}{c}\text { Actual } \\
\text { interfacial } \\
\text { tension } \\
(\text { dyn/cm })\end{array}$ \\
\hline B001107-3-1 & 0.8395 & 18.6 & 17.5 & 18.1 & 0.9703 & 17.5 \\
B001107-3-2 & 0.8395 & 16.8 & 16.9 & 16.9 & 0.9640 & 16.2 \\
B001107-3-3 & 0.8531 & 16.5 & 16.6 & 16.6 & 0.9706 & 16.1 \\
B001107-3-4 & 0.8525 & 16.7 & 16.5 & 16.6 & 0.9704 & 16.1 \\
B001107-3-5 & 0.8516 & 16.6 & 16.5 & 16.6 & 0.9696 & 16.0 \\
B001107-3-6 & 0.8644 & 16.4 & 16.3 & 16.4 & 0.9772 & 16.0 \\
B001107-3-7 & 0.8632 & 16.1 & 16.1 & 16.1 & 0.9748 & 15.7 \\
B001107-3-8 & 0.8819 & 16.0 & 16.0 & 16.0 & 0.9892 & 15.8 \\
B001107-3-9 & 0.8951 & 16.0 & 15.8 & 15.9 & 1.0016 & 15.9 \\
\hline
\end{tabular}

${ }^{a}$ See Table 2 for the composition of the specified solvent. 
Table 17. Interfacial tension versus strip solution

\begin{tabular}{|c|c|c|c|c|c|c|}
\hline \multirow{2}{*}{$\begin{array}{c}\text { Solvent } \\
\text { identification }^{a}\end{array}$} & \multirow{2}{*}{$\begin{array}{l}\text { Density } \\
\left(\mathrm{g} / \mathrm{cm}^{3}\right)\end{array}$} & \multicolumn{2}{|c|}{$\begin{array}{c}\text { Indicated } \\
\text { interfacial tension } \\
(\mathrm{dyn} / \mathrm{cm})\end{array}$} & \multirow{2}{*}{$\begin{array}{l}\text { Instrument } \\
\text { reading, } \\
\text { average } \\
\left(P_{\text {interface }}\right)\end{array}$} & \multirow{2}{*}{$\begin{array}{l}\text { Correction } \\
\text { factor } \\
\text { from Eq. } 3\end{array}$} & \multirow{2}{*}{$\begin{array}{c}\text { Actual } \\
\text { interfacial } \\
\text { tension } \\
(\mathrm{dyn} / \mathrm{cm})\end{array}$} \\
\hline & & Trial 1 & Trial 2 & & & \\
\hline B001107-3-1 & 0.8395 & 16.0 & 16.0 & 16.0 & 0.9599 & 15.4 \\
\hline B001107-3-2 & 0.8395 & 16.0 & 15.9 & 16.0 & 0.9596 & 15.3 \\
\hline B001107-3-3 & 0.8531 & 15.2 & 15.8 & 15.5 & 0.9651 & 15.0 \\
\hline B001107-3-4 & 0.8525 & 16.0 & 15.8 & 15.9 & 0.9670 & 15.4 \\
\hline B001107-3-5 & 0.8516 & 15.2 & 15.7 & 15.5 & 0.9639 & 14.9 \\
\hline B001107-3-6 & 0.8644 & 15.7 & 15.6 & 15.7 & 0.9736 & 15.2 \\
\hline B001107-3-7 & 0.8632 & 15.7 & 15.6 & 15.7 & 0.9727 & 15.2 \\
\hline B001107-3-8 & 0.8819 & 15.6 & 15.8 & 15.7 & 0.9880 & 15.5 \\
\hline B001107-3-9 & 0.8951 & 16.0 & 15.5 & 15.8 & 1.0015 & 15.8 \\
\hline
\end{tabular}

${ }^{a}$ See Table 2 for the composition of the specified solvent.

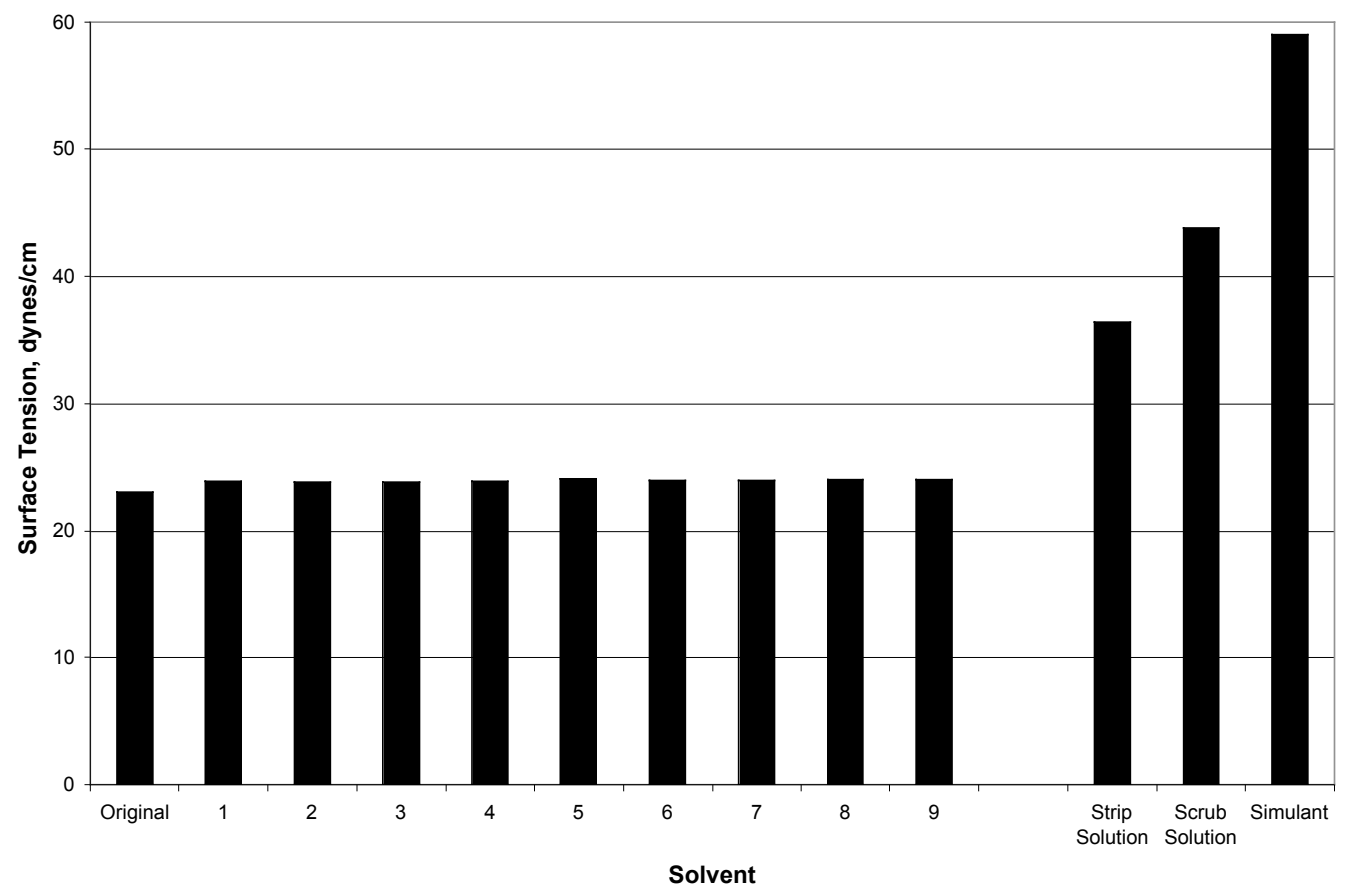

Fig. 11. Solvent and process solution surface tension. The numbers on the abscissa are the test numbers from Table 2 . 


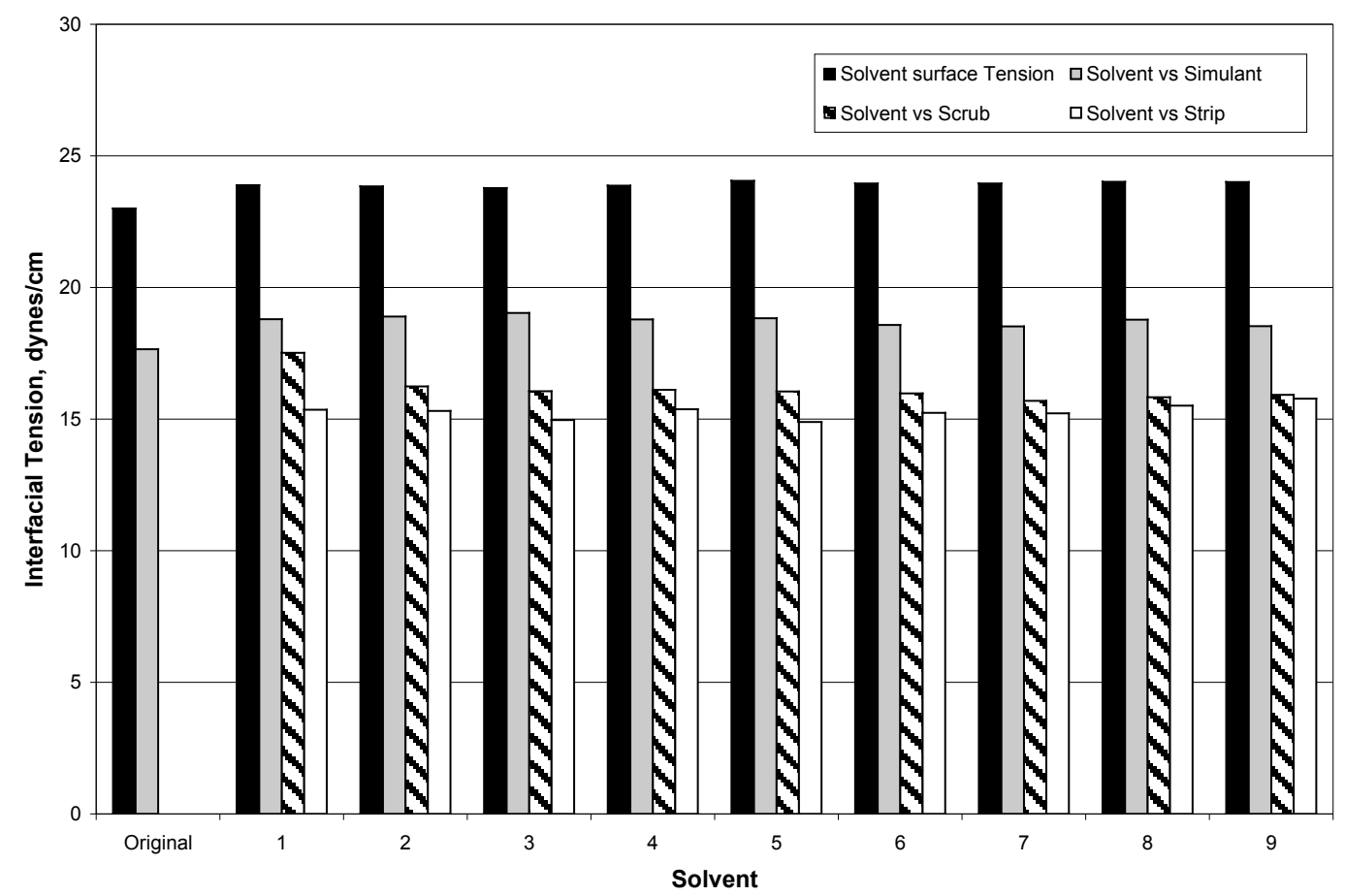

Fig. 12. Solvent interfacial tension in extraction, scrub, and strip contacts. The numbers on the abscissa are the test numbers from Table 2.

\subsection{SOLVENT-COMPOSITION RECOMMENDATION PROCESS}

The process used by the CSSX team to arrive at the solvent-composition recommendation involved several actions. First, the experimental data described in this report were distributed to the team members. Second, two conference calls were held. During the first call, the methods of data acquisition and the significance of the data relative to the selection criteria were discussed [20]. The action item from this discussion was for each participant to make a recommendation concerning the solvent composition and forward this to all of the participants. A compilation of the individual recommendations was distributed prior to the second conference call. The second call focused on the individual recommendations. Between the two calls, a technical presentation was given during the weekly TFA program status review [37]. The recommended composition was a consensus opinion of the CSSX technical team. The rationale used by the CSSX team in arriving at the recommended solvent composition is described in Ref. 20.

The primary criterion involved the selection of a composition that is thermodynamically stable with respect to the crystallization of BOBCalixC6. The fact that BOBCalixC6 has a solubility limit of 7.55 $\mathrm{mM}$ (for a concentration of $\mathrm{Cs}-7 \mathrm{SB}$ of $0.75 \mathrm{M}$ ) suggests that the concentration should be less than 7.5 $\mathrm{mM}$ to accommodate variations in solvent preparation without exceeding this limit. The solubility data also indicate that the thermodynamic solubility value for BOBCalixC6 is linked to the Cs-7SB modifier 
concentration. For example, if the BOBCalixC6 concentration is $7 \mathrm{mM}$, the Cs-7SB modifier concentration should be approximately 100 times higher. The data on third-phase formation also suggest the need for a solvent composition with a BOBCalixC6 concentration of $8 \mathrm{mM}$ or less and a Cs-7SB modifier concentration of at least $0.65 \mathrm{M}$. The density criterion suggests compositions with the Cs-7SB modifier concentration equal to or less than $0.85 \mathrm{M}$. Contactor throughput and phase separation are dependent on the density difference of the two phases; that is, for a given contactor size, throughput is larger and the phase separation performance generally improves as the density difference increases.

Although all of the candidate compositions met the bounding criterion for the $D_{\mathrm{Cs}}$ values, only the previous baseline composition meets the goal. Thus, a composition with $D_{\mathrm{Cs}}$ values close to the goal is preferred because it would provide the ability to process waste blends that have properties that are modestly different from those of the waste simulant composition. The flowsheet robustness calculations suggest a BOBCalixC6 concentration between 6 and $8 \mathrm{mM}$ and a modifier concentration between 0.65 and $0.85 \mathrm{M}$.

The combination of BOBCalixC6 solubility, $D_{\mathrm{Cs}}$ values, and high flowsheet robustness, as well as the desire to have a low density, establishes the basis for the $7 \mathrm{mM}$ BOBCalixC6 and $0.75 \mathrm{M} \mathrm{Cs}-7 \mathrm{SB}$ modifier concentration recommendation.

The recommended TOA concentration increase from $1 \mathrm{mM}$ to $3 \mathrm{mM}$ is based on three considerations. First, the flowsheet robustness calculations indicate that $10 \mathrm{mM}$ TOA will require a major alteration of the solvent flow rate to achieve process performance above the bounding condition. Second, since TOA is the solvent component most susceptible to thermal and radiolytic decomposition, selecting a TOA concentration higher than the $1 \mathrm{mM}$ baseline value will provide the CSSX process more resistance to the variations in anionic impurity content that are certain to be encountered with the different waste blends. Third, a TOA concentration greater than $1 \mathrm{mM}$ will also provide greater flexibility in solvent preparation and process control.

The solvent dispersion numbers for all the solvent compositions tested against the waste simulant, scrub, and strip solutions met the selection criterion and consequently did not provide a means to differentiate between different solvent compositions. However, comparison of solvent dispersion numbers against the $0.01 \mathrm{M} \mathrm{NaOH}$ solvent wash solution indicates the need to re-evaluate the $\mathrm{NaOH}$ concentration used for solvent washing. This need was in fact addressed in contactor tests with the optimized solvent [38], showing that the $10 \mathrm{mM} \mathrm{NaOH}$ wash performs satisfactorily.

Although the viscosity, surface tension, and interfacial tension were not explicitly identified in any of the selection criteria, these physical properties can impact the dispersion number. Therefore, experimental determination of these properties was included in the study to verify that no unexpected behavior occurred. The experimental results did not reveal any such behavior. 



\section{CESIUM DISTRIBUTION BEHAVIOR}

\subsection{INTRODUCTION}

This chapter describes batch cesium distribution behavior of the optimized CSSX solvent. Since the solvent was in fact not explicitly among those tested, but rather an intermediate composition, it was first necessary to determine its extraction, scrub, and strip (ESS) behavior. Second, parameters are needed for estimation of cesium distribution ratios within the range of expected operating temperatures $15-35{ }^{\circ} \mathrm{C}$. Finally, it was desirable to demonstrate recycle of the solvent by showing that results obtained during a second ESS cycle are within experimental error identical to those obtained with the pristine solvent. It may be recalled that $D_{\mathrm{Cs}}$ values on the second and subsequent cycles were found to be higher, especially on stripping, when the previous baseline solvent was employed [11]. This behavior was mainly linked to the presence of the lipophilic anion dibutylphosphate, which is readily removed upon washing the solvent with $\mathrm{NaOH}$, thereby restoring normal function on subsequent cycles. Thus, it was of interest here to observe whether the increased TOA concentration of the optimized solvent suppressed this effect, with or without a $\mathrm{NaOH}$ wash.

\subsection{EXPERIMENTAL SECTION}

The optimized CSSX solvent was employed (Chapter 2), as recommended previously [21,22]. The standard ESS protocol (one extraction at $\mathrm{O}: \mathrm{A}=0.33$, two scrubs at $\mathrm{O}: \mathrm{A}=5$, and four strips at $\mathrm{O}: \mathrm{A}=5$ ) was followed. Contacts were performed in 50-mL Teflon ${ }^{\circledR}$ fluorinated ethylene propylene (FEP) tubes for the extraction step and $15-\mathrm{mL}$ capacity polypropylene tubes for scrubs and strips. The contacting was carried out for 30 minutes using end-over-end rotation in a $25.0 \pm 0.5^{\circ} \mathrm{C}$ constant-temperature air box. ESS tests at low $\left(15^{\circ} \mathrm{C}\right)$ and high $\left(35^{\circ} \mathrm{C}\right)$ temperatures were carried out respectively in a thermostated water bath and in an incubator. Agitation was effected by orbital shaking in the water bath and wheel rotation in the incubator.

\subsection{RESULTS AND DISCUSSION}

\subsubsection{Extraction, Scrub, and Strip Performance}

Experiments involving the determination of cesium distribution ratios with the optimized solvent were carried out in triplicate and compared to the values obtained with the previous baseline solvent. Table 18 presents the results obtained with the optimized solvent where the extraction is performed using the full simulant, the scrub using nitric acid $50 \mathrm{mM}$, and the strip using nitric acid $1 \mathrm{mM}$. The results are very close to the predicted values presented in the Table A1 in Appendix A. The values, calculated from a 
double interpolation of the distribution ratios found for different concentrations of calixarene and modifier, are acceptable for process development. Additional tests were performed using strip solutions mimicking off-normal conditions in which some of the acid is neutralized.

Table 18. Cesium batch ESS performance for previous-baseline and optimized solvents

\begin{tabular}{lccccccc}
\hline \multicolumn{1}{c}{ Conditions $^{a}$} & \multicolumn{7}{c}{$D_{\mathrm{Cs}}$} \\
\cline { 2 - 8 } & Extact & $\begin{array}{c}\text { Scrub } \\
\# 1\end{array}$ & $\begin{array}{c}\text { Scrub } \\
\# 2\end{array}$ & $\begin{array}{c}\text { Strip } \\
\# 1\end{array}$ & $\begin{array}{c}\text { Strip } \\
\# 2\end{array}$ & $\begin{array}{c}\text { Strip } \\
\# 3\end{array}$ & $\begin{array}{c}\text { Strip } \\
\# 4\end{array}$ \\
\hline Standard ESS & 14.05 & 1.14 & 1.35 & 0.115 & 0.076 & 0.117 & 0.053 \\
Standard ESS & 14.14 & 1.14 & 1.35 & 0.118 & 0.081 & 0.093 & 0.052 \\
Standard ESS & 14.30 & 1.13 & 1.34 & 0.113 & 0.080 & 0.063 & 0.053 \\
$\mathrm{NaNO}_{3} 1 \mathrm{mM}$ & 13.53 & 1.13 & 1.35 & 0.119 & 0.125 & 0.078 & 0.066 \\
$\mathrm{NaNO}_{3} 1 \mathrm{mM}$ & 14.33 & 1.14 & 1.34 & 0.128 & 0.223 & 0.078 & 0.066 \\
$\mathrm{NaNO}_{3} 1 \mathrm{mM} / \mathrm{HNO}_{3} 0.05 \mathrm{mM}$ & 14.24 & 1.13 & 1.33 & 0.123 & 0.087 & 0.078 & 0.064 \\
$\mathrm{NaNO}_{3} 1 \mathrm{mM} / \mathrm{HNO}_{3} 0.05 \mathrm{mM}$ & 14.14 & 1.12 & 1.35 & 0.120 & 0.091 & 0.079 & 0.064 \\
$\mathrm{Previous}$ & 17.56 & 1.60 & 1.60 & 0.133 & 0.083 & 0.065 & 0.059 \\
\hline
\end{tabular}

${ }^{a}$ Except where indicated (last line), the optimized solvent was used for each experiment. " $\mathrm{NaNO}_{3} 1$ $\mathrm{mM}$ " indicates that the four strips were carried out using a neutral solution of $1 \mathrm{mM}$ sodium nitrate. "NaNO $1 \mathrm{mM} / \mathrm{HNO}_{3} 0.05 \mathrm{mM}$ " indicates that the four strips were carried out using a mildly acidic solution of $1 \mathrm{mM}$ sodium nitrate and $0.05 \mathrm{mM}$ nitric acid.

Even with mildly acidic or even neutral stripping solutions, the cesium distribution ratios remain acceptable. Of course, the whole range of altered stripping solutions potentially encountered in the system was not tested. It is important to point out that these conditions include an acidic scrub, which is probably sufficient to ensure enough TOA protonation, therefore a good stripping. Poorer results could have been expected in the event that the two scrubs are alkaline due to entrained carryover of waste simulant from extraction.

\subsubsection{Temperature Variation}

Temperature-variation experiments were carried out at three different temperatures encompassing those temperatures that would potentially be encountered during the CSSX process. This experiment permits calculation of an apparent enthalpy change associated with each stage, thereby providing an approximate correction factor for any given temperature. It should be noted that the mechanism of extraction is complex [39], and thus, only an apparent enthalpy change is given as an empirical parameter for estimation purposes. Results are presented in Table 19. 
Table 19. ESS results for three different temperatures

\begin{tabular}{ccccccccc}
\hline$T$ & $1000 / T$ & \multicolumn{7}{c}{$D_{\mathrm{Cs}}$} \\
\cline { 3 - 9 }$\left({ }^{\circ} \mathrm{C}\right)$ & $\left(\mathrm{K}^{-1}\right)$ & Extraction & Scrub \#1 & Scrub \#2 & Strip \#1 & Strip \#2 & Strip \#3 & Strip \#4 \\
\hline 15 & 3.4704 & 27.41 & 4.37 & 3.73 & 0.330 & 0.242 & 0.197 & 0.171 \\
15 & 3.4704 & 24.86 & 4.14 & 3.60 & 0.364 & 0.276 & 0.221 & 0.192 \\
25 & 3.3540 & 12.83 & 0.99 & 1.20 & 0.099 & 0.065 & 0.051 & 0.045 \\
25 & 3.3540 & 12.89 & 0.98 & 1.19 & 0.098 & 0.064 & 0.051 & 0.045 \\
35 & 3.2451 & 7.07 & 0.41 & 0.50 & 0.040 & 0.027 & 0.022 & 0.021 \\
35 & 3.2451 & 7.18 & 0.41 & 0.49 & 0.041 & 0.028 & 0.023 & 0.021 \\
\hline
\end{tabular}

Assuming that only a single equilibrium is involved in the cesium extraction, scrub, or strip steps, it may be shown that there is a direct relationship between the cesium distribution ratio and the formation constant of the considered equilibrium. For example, let's consider the simplest system:

$$
\begin{aligned}
& C s^{+}+N O_{3}^{\square}+\overline{\text { Calix }} \square \square \square \overline{\mathrm{CsNO}_{3} \text { Calix }} \\
& D=\frac{\left[\overline{\mathrm{Cs}^{+}}\right]}{\left[C s^{+}\right]}=\frac{\left[\overline{\mathrm{CsNO}_{3} \text { Calix }}\right]}{\left[\mathrm{Cs}^{+}\right]}=K\left[N O_{3}^{\square}\right][\overline{\text { Calix }}]
\end{aligned}
$$

where overbars indicate organic-phase species. As long as the organic-phase cesium complex is mononuclear and neutral, such a proportionality between $D$ and $K$ should hold for different extraction mechanisms. Assuming that the temperature variation does not impact the loading of the calixarene or the total concentration of nitrate in the aqueous phase, one then may write:

$\operatorname{Ln} D=A+\operatorname{Ln} K$

$\operatorname{Ln} K=\square \frac{\square G_{\text {app }}}{R T}, \quad \operatorname{Ln} K=\square \frac{\square H_{\text {app }}}{R T}+\frac{\square S_{\text {app }}}{R}$

$\operatorname{Ln} D=B \square \frac{\square H_{\text {app }}}{R T}$

where $T$ is expressed in degrees Kelvin; $A$ and $B$ are constants; and $B$ includes $A$ and $\square S_{\text {app }} / R$. The slope of the line Ln $D$ versus 1000/T should give the value of the apparent (app) enthalpies associated with the different stages of the process. The linearity of the different plots is confirmed as seen in Fig. 13. All results per stage are shown in Table 20. 


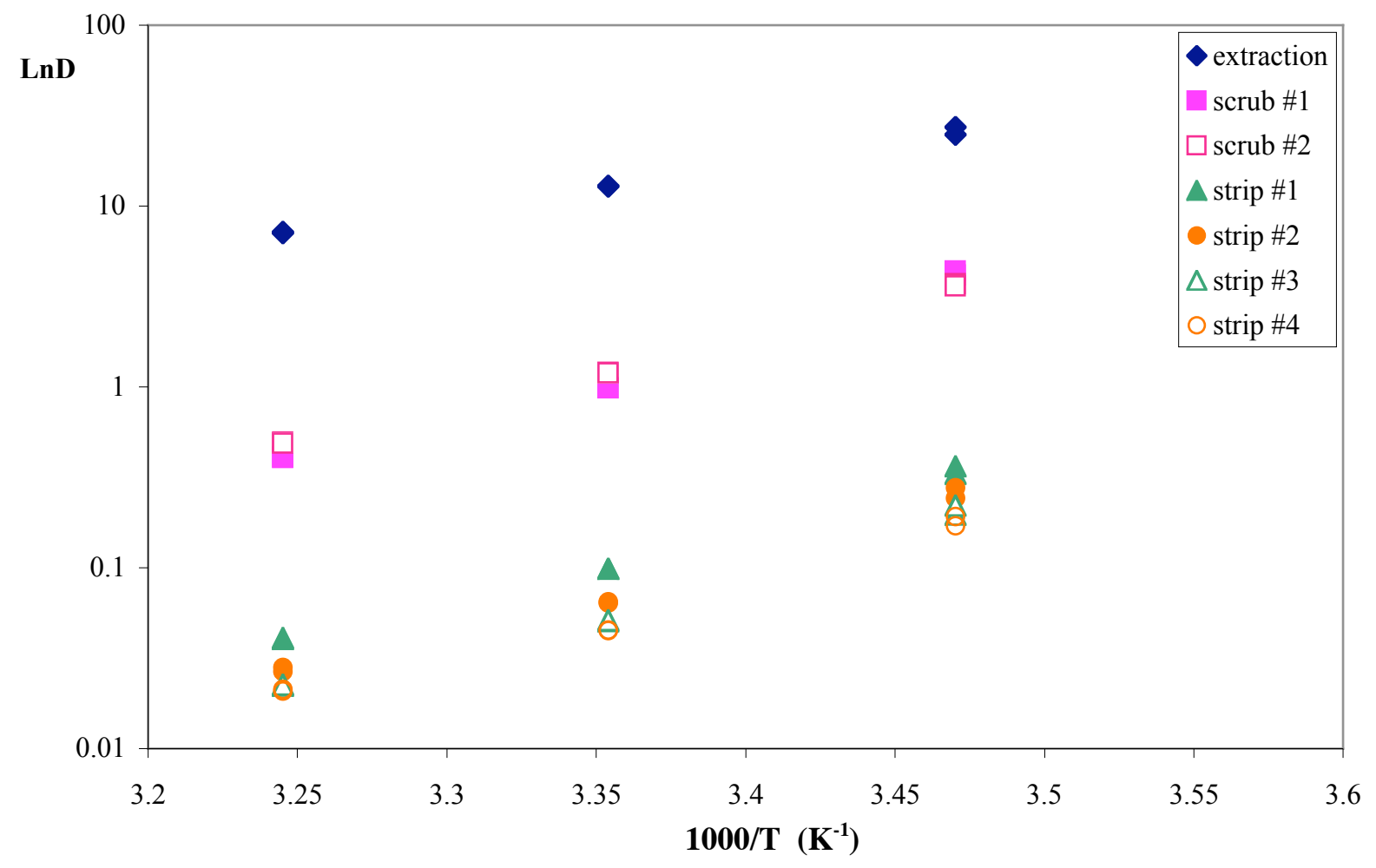

Fig. 13. ESS test at three different temperatures.

Table 20. Apparent enthalpy changes for each ESS stage

\begin{tabular}{cc}
\hline Stage & $\square H_{\text {app }}(\mathrm{kJ} / \mathrm{mol})$ \\
\hline Extraction & -47.95 \\
Scrub \#1 & -86.82 \\
Scrub \#2 & -74.24 \\
Strip \#1 & -79.36 \\
Strip \#2 & -82.94 \\
Strip \#3 & -82.49 \\
Strip \#4 & -79.71 \\
\hline
\end{tabular}

The apparent enthalpy values are close to those obtained with the previous baseline solvent. Less scattering is observed here for the four strip values, probably because of the greater reliability of the data obtained at $15{ }^{\circ} \mathrm{C}$. As observed before [11], the extraction step is the least sensitive to temperature variation, most likely because of the higher loading of BOBCalixC6 with potassium as the temperature decreases. This loading corresponds to a lower concentration of free BOBCalixC6, therefore lower $D_{\mathrm{Cs}}$ values, which in turn give a less steep apparent slope. 


\subsubsection{Multicycle Behavior}

This test reproduces in part the multicycle tests performed in FY 2001. Based on the satisfactory results obtained with the previous baseline solvent, only two cycles were included in this test with the optimized solvent. After the first cycle, one sample was washed with sodium hydroxide $10 \mathrm{mM}(\mathrm{O}: \mathrm{A}=$ 1:1) before going on to the extraction of the second cycle, while the other one was not. Results are summarized in Table 21.

Table 21. Two-cycle ESS tests

\begin{tabular}{lccccccc}
\hline \multirow{2}{*}{ Test } & \multicolumn{7}{c}{$D_{\mathrm{Cs}}$} \\
\cline { 2 - 8 } & Extraction & $\begin{array}{c}\text { Scrub } \\
\# 1\end{array}$ & $\begin{array}{c}\text { Scrub } \\
\# 2\end{array}$ & $\begin{array}{c}\text { Strip } \\
\# 1\end{array}$ & $\begin{array}{c}\text { Strip } \\
\# 2\end{array}$ & $\begin{array}{c}\text { Strip } \\
\# 3\end{array}$ & $\begin{array}{c}\text { Strip } \\
\# 4\end{array}$ \\
\hline $1^{\text {st }}$ cycle & 13.88 & 1.110 & 1.267 & 0.1236 & 0.0721 & 0.0540 & 0.0478 \\
$1^{\text {st }}$ cycle duplicate & 13.34 & 1.165 & 1.177 & 0.1107 & 0.0730 & 0.0532 & 0.0482 \\
$2^{\text {nd }}$ cycle & 13.84 & 1.180 & 1.268 & 0.1356 & 0.0699 & 0.0540 & 0.0508 \\
$2^{\text {nd }}$ cycle with wash & 13.79 & 1.107 & 1.261 & 0.1297 & 0.0724 & 0.0552 & 0.0492 \\
\hline
\end{tabular}

A small increase in $D_{\mathrm{Cs}}$ is noticeable for the first and fourth strips on the second cycle, but this increase is close to, or within, the experimental error for ESS tests, approximately $\pm 7 \%$ [11]. The caustic wash seems to improve slightly the overall behavior.

\subsection{CONCLUSIONS}

The cesium extraction behavior of the optimized solvent is similar to the behavior obtained in FY 2000 and FY 2001 with the previous baseline solvent [11]. As expected, cesium distribution ratios are lower due to the decrease in the calixarene concentration, but the decrease in extraction is somewhat counterbalanced by the decrease in the cesium stripping values. As a result, the decrease in the ratio of $D_{\mathrm{Cs}}$ on extraction to that on stripping is not large, which corresponds to the observation in Chapter 2 that the flowsheet robustness is not unacceptably compromised. Apparent thermodynamic parameters for each stage are also very similar to those obtained with the previous baseline solvent. The results are consistent with the results of other studies showing that the formation constants associated with extraction equilibria did not vary much upon changing the solvent [41]. Finally, batch cesium extraction performance is not altered upon a second cycle, which can be taken as an indication of the effectiveness of the increased TOA concentration in the optimized solvent. 



\section{PARTITIONING OF SOLVENT COMPONENTS}

\subsection{INTRODUCTION}

Partitioning ratios of solvent components are critical parameters of the CSSX process. Loss of any component (particularly of the calixarene extractant) can translate into loss of extraction performance and costs for replenishing the solvent to its original composition. Solvent components can be lost to the aqueous phase through two different mechanisms: partitioning and entrainment. Although BOBCalixC6, Cs-7SB, and TOA are each highly lipophilic, they possess small, finite tendencies to partition into the aqueous process solutions. Among these aqueous phases, the waste feed is the most important, because its flow will be much larger (15-fold in the current flowsheet) than the flow of the strip or wash solutions. Since the solvent will be recycled several thousand times in the course of a year's operation, it is clear that the partition ratios must be sufficiently high to avoid problems. For less than $10 \%$ loss of a reagent per year, the minimum partition ratio is approximately $10^{5}$ (more exactly, assuming 2800 cycles, $P>88,600$ for $\mathrm{O}: \mathrm{A}=1: 3)$. Measurement of such high $P$ values, however, represents a considerable analytical challenge [11]. For the critical, expensive reagent, BOBCalixC6, it was thought likely that the condition of $P>10^{5}$ was met, although only a lower limit $\left(P_{\text {ВОВСalix } 6}>12,500\right)$ could be reported in the case of the previous baseline solvent in contact with waste simulant, strip solution, or wash solution [11]. Partition ratios for Cs-7SB and TOA were high and on the borderline of reliable measurement in that same study. For example, for partitioning into the waste simulant from the previous baseline solvent, these two reagents were found to have partition ratios of respectively $>50,000$ and 38,000-200,000. For TOA, loss to the acidic strip solution would be more significant, since it was found that $P=14,000-55,000$ [11]. Overall, it thus appears likely that partitioning is not a significant issue. However, in view of both the acceptance of an optimized solvent composition and the uncertainty in the previous measurements, especially those for BOBCalixC6, it was judged desirable to address the partitioning issue again with the intent to improve upon analytical technique. Provided that partitioning losses of reagents could be more confidently shown to be small, it would then be possible elsewhere to approach the question of solvent losses in terms of entrainment, namely, the physical loss of solvent to the aqueous phase due to incomplete coalescence of fine droplets.

\subsection{EXPERIMENTAL SECTION}

\subsubsection{Materials and Contacting Method}

Solvent Lot No. PVB B000894-87W (87W) was used for all experiments. This batch of washed solvent has the following composition: 0.007 M BOBCalixC6 (Lot \#000714HMKC-0004), 0.750M Cs-

7SB modifier (Lot \#B000894-64DM), 0.003 M tri- $n$-octylamine (Lot \#B000894-186), and Isopar ${ }^{\circledR}$ L (Lot \#03081001-6-2). Full Simulant, draw \#5 with Cs added to $1.4 \square 10^{-4} \mathrm{M}$, was obtained in FY 2000. 
Sodium hydroxide pellets (Lot \# 41171126) used to prepare all caustic solutions were obtained from EM Science. Nitric acid was ultrapure Ultrex II (J. T. Baker, Lot \#T19541). Dichloromethane (EM Science, Lot 38301846) was used as received.

Solvent $87 \mathrm{~W}$ was contacted with various aqueous phases using O:A ratio of 1:100. The contacts were done by handshaking the two phases in $1 \mathrm{~L}$ Teflon ${ }^{\circledR}$ separatory funnels. The aqueous layers were then drained into $250-\mathrm{mL}$ Teflon ${ }^{\circledR}$ centrifuge bottles and centrifuged for $20 \mathrm{~min}$ at $3000 \mathrm{rpm}$. The aqueous phases were carefully siphoned into clean bottles using small Tygon ${ }^{\circledR}$ capillary tubing to avoid organicphase contamination. Known volumes of the aqueous phases (approx. $200 \mathrm{~mL}$ ) were then back-extracted two times using a small volume $(\sim 10-15 \mathrm{~mL})$ of fresh dichloromethane each time. The dichloromethane was taken to dryness by evaporation or nitrogen blow-down, and the resultant residue prepared for analysis.

\subsubsection{Calixarene and Modifier Analyses}

\section{Sample Preparation}

All samples were originally presented as dichloromethane extracts (approximately $10 \mathrm{~mL}$ each) in 20$\mathrm{mL}$ vials. The solvent was removed using a stream of dry flowing nitrogen while heating the bottom of each vial to $34{ }^{\circ} \mathrm{C}$. The residues were then redissolved in $1 \mathrm{~mL}$ isopropanol and submitted for HPLC analysis.

\section{HPLC Analysis}

All samples were analyzed with a Hewlett-Packard Model 1090 high-pressure liquid chromatograph equipped with an automatic sampler (maximum 100 individual samples; maximum injection volume 250 $\mathrm{mL}$ ), ternary solvent gradient capability, and a diode array detector (wavelength range 190-600 nm). A PRP-1 (polystyrene divinylbenzene) reversed-phase column $(150 \square 4.1 \mathrm{~mm})$, packed with $10 \square \mathrm{m}$ diameter particles (100 ̊ porosity), a product of the Hamilton Co. (Reno, NV), was used for all determinations. The analytes were eluted isocratically from the column using a 60/40 (v/v) mixture of isopropanol/acetonitrile at a flow rate of $1.00 \mathrm{~mL} / \mathrm{min}$. The sample analysis time was 5 minutes per sample; each was analyzed in duplicate. Both the analytical column and the solvent were heated to $40{ }^{\circ} \mathrm{C}$ using the internal column oven.

Because there was a difference of up to four orders of magnitude in the concentrations of BOBCalixC6 and Cs-7SB modifier, each sample was analyzed using two independent HPLC methods. In the first (used for low-level BOBCalixC6), the injection volume was $25 \square \mathrm{L}$; in the second (used for highlevel Cs-7SBT modifier), the injection volume was $10 \square \mathrm{L}$. More significant differences between the two methods are described under "Quantitation" below.

\section{Quantitation}

The quantitation of BOBCalixC6 was performed using the 25- $\square \mathrm{L}$ injection volume described above and a measuring wavelength of $210 \mathrm{~nm}$. The calibration procedure employed seven independentlyprepared standards of BOBCalixC6, ranging in concentration between 0.001 and $0.1 \mathrm{mM}$, using 
isopropanol as the diluent. Each standard was analyzed twice. The calibration data was fit to a leastsquares calibration line, where the coefficient of determination, $r^{2}$, exceeded 0.9995 . The detection limit was taken as the concentration that would produce the peak with the smallest integration, here $0.001 \mathrm{mM}$ (i.e., $\left.10^{-6} \mathrm{M}\right)$.

The quantitation of Cs-7SB modifier was performed using the $10-\square \mathrm{L}$ injection volume described above and a measuring wavelength of $254 \mathrm{~nm}$. The calibration procedure employed seven independentlyprepared standards of Cs-7SB modifier, ranging in concentration between 1 and $100 \mathrm{mM}$, using isopropanol as the diluent. Each standard was analyzed twice. The calibration data was fit to a leastsquares calibration line, where the coefficient of determination, $r^{2}$, exceeded 0.998 .

\subsubsection{Tri- $n$-octylamine Analyses}

\section{Sample Preparation}

The samples, which were originally prepared in an unspecified volume of dichloromethane, were initially taken to dryness at room temperature, then reconstituted in $1.0 \mathrm{~mL}$ dichloromethane. These rediluted samples were then transferred to $2-\mathrm{mL}$ capacity automatic sampler vials for gas chromatographic analysis.

\section{Gas Chromatographic Analysis}

Gas chromatography was performed on a Hewlett Packard HP6850 series GC system using an HP5MS (crosslinked 5\% phenyl methyl siloxane) fused silica capillary column (Agilent Technologies catalog number 190915-433E) of length 30 meters, column internal diameter of $0.25 \mathrm{~mm}$, phase ratio 250 , and film thickness of $0.25 \square \mathrm{m}$. The carrier gas was helium (purity $>99.999 \%$ ) flowing at $1 \mathrm{~mL} / \mathrm{min}$. The sample injection volume was $1 \square \mathrm{L}$, with a split ratio of $1 / 100$. The column oven temperature was programmed from $50{ }^{\circ} \mathrm{C}$ to $280{ }^{\circ} \mathrm{C}$ at $10{ }^{\circ} \mathrm{C} / \mathrm{min}$, with a hold at $280{ }^{\circ} \mathrm{C}$ for $10 \mathrm{~min}$. A flame ionization detector (FID) was used to detect the presence of TOA. The flows of the FID gases (i.e., air, hydrogen, and carrier) were set to factory-recommended values. All injections were performed using an Agilent Model 7683 automatic sampler.

\section{Calibration}

The response of the FID was calibrated using six independently-prepared standards ranging in concentration between 0.05 and $2 \mathrm{mM}$ TOA in dichloromethane. The responses were fit to a linear leastsquares calibration line, whose coefficient of determination, $r^{2}$, exceeded 0.9999 . The detection limit of the FID was taken to be the standard concentration that produced the peak with the smallest integration, here $0.05 \mathrm{mM}$, corresponding to $177 \mathrm{pg}$ actually injected on column. 


\subsection{RESULTS AND DISCUSSION}

In all cases, the partitioning of the three solvent components was measured not only using the aqueous phases encountered in the different stages of the process (simulant, scrub, and strip solutions), but also using several concentrations of nitric acid (to assess the influence on tri- $n$-octylamine) and sodium hydroxide (being the candidate of choice for solvent washes in the process). All organic concentrations presented in the tables were determined by subtracting the measured aqueous concentration from the initial organic concentration. In order to be in the best possible conditions to obtain measurable amounts of organic compounds in the aqueous phases, an O:A ratio of 1:100 was used.

\subsubsection{Calixarene Partitioning}

Precision in calixarene detection was greatly improved compared to results obtained in FY 2000 and FY 2001. Results reported for similar experiments using the previous baseline solvent indicated that all partition ratios were greater than 12,500 based on the detection limit of the method [11]. Table 22 reflects the improved precision, as partition ratios are now at least 10 times greater than reported earlier, confirming the extremely low affinity of BOBCalixC6 for the aqueous phase.

In all cases, the amount of calixarene lost due to the contact with the aqueous phase is negligible. No real trend can be discerned from these experiments. Moreover, the method used to limit the potential contamination of that aqueous phase with the organic phase (siphoning) was the best available, but could not guarantee a complete contamination-free transfer. A mere contamination of 5-10 $\square \mathrm{L}$ of the aqueous phase with the organic phase is sufficient to mask any potential trend.

\subsubsection{Modifier Partitioning}

The modifier Cs-7SB is more soluble in the aqueous phase than the calixarene based on the partition ratios obtained with the previous baseline solvent. Moreover, its greater initial concentration in the optimized solvent ( $50 \%$ greater than the previous baseline solvent) makes it easier to detect in the aqueous phase after contact. Results are presented in Table 23.

Quantities of modifier solubilized in the aqueous phases are again found to be much greater than those of calixarene, which is at first not surprising in that the original amount of modifier is 100 times greater. However, that ratio is no longer maintained, which is a good indication that the technique used for subsampling the aqueous phase was adequate to minimize entrainment. Based on these experiments, it is difficult to assess with precision whether the presence of these organic components in the aqueous phase is due to true partitioning. More lengthy experiments would have been needed to add that detail. However, it can be said that if there is some entrainment contributing to the presence of solvent components in the aqueous phases, while its contribution to the calixarene partitioning is unknown, its contribution to modifier partitioning is negligible. One could assume in an extreme case that all the calixarene present in the aqueous phases is due to entrainment. By implication, this would still leave about $90 \%$ of soluble modifier that ought to be accounted for through true partitioning. 
Table 22. Partition ratios for $\mathrm{BOBCalixC6}^{a}$

\begin{tabular}{lccc}
\hline Aqueous phase & Organic concentration $^{b}(\mathrm{M})$ & Aqueous concentration $(\mathrm{M})$ & Partition ratio \\
\hline Full simulant & $7.00 \mathrm{E}-03$ & $3.31 \mathrm{E}-08$ & $2.12 \mathrm{E}+05$ \\
Full simulant & $7.00 \mathrm{E}-03$ & $3.15 \mathrm{E}-08$ & $2.22 \mathrm{E}+05$ \\
Scrub solution & $7.00 \mathrm{E}-03$ & $4.69 \mathrm{E}-08$ & $1.49 \mathrm{E}+05$ \\
Scrub solution & $7.00 \mathrm{E}-03$ & $4.80 \mathrm{E}-08$ & $1.46 \mathrm{E}+05$ \\
Strip solution & $7.00 \mathrm{E}-03$ & $1.09 \mathrm{E}-08$ & $6.41 \mathrm{E}+05$ \\
Strip solution & $7.00 \mathrm{E}-03$ & $1.34 \mathrm{E}-08$ & $5.22 \mathrm{E}+05$ \\
\hline $1 \mathrm{M} \mathrm{NaOH}$ & $7.00 \mathrm{E}-03$ & $2.59 \mathrm{E}-08$ & $2.70 \mathrm{E}+05$ \\
$1 \mathrm{M} \mathrm{NaOH}$ & $7.00 \mathrm{E}-03$ & $2.56 \mathrm{E}-08$ & $2.74 \mathrm{E}+05$ \\
$0.1 \mathrm{M} \mathrm{NaOH}$ & $7.00 \mathrm{E}-03$ & $4.73 \mathrm{E}-08$ & $1.48 \mathrm{E}+05$ \\
$0.1 \mathrm{M} \mathrm{NaOH}$ & $7.00 \mathrm{E}-03$ & $4.56 \mathrm{E}-08$ & $1.53 \mathrm{E}+05$ \\
$0.01 \mathrm{M} \mathrm{NaOH}$ & $7.00 \mathrm{E}-03$ & $1.23 \mathrm{E}-08$ & $5.68 \mathrm{E}+05$ \\
$0.01 \mathrm{M} \mathrm{NaOH}$ & $7.00 \mathrm{E}-03$ & $1.54 \mathrm{E}-08$ & $4.54 \mathrm{E}+05$ \\
$0.001 \mathrm{M} \mathrm{NaOH}$ & $6.99 \mathrm{E}-03$ & $5.61 \mathrm{E}-08$ & $1.25 \mathrm{E}+05$ \\
$0.001 \mathrm{M} \mathrm{NaOH}$ & $6.99 \mathrm{E}-03$ & $5.54 \mathrm{E}-08$ & $1.26 \mathrm{E}+05$ \\
\hline $1 \mathrm{M}$ nitric acid & $7.00 \mathrm{E}-03$ & $1.00 \mathrm{E}-08$ & $6.97 \mathrm{E}+05$ \\
$1 \mathrm{M}$ nitric acid & $7.00 \mathrm{E}-03$ & $1.18 \mathrm{E}-08$ & $5.93 \mathrm{E}+05$ \\
$0.1 \mathrm{M}$ nitric acid & $7.00 \mathrm{E}-03$ & $9.35 \mathrm{E}-09$ & $7.49 \mathrm{E}+05$ \\
$0.1 \mathrm{M}$ nitric acid & $7.00 \mathrm{E}-03$ & $6.64 \mathrm{E}-09$ & $1.05 \mathrm{E}+06$ \\
$0.01 \mathrm{M}$ nitric acid & $7.00 \mathrm{E}-03$ & $1.77 \mathrm{E}-08$ & $3.96 \mathrm{E}+05$ \\
$0.01 \mathrm{M}$ nitric acid & $7.00 \mathrm{E}-03$ & $2.20 \mathrm{E}-08$ & $3.18 \mathrm{E}+05$ \\
\hline
\end{tabular}

${ }^{a}$ The numeric notation used in this table and some subsequent tables in this report is the normal scientific notation, where 7.00E-03 represents $7.00 \square 10^{-3}$. Both notations are used interchangeably.

${ }^{b}$ Not measured. Values are calculated from the mass balance between the initial concentration of BOBCalixC6 in the solvent $(0.007 \mathrm{M})$ and that measured in the aqueous phase at an O:A of 1:100.

\subsubsection{Tri-n-octylamine Partitioning}

Results for tri- $n$-octylamine partitioning were relatively satisfactory, but inconclusive. Tri- $n$ octylamine was probably present in amounts that were too low to be detected by the method designed to analyze the samples. A complete calibration curve was obtained, with the smallest integrable peak corresponding to $5 \times 10^{-5} \mathrm{M}$. All analyzed samples fell well below the detection limit (not even a hint of peak was noticeable), corresponding to a lower limit for the partition ratio of 6000 . However, based on these observations and previous results [11], it is reasonable to propose that the partitioning of TOA is not an issue for the process. 
Table 23. Partition ratios for modifier Cs-7SB

\begin{tabular}{lccc}
\hline Aqueous phase & Organic concentration $^{a}(\mathrm{M})$ & Aqueous concentration $^{b}(\mathrm{M})$ & Partition ratio \\
\hline Full simulant & $7.50 \mathrm{E}-01$ & BDL & $>3.50 \mathrm{E}+04$ \\
Full simulant & $7.50 \mathrm{E}-01$ & BDL & $>3.50 \mathrm{E}+04$ \\
Scrub solution & $7.44 \mathrm{E}-01$ & $6.41 \mathrm{E}-05$ & $1.16 \mathrm{E}+04$ \\
Scrub solution & $7.44 \mathrm{E}-01$ & $6.40 \mathrm{E}-05$ & $1.16 \mathrm{E}+04$ \\
Strip solution & $7.47 \mathrm{E}-01$ & $3.49 \mathrm{E}-05$ & $2.14 \mathrm{E}+04$ \\
Strip solution & $7.46 \mathrm{E}-01$ & $3.52 \mathrm{E}-05$ & $2.12 \mathrm{E}+04$ \\
\hline $1 \mathrm{M} \mathrm{NaOH}$ & $7.47 \mathrm{E}-01$ & $3.35 \mathrm{E}-05$ & $2.23 \mathrm{E}+04$ \\
$1 \mathrm{M} \mathrm{NaOH}$ & $7.47 \mathrm{E}-01$ & $3.37 \mathrm{E}-05$ & $2.21 \mathrm{E}+04$ \\
$0.1 \mathrm{M} \mathrm{NaOH}$ & $7.45 \mathrm{E}-01$ & $5.48 \mathrm{E}-05$ & $1.36 \mathrm{E}+04$ \\
$0.1 \mathrm{M} \mathrm{NaOH}$ & $7.45 \mathrm{E}-01$ & $5.36 \mathrm{E}-05$ & $1.39 \mathrm{E}+04$ \\
$0.01 \mathrm{M} \mathrm{NaOH}$ & $7.45 \mathrm{E}-01$ & $5.31 \mathrm{E}-05$ & $1.40 \mathrm{E}+04$ \\
$0.01 \mathrm{M} \mathrm{NaOH}$ & $7.45 \mathrm{E}-01$ & $5.31 \mathrm{E}-05$ & $1.40 \mathrm{E}+04$ \\
$0.001 \mathrm{M} \mathrm{NaOH}$ & $7.45 \mathrm{E}-01$ & $5.07 \mathrm{E}-05$ & $1.47 \mathrm{E}+04$ \\
$0.001 \mathrm{M} \mathrm{NaOH}$ & $7.45 \mathrm{E}-01$ & $5.09 \mathrm{E}-05$ & $1.46 \mathrm{E}+04$ \\
\hline $1 \mathrm{M}$ nitric acid & $7.38 \mathrm{E}-01$ & $1.17 \mathrm{E}-04$ & $6.29 \mathrm{E}+03$ \\
$1 \mathrm{M}$ nitric acid & $7.39 \mathrm{E}-01$ & $1.11 \mathrm{E}-04$ & $6.68 \mathrm{E}+03$ \\
$0.1 \mathrm{M}$ nitric acid & $7.44 \mathrm{E}-01$ & $6.09 \mathrm{E}-05$ & $1.22 \mathrm{E}+04$ \\
$0.1 \mathrm{M}$ nitric acid & $7.44 \mathrm{E}-01$ & $6.06 \mathrm{E}-05$ & $1.23 \mathrm{E}+04$ \\
$0.01 \mathrm{M}$ nitric acid & $7.44 \mathrm{E}-01$ & $6.39 \mathrm{E}-05$ & $1.16 \mathrm{E}+04$ \\
$0.01 \mathrm{M}$ nitric acid & $7.44 \mathrm{E}-01$ & $6.39 \mathrm{E}-05$ & $1.16 \mathrm{E}+04$ \\
\hline
\end{tabular}

${ }^{a}$ Not measured. Values were calculated from the mass balance between the initial concentration of modifier in the solvent $(0.75 \mathrm{M})$ and that measured in the aqueous phase at an O:A of 1:100.

${ }^{b} \mathrm{BDL}$ denotes below detection limit.

\subsection{CONCLUSIONS}

Partition ratios for $\mathrm{BOBCalixC6}$ and $\mathrm{Cs}-7 \mathrm{SB}$ have been obtained with improved precision, leading to confidence that partitioning losses of these costly solvent components are small with respect to a goal of less than one solvent replacement per year. In the case of BOBCalixC6, partitioning losses to the aqueous raffinate are expected to amount to less than $4.2 \%$ per year, based on 2800 solvent cycles at O:A $=1: 3$ and $P_{\text {BOBCalix } 6}=2.2 \times 10^{5}$. Taking $P_{\mathrm{Cs}-7 \mathrm{SB}}=3.5 \times 10^{4}$, corresponding losses of Cs-7SB are expected to be $27 \%$ per year. The partitioning of TOA to the aqueous phase was below the detection limit of the gaschromatographic technique employed, giving $P_{\mathrm{TOA}}>6000$. No conclusion is therefore possible for TOA, but in view of results on the previous baseline solvent [11], the value of $P_{\mathrm{TOA}}$ is likely more than an order of magnitude larger than 6000. Based on chemical reasoning, it may be expected that loss of TOA will be more significant to the strip solution, and if one takes $P_{\mathrm{TOA}}>6000$ for 2800 solvent cycles at O:A $=5: 1$, the implied loss of TOA will be less than $9.3 \%$. Given that TOA is critical for good stripping, it is 
recommended that more definite measurements of TOA partitioning be sought. It may be noted that commercially available trialkylamines having a higher molecular weight, such as tridecyl- or tridodecylamine, can be substituted for TOA to obtain greater lipophilicity and lower partitioning losses, if desired. On the other hand, recalling that the major breakdown product of TOA is dioctylamine, which is expected to be washed out by the strip solution [11], the analogous breakdown products of more lipophilic trialkylamines will be more difficult to wash out, making solvent cleanup possibly more difficult over extended cycling.

One of the questions asked regarding the present results is whether partitioning and entrainment can be distinguished. Based on the data obtained, it can be deduced that the predominant portion of the modifier present in the aqueous phase is due to solubility, not entrainment. It is less certain that this is the case for BOBCalixC6, since minute traces of entrainment or other artifacts (e.g., suspended dust) can mask its true partition ratio. It is again worth noting that the theoretically expected partition ratio for BOBCalixC6 is astronomical [11]. While the data obtained overall imply small partitioning losses of the solvent components, the expected gradual losses of Cs-7SB and possibly TOA likely necessitate periodic replenishment throughout the course of a year. 



\section{DISTRIBUTION OF MINOR ORGANIC AND INORGANIC COMPONENTS}

\subsection{INTRODUCTION}

Besides understanding how the element of interest, cesium, and the solvent components distribute in the CSSX flowsheet, it is necessary to understand the fate of key minor inorganic and organic components. These may be introduced into the system from the waste feed or by degradation of the solvent components. Studies in FY 2001 with the previous baseline solvent showed that the strip effluent contained almost exclusively cesium nitrate in $1 \mathrm{mM}$ nitric acid [11]. All other inorganic constituents of the simulant were either not detectably extracted or scrubbed out readily. Certain minor organic species extractable as anions or as neutral weak acids were found to impair stripping if present in sufficient concentration, but washing with dilute aqueous sodium hydroxide was effective in removing them and restoring solvent performance. Such organic species included dibutylphosphate, found in the waste as a breakdown product of tributylphosphate, phenol derivatives formed by degradation of Cs-7SB, or surfactants having 12 carbon atoms or less. Among the different tests run in FY 2001 with the previous baseline solvent, three experiments in which the distribution of minor organic or inorganic components may be impacted due to the change in solvent composition were chosen for repetition with the optimized solvent. Inorganic species included the competing alkali metals $\mathrm{Na}$ and $\mathrm{K}$, radioactive metals $\mathrm{Tc}$ (as pertechnetate) and $\mathrm{Sr}$, certain transition metals (e.g., $\mathrm{Mn}$ and $\mathrm{Fe}$ ), noble metals, other metals ( $\mathrm{Ca}$ and $\mathrm{Al}$ ), and anions (nitrate, nitrite, and sulfate). Organic species included dibutylphosphate and the surfactant

dodecanoate. Actinides were previously indicated to be negligibly extracted in simulant tests [11], as was confirmed on tests with real waste [40], and therefore actinides were not included in the present study.

\subsection{EXPERIMENTAL SECTION}

Phosphorus-31 Nuclear Magnetic Resonance spectra were obtained on a Bruker Avance 400 widebore spectrometer as described in Chapter 2. Chemical shifts were referenced against phosphoric acid, set to $0.0 \mathrm{ppm}$ by way of a separate standard sample (sealed tube from Bruker). Preliminary contacts between the solvent $87 \mathrm{~W}$ and the scrub, strip, or sodium hydroxide at different concentrations were performed in $15-\mathrm{mL}$ polypropylene tubes at $25^{\circ} \mathrm{C}$ with an O:A ratio of $1: 1$. Two types of experiments were performed; simulant compositions were described previously [11]. Either the full simulant $\left(5^{\text {th }}\right.$ draw) was placed in contact with the solvent with an O:A ratio of 1:3, or the "salts+metals" simulant was used at an O:A ratio of 1:3 with the solvent in which a spike corresponding to $75 \mathrm{ppm}$ of dibutylphosphate was added. The "salts+metals" simulant was the same as the full simulant but lacked the minor organic components [11]. The distribution of dibutylphosphate between the solvent $87 \mathrm{~W}$ and the simulant, scrub, strip, or $\mathrm{NaOH}$ solutions were carried out as follows: solvent samples were analyzed directly with no dilution or addition of reagents for integration standards. Aliquots of solvent or simulant were placed directly into $10-\mathrm{mm}$ quartz tubes. A quartz insert containing tributylphosphate (TBP) at 1 
$\mathrm{mM}$ in deuterochloroform was placed inside the $10-\mathrm{mm}$ tube, and this solution external to the sample was used as the deuterium lock and integration standard. The insert permitted solvent or simulant samples to be run neat without the need to dilute or mix with a standard solution. Before running sample unknowns, spectra of the empty external tube with the insert and of the solvent containing $1 \mathrm{mM}$ dibutylphosphate (210 ppm) were acquired. For unknown samples, an overnight acquisition (10k-12k scans) was performed to ensure that a reasonable signal/noise ratio was achieved. Data point files for each spectrum were converted to ASCII files and treated under MS Excel for deconvolution. Each peak was considered as a pure Lorentzian and approximated this way. This manipulation allowed more precise determination of the peak areas. The procedure was similar to that used earlier, and further details can be found in that document [11].

Tests involving the distribution of inorganic components (simulant components) were carried out through the regular ESS protocol [11]. The scrub and strip acidic phases were analyzed directly by inductively coupled argon plasma atomic emission spectrometry (ICAP-AES). Solvent samples were analyzed by first adding an equal volume of 1,3-diisopropylbenzene, stripping with an equal volume of deionized water, and analysis of the water layer by ICAP-AES. Strontium and technetium were added separately to the full simulant (originally prepared by Roger Spence, August 2000, filtered draw \#5). Technetium was obtained from ORNL Isotope Sales as the ammonium pertechnetate form. A stock solution of $3 \square 10^{-3} \mathrm{M}$ was used, and a spike of $0.15 \mathrm{~mL}$ was added to $45 \mathrm{~mL}$ of simulant to obtain a final Tc concentration of $10^{-5} \mathrm{M}$. Strontium nitrate was obtained from J. T. Baker. An aliquot of a $0.01 \mathrm{M}$ $\mathrm{Sr}\left(\mathrm{NO}_{3}\right)_{2}$ solution was used to spike the simulant.

The surfactant tested was lauric acid (dodecanoic acid), 99\%, Emery Industries, Inc., Downey, CA. The surfactant was tested in the optimized solvent at $2 \square 10^{-5} \mathrm{M}$. A 5-mM stock solution of dodecanoate was made by dissolving via sonication $10.1 \mathrm{mg}$ of dodecanoic acid in $10 \mathrm{~mL}$ of Isopar ${ }^{\square} \mathrm{L}$ (Exxon, Lot \#0306 10967). A 48- $\square \mathrm{L}$ volume of $5 \mathrm{mM}$ dodecanoate was added to $12 \mathrm{~mL}$ of Cs-7SB solvent, making an effective concentration of $2 \square 10^{-5} \mathrm{M}$ dodecanoate in the solvent. To wash out the surfactant, an equal volume of $10 \mathrm{mM} \mathrm{NaOH}$ was contacted with the dodecanoate-containing Cs-7SB solvent by end-overend rotation inside a $25{ }^{\circ} \mathrm{C}$ constant-temperature air box for 30 minutes. The tube was then centrifuged and the solvent layer isolated. Three samples were subjected to the ESS protocol. Solvent designated 87P was pristine solvent; 87SS was solvent containing $2 \square 10^{-5} \mathrm{M}$ dodecanoate; 87WSS was dodecanoatecontaining solvent that was subsequently subjected to the $10-\mathrm{mM} \mathrm{NaOH}$ wash procedure. The standard ESS protocol (extraction, two scrubs, and four strips) was followed. Contacts were performed in 50-mL Teflon ${ }^{\circledR}$ FEP tubes for the extraction step and 17-mL capacity polypropylene tubes for scrubs and strips. Contacts lasted 30 minutes using end-over-end rotation in a $25^{\circ} \mathrm{C}$ air box. 


\subsection{RESULTS AND DISCUSSION}

\subsubsection{Distribution of Dibutylphosphate}

The distribution of dibutylphosphate between the optimized solvent and various aqueous phases could differ from the values obtained in FY 2001 because of the variation in the solvent composition. However, the differences were found to be relatively minor. The same deconvolution technique was used to measure as precisely as possible the area of the peaks. As observed previously, dibutylphosphate partitions quantitatively to the aqueous phase when using a sodium hydroxide wash. The slight increase in the distribution value for larger concentrations of sodium hydroxide is actually due to the necessity of adding more dibutylphosphate to the system; that component was added in its acid form, and consequently some of the hydroxide was consumed.

The moderate partitioning of dibutylphosphate into the solvent was confirmed by using either the full simulant (containing the organic species) or the salts+metals simulant and a spike of dibutylphosphate to the solvent. In both cases, the partition ratios are identical. All results are summarized in Table 24.

Table 24. Partitioning of dibutylphosphate

\begin{tabular}{lcccc}
\hline & O:A & $\begin{array}{c}\text { Initial } \\
\text { concentration } \\
(\mathrm{ppm})\end{array}$ & $\begin{array}{c}\text { Concentration in the organic } \\
\text { phase after contact } \\
(\mathrm{ppm})\end{array}$ & Partition ratios \\
\hline Simulant & $1: 3$ & $25^{a}$ & 43 & 4.1 \\
Simulant & $1: 3$ & $75^{b}$ & 43 & 4.1 \\
$\mathrm{HNO}_{3} 0.05 \mathrm{M}$ & 1 & 500 & 60 & 0.12 \\
$\mathrm{HNO}_{3} 0.001 \mathrm{M}$ & 1 & 500 & 64 & 0.13 \\
$\mathrm{NaOH} \mathrm{0.001} \mathrm{M}$ & 1 & 500 & 1.5 & $3.0 \square 10^{-3}$ \\
$\mathrm{NaOH} \mathrm{0.01} \mathrm{M}$ & 1 & 500 & $\mathrm{BDL}^{c}$ & $<5 \square 10^{-4}$ \\
$\mathrm{NaOH} \mathrm{0.1} \mathrm{M}$ & 1 & 3750 & 6 & $1.6 \square 10^{-3}$ \\
$\mathrm{NaOH} \mathrm{1M}$ & 1 & 6660 & 120 & $1.8 \square 10^{-2}$ \\
\hline
\end{tabular}

${ }^{a}$ Dibutylphosphate is originally in the simulant. Pristine simulant was used.

${ }^{b}$ The solvent was spiked. The simulant used in this case was the Salts+Metals simulant.

${ }^{c}$ Below detection limit.

\subsubsection{Distribution of Other Metals and Selected Radionuclides}

The extraction of metals originally present in the waste simulant can be influenced by the change in solvent composition. It was determined in FY 2001 that the number of elements and their concentration in stages past the first scrub was negligible compared to the amount of cesium nitrate and nitric acid eventually present in the strip effluent. Two radionuclides potentially found in the actual waste (but not present in the baseline simulant composition [11]), strontium and technetium, were included in this study. 
Concentrations presented in the three tables below were determined by stripping the organic phase, to which an equal volume of 1,3-diisopropyl benzene was added, with water. Elements presented in Table 25 along with their detection limits were not extracted by the optimized solvent. This is consistent with the results obtained with the previous baseline solvent.

Table 25. Detection limits of non-extractable metals

\begin{tabular}{llc}
\hline & \multicolumn{2}{c}{ Detection limits } \\
\cline { 2 - 3 } & $(\mathrm{mg} / \mathrm{L})$ & $(\mathrm{M})$ \\
\hline $\mathrm{Ag}$ & 0.54 & $5.0 \mathrm{E}-06$ \\
$\mathrm{Cr}$ & 0.021 & $4.1 \mathrm{E}-07$ \\
$\mathrm{Cu}$ & 0.0027 & $4.2 \mathrm{E}-08$ \\
$\mathrm{Hg}$ & 0.098 & $4.9 \mathrm{E}-07$ \\
$\mathrm{Mn}$ & 0.0006 & $1.1 \mathrm{E}-08$ \\
$\mathrm{Mo}$ & 0.014 & $1.5 \mathrm{E}-07$ \\
$\mathrm{~Pb}$ & 0.40 & $2.0 \mathrm{E}-06$ \\
$\mathrm{Pd}$ & 0.010 & $9.6 \mathrm{E}-08$ \\
$\mathrm{Rh}$ & 0.11 & $1.1 \mathrm{E}-06$ \\
$\mathrm{Ru}$ & 0.094 & $9.3 \mathrm{E}-07$ \\
$\mathrm{Sn}$ & 0.047 & $4.0 \mathrm{E}-07$ \\
$\mathrm{Zn}$ & 0.0048 & $7.3 \mathrm{E}-08$ \\
\hline
\end{tabular}

Elements present in the simulant and their concentrations actually detected in one of the process stages are summarized in Table 26.

Table 26. Concentrations of metals present in the solvent after extraction ${ }^{a}$

\begin{tabular}{lccccc}
\hline \multirow{2}{*}{ Stage } & \multicolumn{5}{c}{ Concentrations (M) } \\
\cline { 2 - 6 } & $\mathrm{Al}$ & $\mathrm{Ca}$ & $\mathrm{Fe}$ & $\mathrm{K}$ & $\mathrm{Na}$ \\
\hline Extraction & $6.60 \mathrm{E}-06$ & $7.29 \mathrm{E}-07$ & $1.17 \mathrm{E}-05$ & $5.50 \mathrm{E}-03$ & $3.82 \mathrm{E}-03$ \\
Scrub \#1 & BDL & $5.52 \mathrm{E}-06$ & $5.20 \mathrm{E}-06$ & $1.49 \mathrm{E}-04$ & $1.83 \mathrm{E}-05$ \\
Scrub \#2 & $\mathrm{BDL}$ & $\mathrm{BDL}$ & $\mathrm{BDL}$ & $1.20 \mathrm{E}-05$ & $4.03 \mathrm{E}-05$ \\
Strip \#1 & $\mathrm{BDL}$ & $\mathrm{BDL}$ & $\mathrm{BDL}$ & $\mathrm{BDL}$ & $3.24 \mathrm{E}-05$ \\
\hline \multicolumn{4}{c}{${ }^{a} \mathrm{BDL}=$ below detection limit. } & Detection limits are respectively $4.2 \square 10^{-6} \mathrm{M}$ for Al, 3.0 $\square 10^{-8} \mathrm{M}$ for \\
$\mathrm{Ca}, 7.0 \square 10^{-8} \mathrm{M}$ for Fe, 3.9 $\square 10^{-6} \mathrm{M}$ for K, and $4.3 \square 10^{-6} \mathrm{M}$ for Na.
\end{tabular}


As expected, potassium and sodium are fairly well extracted and remain in the system following the cesium pattern. Except for sodium, all elements are scrubbed from the solvent by the second scrub stage. The analysis involved also the major anions present in the system. Results for nitrite, nitrate, and sulfate are shown in Table 27.

Table 27. Concentrations of anions present in the solvent at each stage ${ }^{a}$

\begin{tabular}{lccc}
\hline & $\mathrm{NO}_{2}{ }^{-}$ & $\mathrm{NO}_{3}{ }^{-}$ & $\mathrm{SO}_{4}{ }^{2-}$ \\
\hline Extraction & $3.79 \mathrm{E}-04$ & $1.06 \mathrm{E}-03$ & $2.10 \mathrm{E}-05$ \\
Scrub \#1 & $\mathrm{BDL}$ & $4.72 \mathrm{E}-03$ & $1.12 \mathrm{E}-05$ \\
Scrub \#2 & $\mathrm{BDL}$ & $9.54 \mathrm{E}-03$ & $5.12 \mathrm{E}-06$ \\
Strip \#1 & $\mathrm{BDL}$ & $1.56 \mathrm{E}-03$ & $\mathrm{BDL}$ \\
\hline
\end{tabular}

${ }^{a} \mathrm{BDL}=$ below detection limit. Detection limits are respectively 2.2 $\square 10^{-6} \mathrm{M}$ for $\mathrm{NO}_{2}^{-}, 8.1 \square 10^{-6} \mathrm{M}_{\text {for }} \mathrm{NO}_{3}^{-}$, and $2.0 \square 10^{-6} \mathrm{M}^{-}$for $\mathrm{SO}_{4}{ }^{2-}$.

As expected, only nitrate remains after the second scrub. Its concentration increases in the two scrub stages because of the protonation of tri-n-octylamine. Two other anions were taken under consideration,

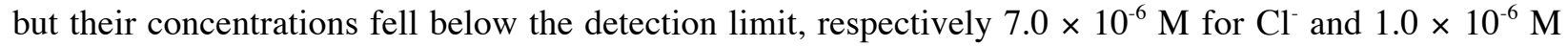
for $\mathrm{PO}_{4}{ }^{3-}$. Chloride and phosphate did not appear in any of the phases analyzed above.

Based on the direct aqueous measurements (first part of Table 28) and the washes (indirect measurements of the organic phase), it is reasonable to say that strontium is very poorly extracted and is readily scrubbed from the solvent.

Table 28. Concentrations of strontium in the aqueous phase at each stage ${ }^{a}$

\begin{tabular}{lc}
\hline Stage & Aqueous [Sr] (M) \\
\hline Scrub \#1 & $3.99 \mathrm{E}-08$ \\
Scrub \#2 & BDL \\
Strip & $7.99 \mathrm{E}-09$ \\
Extraction wash & $6.85 \mathrm{E}-09$ \\
Scrub \#1 wash & BDL \\
Scrub \#2 wash & BDL \\
Strip wash & BDL \\
\hline
\end{tabular}

${ }^{a}$ Washes were performed by adding to the organic phase an equal volume of 1,3-diisopropyl benzene and contacting that phase with deionized water. BDL denotes analysis was below detection limit, which is $15 \mathrm{ppb}$ or $1.71 \square 10^{-9} \mathrm{M}$ for strontium. 
On the contrary, it was found that, while technetium is poorly extracted, it remains in the solvent as long as the aqueous phase in contact is acidic. However, its build-up in the solvent is not a concern in that a sodium hydroxide wash (concentrations $10-300 \mathrm{mM}$ ) is sufficient to remove it quantitatively from the solvent. Table 29 presents the results obtained at each stage and also for a water wash done on solvent after each contact.

Table 29. Distribution ratios of technetium obtained in ESS tests

\begin{tabular}{lcc}
\hline Stage & \multicolumn{1}{c}{$D_{\mathrm{Tc}}$} & $\begin{array}{c}D_{\mathrm{Tc}} \text { upon stripping the } \\
\text { organic phase with water }\end{array}$ \\
\hline Extraction & $3.78 \mathrm{E}-02$ & $2.61 \mathrm{E}-02$ \\
Scrub \#1 & $9.35 \mathrm{E}-01$ & $5.27 \mathrm{E}+00$ \\
Scrub \#2 & $6.77 \mathrm{E}-01$ & $4.21 \mathrm{E}+00$ \\
Strip \#1 & $9.03 \mathrm{E}+00$ & $4.61 \mathrm{E}+00$ \\
Strip \#2 & $9.73 \mathrm{E}+00$ & \\
Strip \#3 & $1.31 \mathrm{E}+01$ & \\
Wash of strip \#3 with $0.01 \mathrm{M} \mathrm{NaOH}$ & $2.85 \mathrm{E}-02$ & \\
Wash of strip \#3 with $0.3 \mathrm{M} \mathrm{NaOH}$ & $1.21 \mathrm{E}-02$ & \\
\hline
\end{tabular}

All inorganic elements identified to be potentially in the actual wastes have been determined to be of no impact on the extraction system. The change in solvent composition does not affect the previous conclusions regarding the partition of inorganic components and confirms the robustness of the solvent found in FY 2001.

\subsubsection{Effect of Organic Surfactants}

Distribution of organic surfactants has been considered to be of major interest [11], particularly after anticaking agents present in salts used to prepare waste simulants were found to create stripping problems [41]. This aspect of the process chemistry had been extensively investigated with the previous baseline solvent, and a remedy was found in every case, the best one being the TOA already present in the solvent. A repeat experiment involving solely sodium dodecanoate has been performed in the present work using the regular ESS test, with and without a wash of the solvent using sodium hydroxide. The results are presented in Table 30.

From the data, it may be observed that dodecanoate-containing solvent (at $2 \square 10^{-5} \mathrm{M}$ ) performed almost no differently than the pristine or $\mathrm{NaOH}$-washed solvent. The higher level of TOA chosen for the optimized solvent apparently offsets effects of the surfactant at this low concentration. 
Table 30. Effect of dodecanoate on cesium extraction in ESS tests

\begin{tabular}{lccccccc}
\hline Test & \multicolumn{7}{c}{$D_{\mathrm{Cs}}$} \\
\cline { 2 - 8 } & Extraction & Scrub \#1 & Scrub \#2 & Strip \#1 & Strip \#2 & Strip \#3 & Strip \#4 \\
\hline 87P $^{a}$ & 13.36 & 0.9765 & 1.235 & 0.0923 & 0.0594 & 0.0494 & 0.0430 \\
87SS $^{b}$ & 13.50 & 0.9428 & 1.195 & 0.0917 & 0.0596 & 0.0472 & 0.0445 \\
87WSS $^{c}$ & 13.83 & 0.9569 & 1.139 & 0.0912 & 0.0600 & 0.0479 & 0.0424 \\
\hline
\end{tabular}

${ }^{a} 87 \mathrm{P}$ indicates pristine solvent.

${ }^{b} 87 \mathrm{SS}$ indicates solvent initially containing dodecanoate at an initial concentration of $2 \square 10^{-5} \mathrm{M}$.

c87WSS indicates solvent initially containing dodecanoate at an initial concentration of $2 \square 10^{-5} \mathrm{M}$ that was, prior to the ESS test, washed with $10 \mathrm{mM} \mathrm{NaOH}$ at a $1: 1$ ratio by end-over-end rotation for 30 minutes on a Glas-Col Rugged Rotator in a $25^{\circ} \mathrm{C}$ airbox.

\subsection{CONCLUSIONS}

The distribution of the solvent constituents and of the trace organic and inorganic components was characterized. The major difference noticed between the results [11] involving the previous baseline solvent and the present results involving the optimized solvent is the demonstration of the ineffective stripping of technetium (as the pertechnetate anion form) from acidic solutions and the need to have a caustic wash following the last strip. All other components behaved as expected based on the results obtained earlier with the previous baseline solvent. 



\section{THERMAL STABILITY}

\subsection{INTRODUCTION}

Experiments conducted in FY 2001 involved a series of extraction, scrub, and strip steps where the solvent was allowed to remain in contact with one of the corresponding aqueous phases for an extended period of time at $35{ }^{\circ} \mathrm{C}$ or $60{ }^{\circ} \mathrm{C}$. The ultimate conclusion was that chemical and thermal stability of the previous baseline solvent significantly exceeds requirements. Logically, the optimized solvent is not expected to differ in this regard in that its chemical constituents are the same, and the work described in this chapter was accordingly intended to provide experimental support for this expectation [11]. In addition to a repeat of the ESS experiments run at the two temperatures $35{ }^{\circ} \mathrm{C}$ and $60{ }^{\circ} \mathrm{C}$, experiments at two low temperatures were added, simulating conditions potentially encountered by the solvent upon shipping during winter months. Since only the solvent would be subject to such temperature stress, no contact with aqueous phases was performed before warming the solvent back to room temperature. Performance of the optimized solvent having been subjected to the different thermal and chemical conditions was assessed by ESS experiments uniformly performed at $25^{\circ} \mathrm{C}$.

\subsection{EXPERIMENTAL SECTION}

\subsubsection{Materials, Equipment, and Contacting Method}

Three different solvents were used for these tests: two different batches of the previous baseline solvent and the optimized solvent. Batches PVB B000718-156W and B000718-124W of the previous baseline solvent are composed of 0.010 M BOBCalixC6 (IBC Advanced Technologies, Lot No. B000718-100CP), 0.50 M Cs-7SB modifier (Lot No. PVB B000718-10DMP), $0.001 \mathrm{M}$ tri- $n$-octylamine (Lot No. PVB B000718-105L) in Isopar ${ }^{\square}$ L (ExxonMobil, Lot No. 0306 10967A). The optimized solvent (Batch PVB B000894-87W) is composed of 0.007 M BOBCalixC6 (IBC Advanced Technologies, Lot No. 000714HMKC-004), 0.75 M Cs-7SB modifier (Lot No. B000894-64DM), 0.003 M tri- $n$-octylamine (Lot No. PVB B000894-86) in Isopar ${ }^{\square}$ L (ExxonMobil, Lot No. 03081001-6-2).

Low-temperature experiments involving the solvents were carried out in a VWR laboratory refrigerator $\left(0{ }^{\circ} \mathrm{C}\right)$ and in the freezer section of VWR combination refrigerator-freezer $\left(-24{ }^{\circ} \mathrm{C}\right)$. Calibrated thermometers were used to determine the temperatures in the freezer and the refrigerator.

Experiments conducted at $35 \pm 0.5^{\circ} \mathrm{C}\left(35^{\circ} \mathrm{C}\right)$ and $60 \pm 0.5^{\circ} \mathrm{C}\left(60{ }^{\circ} \mathrm{C}\right)$ were performed in Labline Imperial III (Model 305PI) incubators. The samples were agitated by end-over-end rotation on Glas-Col rugged rotators placed inside the incubators. Manipulations of the solvent and aqueous phases were performed using calibrated Eppendorf pipettes. ESS performance tests were run in standard order beginning with the solvent phase that had undergone thermal exposure over a 43-day contacting period. 


\subsubsection{ESS Analyses of Phase-Stability Samples}

In order to remix the phases that had separated at low temperature, the test samples were agitated by end-over-end rotation on a Glas-Col rugged rotator located in an air box under a constant temperature of $25{ }^{\circ} \mathrm{C}$. The optimized-solvent $(-87 \mathrm{~W})$ samples were placed on the wheel first, and the $-156 \mathrm{~W}$ baseline samples followed two days later.

The ESS testing was performed on the $-87 \mathrm{~W}$ samples after 7 days on the wheel in the $25{ }^{\circ} \mathrm{C}$ airbox and involved an extraction step $(\mathrm{O}: \mathrm{A}=1: 3)$, two scrub steps $(\mathrm{O}: \mathrm{A}=5: 1)$, and four strips $(\mathrm{O}: \mathrm{A}=5: 1)$. Waste simulant (SRS full simulant, draw \#5 with $1.4 \times 10^{-4} \mathrm{M}$ Cs added) was spiked with ${ }^{137} \mathrm{CsCl}$ at an activity of $0.30 \square \mathrm{Ci} / \mathrm{mL}(56.25 \square \mathrm{L}$ of $80 \square \mathrm{Ci} / \mathrm{mL}$ into $15 \mathrm{~mL}$ of simulant using a calibrated Eppendorf pipette). In order to have sufficient counts for the third and fourth strips, a second spike (5 $\square \mathrm{L}$ of 88 $\square \mathrm{Ci} / \mathrm{mL}^{137} \mathrm{CsNO}_{3}$, affording a ${ }^{137} \mathrm{Cs}$ activity of $0.629 \square \mathrm{Ci} / \mathrm{mL}$, in the aqueous phase) was added to the third strip.

Teflon ${ }^{\circledR}$ FEP tubes $(50 \mathrm{~mL})$ were used for extraction, whereas $17-\mathrm{mL}$ capacity polypropylene tubes were used in scrubs and strips. All tubes were washed prior to use according to the standard tubewashing protocol [11]. Individual tubes were shaken 10 times before being rotated on the wheel for 35 minutes. Phase separation was accomplished by centrifuging for 3 minutes at $2910 \mathrm{rpm}$ in a refrigerated tabletop centrifuge (set point of $25{ }^{\circ} \mathrm{C}$ ). A $0.250-\mathrm{mL}$ sample was removed from each phase for ${ }^{137} \mathrm{Cs}$ gamma counting using a Packard Cobra Quantum Model 5003 gamma counter equipped with a 3-inch $\mathrm{NaI}$ (T1) crystal through-hole detector. A count time of 10-minutes duration was used with a window setting of $580-750 \mathrm{keV}\left({ }^{137 \mathrm{~m}} \mathrm{Ba}\right)$ for determining ${ }^{137} \mathrm{Cs}$ activity. The protocol is represented in Fig. 14.

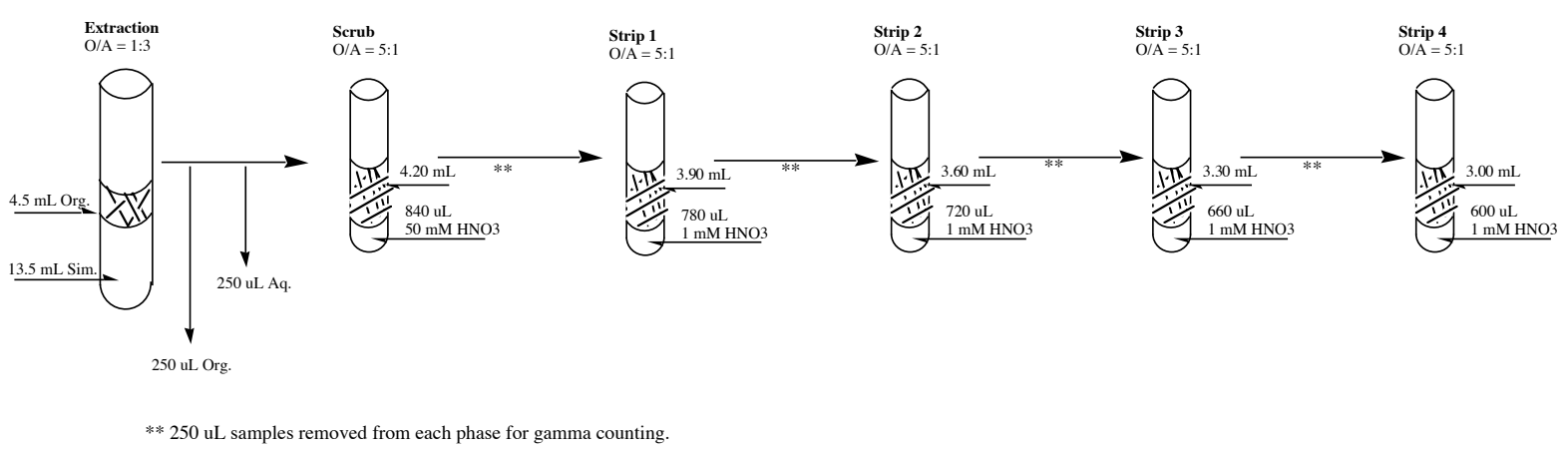

Fig. 14. ESS protocol for optimized solvent phase-stability test. 


\subsubsection{HPLC Analyses of Phase-Stability Samples}

In the cases where solvent samples displayed stratification (separation into different layers) upon cooling in the refrigerator and freezer, aliquots of each layer were submitted for compositional analysis by HPLC. Samples were prepared for HPLC analysis by diluting $100 \square \mathrm{L}$ of the solvent with 2-propanol to a final volume of $1 \mathrm{~mL}$. All samples were analyzed according to the method described in section 5.2.2.

\section{Quantitation}

The analytes, BOBCalixC6 and Cs-7SB modifier, were quantitated using the wavelengths $226 \mathrm{~nm}$ and $254 \mathrm{~nm}$, respectively, set using the diode array detector. Each analyte was calibrated using seven independent standards prepared in isopropanol/Isopar ${ }^{\circledR} \mathrm{L}$, each analyzed in duplicate. The calibration ranges for BOBCalixC6 and Cs-7SB modifier were 0.02 to $2 \mathrm{mM}$ and 1 to $100 \mathrm{mM}$, respectively. The measured integrated peak areas were fit to a linear least-squares line, where the coefficient of determination, $r^{2}$, exceeded 0.999 .

\subsection{RESULTS AND DISCUSSION}

Experiments involving the temperatures of $-24{ }^{\circ} \mathrm{C}$ and $0{ }^{\circ} \mathrm{C}$ are presented below in section 6.3.1. Experiments in which the solvent was contacted for an extended period of time with simulant, scrub, or strip solutions at $35^{\circ} \mathrm{C}$ or $60^{\circ} \mathrm{C}$ are described in section 6.3.2.

\subsubsection{Phase Stability at Low Temperature}

Samples of the pristine previous-baseline and optimized solvents that were stored in the refrigerator at $0{ }^{\circ} \mathrm{C}$ in $10-\mathrm{mL}$ volumetric flasks overnight were observed to have split into two phases (Figure 15). As the density of the modifier $\left(1.197 \mathrm{~g} / \mathrm{mL}\right.$ at $\left.25^{\circ} \mathrm{C}\right)$ is substantially more than the Isopar ${ }^{\circledR} \mathrm{L}$ diluent $(0.76$ $\mathrm{g} / \mathrm{mL}$ at $20^{\circ} \mathrm{C}$ ), the lower, heavier phase was presumed to be enriched in modifier relative to the upper, lighter phase. The thickness of the heavier layer was observed to increase with storage time over the course of 4 days (Table 31), after which the phase thickness was essentially unchanged. The composition of lower and upper layers for both solvents was determined by HPLC analysis (Table 32). 


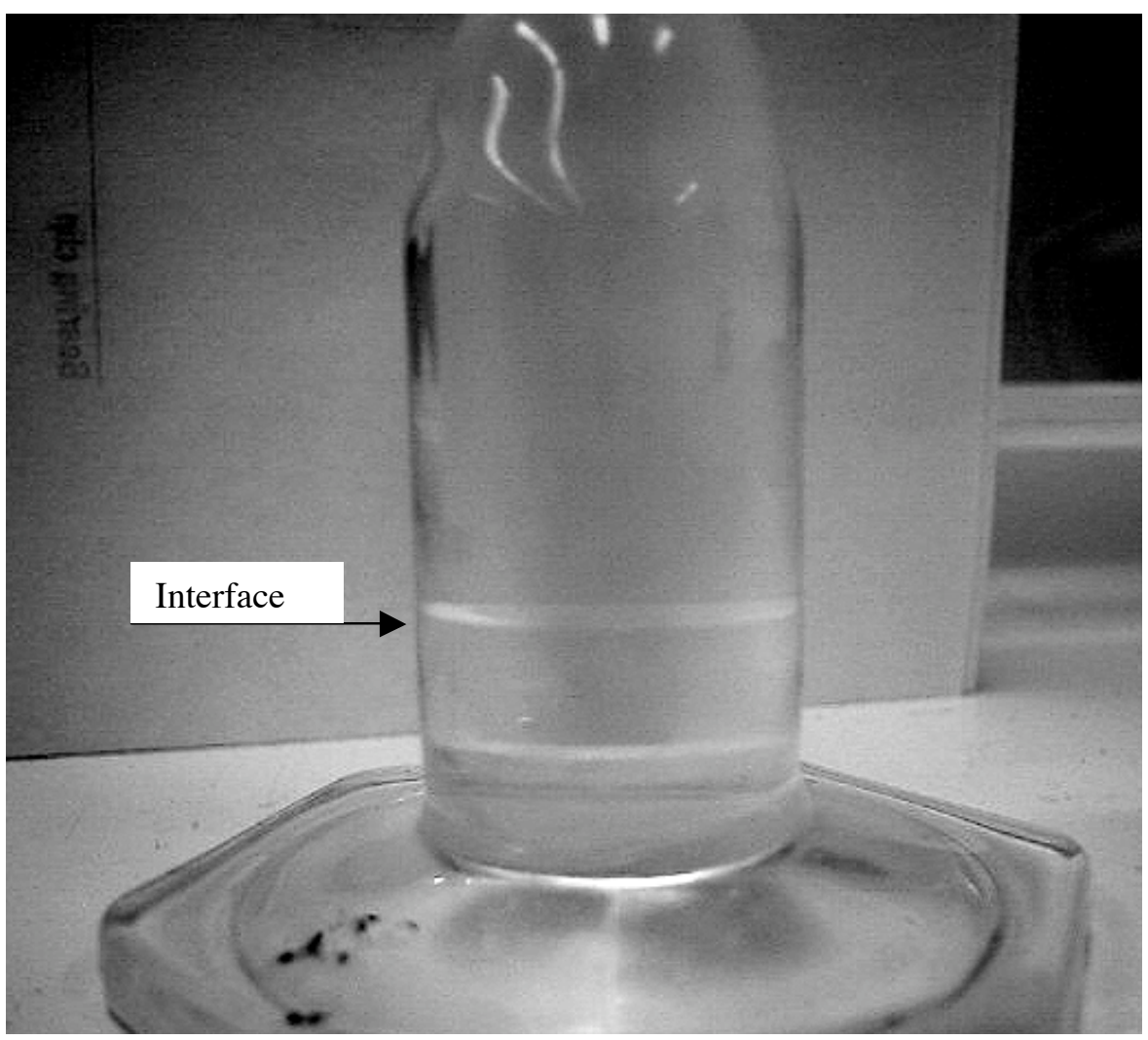

Fig. 15. Phase separation in the optimized solvent at $0{ }^{\circ} \mathrm{C}$.

Table 31. Phase separation at $0{ }^{\circ} \mathrm{C}$ for the previous-baseline and the optimized solvents

\begin{tabular}{|c|c|c|c|c|c|c|}
\hline \multicolumn{4}{|c|}{ Optimized solvent $-87 \mathrm{~W}$} & \multicolumn{3}{|c|}{ Original solvent $-156 \mathrm{~W}$} \\
\hline Phase & $\begin{array}{l}\text { Phase } \\
\text { mass } \\
(\mathrm{g})\end{array}$ & $\begin{array}{l}\text { Phase } \\
\text { density } \\
(\mathrm{g} / \mathrm{mL})\end{array}$ & $\begin{array}{l}\text { Calculated } \\
\text { volume } \\
(\mathrm{mL})\end{array}$ & $\begin{array}{c}\text { Phase } \\
\text { mass } \\
(\mathrm{g})\end{array}$ & $\begin{array}{l}\text { Phase } \\
\text { density } \\
(\mathrm{g} / \mathrm{mL})\end{array}$ & $\begin{array}{l}\text { Calculated } \\
\text { volume } \\
(\mathrm{mL})\end{array}$ \\
\hline Top & 5.9115 & 0.826 & 7.157 & 7.517 & 0.825 & 9.111 \\
\hline Bottom & 2.2776 & 0.969 & 2.350 & 0.6777 & 0.985 & 0.688 \\
\hline TOTAL & 8.1891 & & 9.51 & 8.1947 & & 9.80 \\
\hline
\end{tabular}


Table 32. Phase compositions at $0{ }^{\circ} \mathrm{C}$ for the previous-baseline and the optimized solvents

\begin{tabular}{lccccc}
\hline & & \multicolumn{2}{c}{ Optimized solvent } & \multicolumn{2}{c}{ Original solvent } \\
\cline { 3 - 6 } & & Repeats $(\mathrm{mM})$ & Avg. $(\mathrm{mM})$ & Repeats $(\mathrm{mM})$ & Avg. $(\mathrm{mM})$ \\
\hline Top layer & BOBCalixC6 & 2.81 & 2.85 & 7.05 & 7.04 \\
& & 2.88 & & 7.02 & \\
& Cs-7SB & 412.7 & 417.8 & 409.7 & 408.6 \\
\hline Bottom & & 422.9 & 407.5 & 40.5 \\
& BOBCalixC6 & 18.9 & 17.9 & 40.5 & 40.5 \\
& & 16.9 & & 1557.1 & \multirow{2}{*}{1555.8} \\
\hline
\end{tabular}

A similar experiment was performed by placing $10-\mathrm{mL}$ volumetric flasks filled with the optimized and previous baseline solvents in the freezer at $-24^{\circ} \mathrm{C}$ overnight. The result is shown in Fig. 16, where, in spite of the frost, it is clearly evident that a white phase had separated. That heavier phase also seems to be frozen, likely due to the water contained in the solvent from the solvent-washing operation.

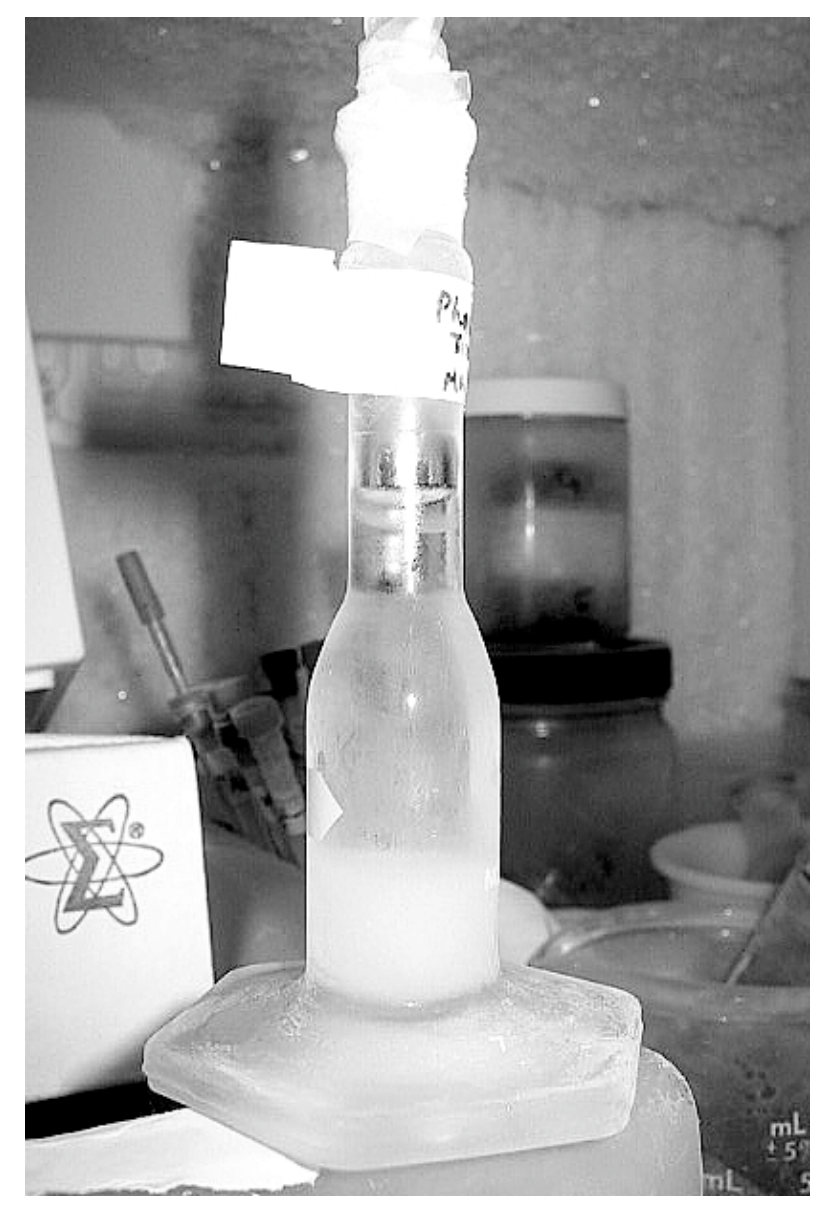

Fig. 16. Phase separation in the optimized solvent at $-24^{\circ} \mathrm{C}$. 
Table 33. Phase separation at $-24^{\circ} \mathrm{C}$ for the previous-baseline and the optimized solvents

\begin{tabular}{lccccccc}
\hline & \multicolumn{3}{c}{ Optimized solvent $-87 \mathrm{~W}$} & & \multicolumn{3}{c}{ Original solvent $-156 \mathrm{~W}$} \\
\cline { 1 - 2 } Phase & $\begin{array}{c}\text { Phase } \\
\text { mass } \\
(\mathrm{g})\end{array}$ & $\begin{array}{c}\text { Phase } \\
\text { density } \\
(\mathrm{g} / \mathrm{mL})\end{array}$ & $\begin{array}{c}\text { Calculated } \\
\text { volume } \\
(\mathrm{mL})\end{array}$ & & $\begin{array}{c}\text { Phase } \\
\text { mass } \\
(\mathrm{g})\end{array}$ & $\begin{array}{c}\text { Phase } \\
\text { density } \\
(\mathrm{g} / \mathrm{mL})\end{array}$ & $\begin{array}{c}\text { Calculated } \\
\text { volume } \\
(\mathrm{mL})\end{array}$ \\
\hline Top & 5.1245 & 0.803 & 6.382 & & 6.1929 & 0.788 & 7.859 \\
Bottom & 3.0263 & 1.006 & 3.008 & & 1.9418 & 1.036 & 1.874 \\
TOTAL & 8.1508 & & 9.39 & & 8.1347 & & 9.73 \\
\hline
\end{tabular}

Table 34. Phase compositions at $-24^{\circ} \mathrm{C}$ for the previous-baseline and the optimized solvents

\begin{tabular}{lccccc}
\hline & & \multicolumn{2}{c}{ Optimized solvent } & \multicolumn{2}{c}{ Original solvent } \\
\cline { 3 - 6 } & & Repeats $(\mathrm{mM})$ & Avg. $(\mathrm{mM})$ & Repeats $(\mathrm{mM})$ & Avg. $(\mathrm{mM})$ \\
\hline Top layer & BOBCalixC6 & 0.49 & 0.49 & 0.87 & 0.88 \\
& & 0.48 & & 0.89 & \\
& Cs-7SB & 119.5 & 117.9 & 93.6 & 93.7 \\
\hline Bottom & 116.4 & 20.0 & 43.0 & 43.0 \\
& BOBCalixC6 & 20.0 & & & \\
& & 20.0 & 1916.2 & 2012.5 & 2012.5 \\
\hline
\end{tabular}

When the refrigerator-cooled samples were allowed to stand at room temperature for about four hours, the interface or boundary separating the two layers was no longer visible. However, when the samples were shaken gently, schlieren effects ("swirls" in the solvent) were visible suggesting that the solvent was not yet homogeneous (a density gradient still remained). Subsamples at the very top and very bottom of the flasks were taken, and the composition of these phases were again determined by HPLC. Note that the concepts of "very top" and "very bottom" are subjective. Results are presented in Table 35.

Table 35. Solvent compositions at $0^{\circ} \mathrm{C}$ for the previous-baseline and the optimized solvents

\begin{tabular}{ccccc}
\hline & \multicolumn{2}{c}{ Optimized Solvent } & \multicolumn{2}{c}{ Original Solvent } \\
\cline { 2 - 5 } & Repeats $(\mathrm{mM})$ & Avg. $(\mathrm{mM})$ & Repeats $(\mathrm{mM})$ & Avg. $(\mathrm{mM})$ \\
\hline Top Surface BOBCalixC6 & 3.35 & 3.36 & 9.78 & 9.77 \\
& 3.37 & & 9.75 & \\
Cs-7SB & 458.5 & 459.7 & 475.9 & 474.9 \\
& 461.0 & 14.8 & 9.6 & 9.70 \\
Very Bottom BOBCalixC6 & 14.7 & & 9.7 & \\
& 14.9 & 1355.5 & 481.9 & 483.6 \\
\hline
\end{tabular}


Similarly, the freezer-cooled samples were allowed to stand at room temperature to see how long it would take for the interface between the layers to be no longer visible. After a couple of days at room temperature, the interface was gone, and the "very top" and "very bottom" portions of the solvent in the flasks were again analyzed by HPLC (Table 36). It is noteworthy that, despite there being no visible sign of a phase separation, there remained a density gradient in the static samples. Of course, mixing the solvent results in homogenization.

Table 36. Solvent compositions at $-24^{\circ} \mathrm{C}$ for the previous-baseline and the optimized solvents

\begin{tabular}{cccccc}
\hline & \multicolumn{2}{c}{ Optimized solvent } & \multicolumn{2}{c}{ Original solvent } \\
\cline { 2 - 5 } & & Repeats $(\mathrm{mM})$ & Avg. $(\mathrm{mM})$ & Repeats $(\mathrm{mM})$ & Avg. $(\mathrm{mM})$ \\
\hline Top surface & BOBCalixC6 & 0.65 & 0.67 & 1.06 & 1.06 \\
& 0.68 & & 1.06 & \\
Cs-7SB & 156.1 & 157.7 & 125.6 & 126.1 \\
& 159.4 & 19.0 & 34.6 & 34.2 \\
\hline Very bottom BOBCalixC6 & 18.8 & & 33.8 & \\
& 19.1 & 1594.2 & 1574.3 \\
\hline
\end{tabular}

It is apparent and not surprising that the miscibility of the nonpolar aliphatic diluent $\operatorname{Isopar}^{\circledR} \mathrm{L}$ and the polar fluorinated alcohol modifier is not infinite at all temperatures. Thus, static storage of the wet solvent at temperatures at or below freezing can result in phase separation, in which the concentrations of the solvent components in each layer are quite different. The phase separation is presumed to be fully reversible upon mixing and warming, but to verify that this is the case, the cesium-distribution behavior of the solvent following remixing was determined. After a 1-week equilibration at room temperature, solvents were subjected to ESS testing. Experiments were run in duplicate, and a pristine-solvent control was added to the series. These tests were done for both previous-baseline and optimized solvents. Results are summarized in Tables 37 and 38.

Table 37. ESS tests at $25^{\circ} \mathrm{C}$ using the low temperature-conditioned previous baseline solvent

\begin{tabular}{cllllll}
\hline \multirow{2}{*}{ Conditions } & \multicolumn{7}{c}{$D_{\mathrm{Cs}}$} \\
\cline { 2 - 7 } & Extraction & Scrub \#1 & Strip \#1 & Strip \#2 & Strip \#3 & Strip \#4 \\
\hline $0{ }^{\circ} \mathrm{C}$ & 17.03 & 1.521 & 0.133 & 0.074 & 0.055 & 0.052 \\
$0{ }^{\circ} \mathrm{C}$ & 17.41 & 1.542 & 0.135 & 0.076 & 0.056 & 0.053 \\
$-24{ }^{\circ} \mathrm{C}$ & 17.03 & 1.487 & 0.138 & 0.081 & 0.061 & 0.055 \\
$-24{ }^{\circ} \mathrm{C}$ & 16.87 & 1.482 & 0.136 & 0.078 & 0.058 & 0.050 \\
Control & 17.54 & 1.537 & 0.140 & 0.075 & 0.057 & 0.048 \\
\hline
\end{tabular}


Table 38. ESS tests at $25^{\circ} \mathrm{C}$ using the low temperature-conditioned optimized solvent

\begin{tabular}{cccccccc}
\hline Conditions & \multicolumn{7}{c}{$D_{\mathrm{Cs}}$} \\
\cline { 2 - 8 } & Extraction & Scrub \#1 & Scrub \#2 & Strip \#1 & Strip \#2 & Strip \#3 & Strip \#4 \\
\hline $0{ }^{\circ} \mathrm{C}$ & 13.39 & 1.03 & 1.15 & 0.103 & 0.066 & 0.054 & 0.048 \\
$0{ }^{\circ} \mathrm{C}$ & 13.57 & 1.01 & 1.24 & 0.102 & 0.066 & 0.052 & 0.047 \\
$-24{ }^{\circ} \mathrm{C}$ & 13.34 & 1.03 & 1.25 & 0.107 & 0.068 & 0.055 & 0.048 \\
$-24{ }^{\circ} \mathrm{C}$ & 13.46 & 1.05 & 1.23 & 0.102 & 0.065 & 0.053 & 0.046 \\
Control & 13.29 & 1.04 & 1.23 & 0.098 & 0.064 & 0.052 & 0.048 \\
\hline
\end{tabular}

The results indicate that cold conditions did not impair the performance of the solvents, previousbaseline or optimized, and that the phase separation is a fully reversible phenomenon. The cesium distribution behavior of the "cold-conditioned" solvents is comparable to their corresponding controls.

\subsubsection{Chemical Stability at High Temperature}

Stability tests at elevated temperatures $\left(35^{\circ} \mathrm{C}\right.$ and $\left.60{ }^{\circ} \mathrm{C}\right)$ were similar to those carried out in FY 2001. Solvent samples were carried partially through an ESS procedure and allowed to remain in prolonged contact with one of the aqueous solutions used in the sequence: the waste simulant, scrub solution, or strip solution. For example, to test the stability of the solvent to prolonged contact with strip solution, the solvent sample would undergo an extraction and two scrubs before being placed in prolonged contact with the strip solution. The experiments were carried out for 43 days. Cesium extraction performance of the thermally treated solvent samples was assessed by running ESS tests at 25 ${ }^{\circ} \mathrm{C}$. Results are summarized in Table 39. Explanations for the entry nomenclature are given in the footnotes to the table, where the numbers in the sample codes indicate the temperature of the prolonged contact, either 35 or $60{ }^{\circ} \mathrm{C}$.

In all cases, the solvents behaved similarly to the controls and furthermore gave ESS results remarkably close to those obtained in Chapter 3 with pristine solvent. Over a 43-day treatment, performance remained essentially unchanged for both $35{ }^{\circ} \mathrm{C}$ and $60{ }^{\circ} \mathrm{C}$ samples. In only one case, TS60SCB (treatment over scrub solution at $60{ }^{\circ} \mathrm{C}$ ), did the $D_{\mathrm{Cs}}$ value seem high on stripping, but only for the second strip. This thermal-stability study thus yielded results comparable to those obtained in FY 2001.

\subsection{CONCLUSIONS}

The results validate the expectation that the optimized solvent would possess adequate thermal stability. It was clear from the thermal-stability tests on the previous baseline solvent [11] that the solvent undergoes degradation only when in contact with the acidic scrub and strip solutions, owing to 
Table 39. ESS tests at $25^{\circ} \mathrm{C}$ using the high temperature-stressed optimized solvent

\begin{tabular}{lcccccccccc}
\hline \multirow{2}{*}{ Test } & \multicolumn{10}{c}{$D_{\mathrm{Cs}}$} \\
& \cline { 2 - 11 } & Extract & $\begin{array}{c}\text { Scrub } \\
\# 1\end{array}$ & $\begin{array}{c}\text { Scrub } \\
\# 2\end{array}$ & $\begin{array}{c}\text { Strip } \\
\# 1\end{array}$ & $\begin{array}{c}\text { Strip } \\
\# 2\end{array}$ & $\begin{array}{c}\text { Strip } \\
\# 3\end{array}$ & $\begin{array}{c}\text { Strip } \\
\# 4\end{array}$ & $\begin{array}{c}\text { Extract } \\
\text { Scrub } \\
\# 1\end{array}$ & $\begin{array}{c}\text { Scrub } \\
\# 2\end{array}$ \\
\hline TS35P $^{a}$ & 14.69 & 1.096 & 1.276 & 0.1065 & 0.0647 & 0.0513 & 0.0486 & & & \\
TS60P $^{a}$ & 13.90 & 1.101 & 1.298 & 0.1164 & 0.0718 & 0.0547 & 0.0485 & & & \\
TS35S $^{b}$ & 13.88 & 1.110 & 1.267 & 0.1344 & 0.0673 & 0.0516 & 0.0472 & & & \\
TS60S $^{b}$ & 13.34 & 1.165 & 1.177 & 0.1109 & 0.0693 & 0.0544 & 0.0475 & & & \\
TS35SCB $^{c}$ & & 1.063 & 1.273 & 0.1018 & 0.0696 & 0.0539 & 0.0483 & 13.89 & & \\
TS60SCB $^{c}$ & & 1.165 & 1.305 & 0.1240 & 0.0971 & 0.0602 & 0.0484 & 13.90 & & \\
TS35ST $^{d}$ & & & & 0.1156 & 0.0699 & 0.0540 & 0.0478 & 13.84 & 1.180 & 1.268 \\
TS60ST $^{d}$ & & & & 0.1397 & 0.0724 & 0.0552 & 0.0482 & 13.79 & 1.107 & 1.261 \\
\hline
\end{tabular}

${ }^{a}$ TS35P or TS60P indicates use of pristine solvent, no contact with aqueous phases over the course of 43 days at either $35^{\circ} \mathrm{C}$ or $60{ }^{\circ} \mathrm{C}$.

${ }^{b} \mathrm{TS} 35 \mathrm{~S}$ or TS60S indicates use of solvent that was in contact with simulant at O:A $=1: 3$ (draw \#5 to which was added $1.4 \square 10^{-4} \mathrm{M} \mathrm{Cs}$ ) via end-over-end rotation for 43 days at either $35^{\circ} \mathrm{C}$ or $60{ }^{\circ} \mathrm{C}$.

${ }^{c}$ TS35SCB or TS60SCB indicates use of solvent that was contacted with simulant for 30 minutes at $25{ }^{\circ} \mathrm{C}$ via end-over-end rotation; the solvent phase was then contacted at $\mathrm{O}: \mathrm{A}=5: 1$ with scrub solution via end-over-end rotation for 43 days at either $35^{\circ} \mathrm{C}$ or $60{ }^{\circ} \mathrm{C}$.

${ }^{d} \mathrm{TS} 35 \mathrm{ST}$ or TS60ST indicates use of solvent that was contacted with simulant for 30 minutes at $25{ }^{\circ} \mathrm{C}$ via end-over-end rotation; the solvent phase was then contacted at $\mathrm{O}: \mathrm{A}=5: 1$ with scrub solution for 30 minutes $t 25^{\circ} \mathrm{C}$ via end-over-end rotation; the solvent phase then contacted at $\mathrm{O}: \mathrm{A}=5: 1$ with strip solution for 43 days via end-over-end rotation at either $35^{\circ} \mathrm{C}$ or $60^{\circ} \mathrm{C}$.

degradation of the TOA. This effect was only detectable for the elevated-temperature samples $\left(61{ }^{\circ} \mathrm{C}\right)$ held for 46 days or more. Pristine solvent held for 235 days at $61{ }^{\circ} \mathrm{C}$ underwent no noticeable degradation in performance, which was also true of solvent contacted with the waste simulant for 235 days at $61{ }^{\circ} \mathrm{C}$. The present study reflects almost the same behavior, though the duration of the test (43 days) was insufficient to detect any impact to performance at either temperature. Making the assumption that only $4.4 \%$ of the solvent inventory resides in the scrub and strip sections of the flowsheet at any given time and that negligible degradation occurs outside of these sections [11], 43 days at the maximum normal operating temperature of $35^{\circ} \mathrm{C}$ corresponds to a minimum of 977 days of solvent lifetime. Thus, it can be reasonably said that thermal stress should not have a significant impact on the performance of the optimized solvent.

It also was informative to examine the behavior of the optimized solvent under low-temperature conditions, which may be encountered during storage or shipping in winter months. The phase separation that occurs at low temperature does not impair the solvent performance upon warming and remixing. ESS experiments proved that the cesium extraction performance of the previous-baseline and optimized solvents is not altered by a cold-temperature conditioning resulting in a phase separation, possibly even a freezing of these phases. It is clear that solvent stored or shipped under cold conditions should be remixed at room temperature to ensure good quality results. 



\section{PHYSICAL-PROPERTIES MEASUREMENTS}

\subsection{INTRODUCTION}

Laboratory-scale physical-property evaluations of the optimized Caustic-Side Solvent Extraction (CSSX) formulation have been completed to help determine the operating characteristics for design of the centrifugal contactors used in cesium removal at the Savannah River Site [20]. The properties measured in these tests were solvent density, viscosity, and dispersion numbers for the solvent against full simulant, scrub, and strip solutions at temperatures between 15 and $35^{\circ} \mathrm{C}$.

The evaluations included determination of phase separation by gravity settling under conditions present in the extraction, scrubbing, and stripping sections of the CSSX cascade, measurement of solvent density, measurements of solvent viscosity at several temperatures, and measurements of solvent surface tension and the interfacial tension of each solvent/simulant, solvent scrub, and solvent/strip combination. Results of these tests show that all of the formulations will perform the required separations and will perform satisfactorily in the contactors.

\subsection{EXPERIMENTAL PROCEDURES}

\subsubsection{Chemicals}

The CSSX solvent is a blend of the organic materials listed above. Scrub (0.05 $\left.\mathrm{M} \mathrm{HNO}_{3}\right)$ and strip $\left(0.001 \mathrm{M} \mathrm{HNO}_{3}\right)$ aqueous solutions were formulated using $1.0 \mathrm{M} \mathrm{HNO}_{3}$, procured from J. T. Baker Co. and diluted with water that had been deionized using a Barnstead Nanopure B filtration system. Sodium hydroxide solutions used to wash the solvent were formulated using a standard $0.1 \mathrm{M}$ sodium hydroxide solution (ACS reagent grade, procured from the J. T. Baker Co.). SRS waste supernatant simulant was formulated according to SRS procedure [23], but the composition listed in that document for "average" SRS supernatant simulant was adjusted slightly as shown in Table 1 to match the new average simulant. The cesium concentration in the simulant batch used in testing was $0.000143 \mathrm{M}$. The simulant was prepared by first combining the ingredients shown below except for the cesium and silica. These were added along with the metals and organic components shown in Table 2 to make the complete simulant. After the materials in Tables 40 and 41 were all combined and allowed to age over a three-day period, the simulant was filtered through a $0.45-\square \mathrm{m}$ Gelman polypropylene groundwater filter to remove any precipitates formed. The simulant remained clear after filtration during all remaining testing. 


\subsubsection{Determination of Dispersion Number}

The purpose of these tests was to determine phase-separation performance of the optimized CSSX solvent under conditions approximating those present in the extraction, scrubbing, and stripping sections of the CSSX cascade. Phase-separation performance was quantified in terms of dimensionless dispersion numbers, determined at temperatures ranging from $15{ }^{\circ} \mathrm{C}$ to $35{ }^{\circ} \mathrm{C}$. Prior to phase-separation determinations, the solvent was equilibrated according to the test condition. Extraction-condition test solvent was equilibrated under extraction conditions.

Table 40. Simulant composition (major components)

\begin{tabular}{|c|c|c|c|c|c|}
\hline Component & $\begin{array}{l}\text { Avg. SRS } \\
\text { simulant } \\
\text { (M) }\end{array}$ & $\begin{array}{c}\text { New Avg. SRS } \\
\text { waste diluted } \\
\text { with } \mathrm{H}_{2} \mathrm{O}(\mathrm{M})\end{array}$ & $\begin{array}{c}\text { Compound } \\
\text { used }\end{array}$ & $\begin{array}{c}\text { Mol. } \\
\text { Wt. }\end{array}$ & $\begin{array}{c}\text { Mass for } \\
\text { new avg. } \\
(\mathrm{g} / \mathrm{L})\end{array}$ \\
\hline $\mathrm{Na}^{+}$ & 5.6 & 5.6 & & & \\
\hline $\mathrm{Cs}^{+}$ & 0.00014 & 0.000143 & $\mathrm{CsCl}$ & 168.37 & 0.024077 \\
\hline $\mathrm{K}^{+}$ & 0.015 & 0.0146 & $\mathrm{KNO}_{3}$ & 101.10 & 1.47606 \\
\hline $\mathrm{OH}^{-}$ & 1.91 & 2.086 & $\mathrm{NaOH}$ & 40.00 & 81.56 \\
\hline $\mathrm{NO}_{3}^{-}$ & 2.14 & 2.039 & $\mathrm{NaNO}_{3}$ & 84.99 & 173.295 \\
\hline $\mathrm{NO}_{2}^{-}$ & 0.52 & 0.494 & $\mathrm{NaNO}_{2}$ & 69.00 & 34.086 \\
\hline $\mathrm{AlO}_{2}^{-}$ & 0.31 & 0.289 & $\mathrm{Al}\left(\mathrm{NO}_{3}\right)_{3} \cdot 9 \mathrm{H}_{2} \mathrm{O}$ & 375.14 & 108.415 \\
\hline $\mathrm{CO}_{3}{ }^{2-}$ & 0.16 & 0.147 & $\mathrm{Na}_{2} \mathrm{CO}_{3} \cdot \mathrm{H}_{2} \mathrm{O}$ & 124.01 & 18.2295 \\
\hline $\mathrm{SO}_{4}{ }^{2-}$ & 0.15 & 0.137 & $\mathrm{Na}_{2} \mathrm{SO}_{4}$ & 142.04 & 19.4595 \\
\hline $\mathrm{Cl}^{-}$ & 0.025 & 0.025 & $\mathrm{NaCl}$ & 58.44 & 1.4610 \\
\hline $\mathrm{F}^{-}$ & 0.032 & 0.030 & $\mathrm{NaF}$ & 41.99 & 1.2597 \\
\hline $\mathrm{PO}_{4}^{3-}$ & 0.010 & 0.007 & $\mathrm{Na}_{2} \mathrm{HPO}_{4} \cdot 7 \mathrm{H}_{2} \mathrm{O}$ & 268.09 & 1.8766 \\
\hline $\mathrm{C}_{2} \mathrm{O}_{4}^{2-}$ & 0.008 & 0.018 & $\begin{array}{l}\mathrm{Na}_{2} \mathrm{C}_{2} \mathrm{O}_{4} \\
\text { (Sodium } \\
\text { Oxalate) }\end{array}$ & 134.00 & 2.412 \\
\hline $\mathrm{SiO}_{3}^{2-}$ & 0.004 & 0.003 & $\mathrm{Na}_{2} \mathrm{SiO}_{3} \cdot 9 \mathrm{H}_{2} \mathrm{O}$ & 284.20 & 0.8526 \\
\hline $\mathrm{MoO}_{4}{ }^{2-}$ & 0.0002 & 0.0002 & $\mathrm{Na}_{2} \mathrm{MoO}_{4} \cdot 2 \mathrm{H}_{2} \mathrm{O}$ & 241.95 & 0.04839 \\
\hline
\end{tabular}

${ }^{a}$ WSRC-RP-98-00168, Rev. 1.

${ }^{b}$ WSRC-RP-99-00006, Rev. 3. 
Table 41. Materials for full simulant (added trace metals and organic species)

\begin{tabular}{|c|c|c|c|c|}
\hline Component & $\begin{array}{l}\text { Concentration } \\
\text { in simulant } \\
\text { (M) }\end{array}$ & $\begin{array}{l}\text { Compound } \\
\text { used }\end{array}$ & Molecular weight & $\begin{array}{l}\text { Mass } \\
(\mathrm{g} / \mathrm{L})\end{array}$ \\
\hline $\mathrm{Cu}^{2+}$ & $2.27 \square 10^{-5}$ & $\mathrm{CuSO}_{4} \cdot 5 \mathrm{H}_{2} \mathrm{O}$ & 249.68 & 0.00566 \\
\hline $\mathrm{Cr}^{6+}$ & $1.44 \square 10^{-3}$ & $\mathrm{Na}_{2} \mathrm{CrO}_{4}$ & 161.97 & 0.2336 \\
\hline $\mathrm{Zn}^{2+}$ & $1.22 \square 10^{-4}$ & $\mathrm{Zn}\left(\mathrm{NO}_{3}\right)_{2} \cdot 6 \mathrm{H}_{2} \mathrm{O}$ & 297.47 & 0.0364 \\
\hline $\mathrm{Pb}^{2+}$ & $1.01 \square 10^{-5}$ & $\mathrm{~Pb}\left(\mathrm{NO}_{3}\right)_{2}$ & 331.20 & 0.00336 \\
\hline $\mathrm{Fe}^{3+}$ & $2.58 \square 10^{-5}$ & $\mathrm{Fe}\left(\mathrm{NO}_{3}\right)_{3} \cdot 9 \mathrm{H}_{2} \mathrm{O}$ & 404.00 & 0.01042 \\
\hline $\mathrm{Sn}^{2+}$ & $2.02 \square 10^{-5}$ & $\mathrm{SnCl}_{2} \cdot 2 \mathrm{H}_{2} \mathrm{O}$ & 225.63 & 0.00456 \\
\hline $\mathrm{Hg}^{2+}$ & $2.49 \square 10^{-7}$ & $\mathrm{Hg}\left(\mathrm{NO}_{3}\right)_{2} \cdot \mathrm{H}_{2} \mathrm{O}$ & 342.61 & 0.0000854 \\
\hline $\mathrm{Rh}^{3+}$ & $2.04 \square 10^{-6}$ & $\mathrm{Rh}\left(\mathrm{NO}_{3}\right)_{3} \cdot 2 \mathrm{H}_{2} \mathrm{O}$ & 324.95 & 0.000663 \\
\hline $\mathrm{Pd}^{2+}$ & $3.85 \square 10^{-6}$ & $\mathrm{Pd}\left(\mathrm{NO}_{3}\right)_{2}$ & 230.43 & 0.000888 \\
\hline $\mathrm{Ag}^{+}$ & $9.27 \square 10^{-8}$ & $\mathrm{AgNO}_{3}$ & 169.87 & 0.0000157 \\
\hline $\mathrm{Ru}^{3+}$ & $8.11 \square 10^{-6}$ & $\mathrm{RuCl}_{3}$ & 207.43 & 0.00168 \\
\hline TPB & $1.88 \square 10^{-6}$ & Tributylphosphate & 266.32 & 0.0005 \\
\hline DBP & $1.19 \square 10^{-4}$ & Dibutylphosphate & 210.21 & 0.025 \\
\hline MBP & $1.62 \square 10^{-4}$ & Monobutylphosphate & 154.10 & 0.025 \\
\hline$n$-Butanol & $2.70 \square 10^{-5}$ & $\mathrm{C}_{4} \mathrm{H}_{9} \mathrm{OH}$ & 74.12 & 0.002 \\
\hline $\mathrm{CHO}_{2}^{-}$ & $3.33 \square 10^{-2}$ & $\begin{array}{c}\mathrm{NaCHO}_{2} \\
\text { (sodium formate) }\end{array}$ & 68.01 & 1.5 \\
\hline TMA & $1.69 \square 10^{-4}$ & Trimethylamine & 59.11 & 0.01 \\
\hline
\end{tabular}

Scrub-conditioned solvent was obtained from extraction-equilibrated solvent and was batch equilibrated with scrub solution prior to testing. Strip-conditioned solvent was obtained from extractionand scrub-equilibrated solvent, and was equilibrated with strip solution prior to testing. Single-batch preequilibrations were used to mitigate errors that might be introduced due to variations in technique that could affect split-batch operations. Dispersion numbers were determined as described in Chapter 2.

\subsubsection{Laboratory Dispersion-Number Procedures}

The procedure above was used with the solvent for each extraction, scrub, and strip contact at each temperature from 15 to $35{ }^{\circ} \mathrm{C}$ at $5{ }^{\circ} \mathrm{C}$ increments simulating the operations in each step of the CSSX process. A total of $300 \mathrm{~mL}$ of optimized solvent, $1500 \mathrm{~mL}$ of simulated SRS waste supernatant (full recipe), $200 \mathrm{~mL}$ of CSSX scrub solution (0.05 $\left.\mathrm{M} \mathrm{HNO}_{3}\right)$, and $100 \mathrm{~mL}$ of CSSX strip solution (0.001 M $\left.\mathrm{HNO}_{3}\right)$ were required for the tests. Glass graduated cylinders $(100 \mathrm{~mL})$ with ground glass stoppers, an electronic stopwatch, a thermometer (LaPine 398-12-53), a refrigerated water bath (VWR model 13270615 circulation bath, with 190 watts cooling and operated at about $5 \mathrm{~L} / \mathrm{min}$ coolant recirculation rate and filled with distilled water), and a millimeter scale rule were used. Prior to use, all new or previously used 
glassware and plastic vessels were washed by rinsing with tap water three times, rinsing with demineralized water three times, rinsing with ethanol two times, and rinsing with acetone two times. The equipment was allowed to air dry or dried with a stream of dry nitrogen or argon before use.

To pre-equilibrate the solvent to extraction conditions, $300 \mathrm{~mL}$ of solvent was combined with $936 \mathrm{~mL}$ of supernatant simulant and $60 \mathrm{~mL}$ of scrub solution in a $2-\mathrm{L}$ flask at room temperature $\left(24.5^{\circ} \mathrm{C}\right)$. The flask was shaken vigorously for $20 \mathrm{~s}$, held for $10 \mathrm{~s}$, agitated for $20 \mathrm{~s}$, held for $10 \mathrm{~s}$, and agitated for $20 \mathrm{~s}$ again. The dispersion was allowed to separate, the solvent phase was collected, and the aqueous simulant solution was discarded.

\subsection{DISPERSION-NUMBER DETERMINATIONS}

\subsubsection{Extraction Dispersion-Number Determinations}

Extraction dispersion-number determinations were made using the full SRS simulant containing salts, metals, and organics and with non-radioactive cesium at a cesium concentration of $0.000143 \mathrm{M}$ as shown in Tables 40 and 41 . The tests were begun by placing $17.66 \mathrm{~mL}$ of solvent, $3.53 \mathrm{~mL}$ of scrub solution, and $53.81 \mathrm{~mL}$ of simulant in each graduated cylinder using Rainin EDP electronic 1 and 10-mL digital pipettes. The position of the stable interface between organic and aqueous phases and the height of the liquid column were measured. The cylinders were then placed in the temperature bath. After reaching the desired test temperature, the solution temperature was measured and each stoppered cylinder was removed from the bath and manually agitated for $20 \mathrm{~s}$, held still for $10 \mathrm{~s}$, and agitated for another for another $20 \mathrm{~s}$, and then placed back into the water bath. The time elapsed between cessation of agitation and the return of the interface to its original position (i.e., the collapse of the dispersion) was recorded. The total height of the dispersion column in the graduate at the beginning of the settling period was also recorded. (If agitated correctly, the dispersion column height should be the height of the liquid column inside the graduate.) This was repeated two more times, and after the third time, the temperature of the solution in the graduate was measured again. This procedure was then repeated for $20,25,30$, and $35{ }^{\circ} \mathrm{C}$ temperatures.

An additional extraction dispersion-number determination was made, again using the full simulant. The solvent $(40 \mathrm{~mL})$ was again pre-equilibrated with simulant $(124.9 \mathrm{~mL})$ and $8 \mathrm{~mL}$ of scrub solution as described above. The $17.66 \mathrm{~mL}$ of solvent, $3.53 \mathrm{~mL}$ of scrub solution, and $53.81 \mathrm{~mL}$ of simulant was added to each of the graduates and the extraction contacts were completed at $15,20,25,30$, and $35^{\circ} \mathrm{C}$.

A separate experiment following a similar procedure as that described above was completed using solvent that was not pre-equilibrated with simulant. The first time this was attempted, at $15{ }^{\circ} \mathrm{C}$, one of the two graduates, when shaken, had the look of a gel for the dispersion and this took longer to separate. At $20{ }^{\circ} \mathrm{C}$, the other one had the gel-like look and took longer to separate. That graduate continued to have the gel-look when shaken at the rest of the temperatures and the gel-like dispersion took longer to separate than the other. When it was separated, though, there was no visual difference between the two graduates except that in the one that had the gel-like formation, both organic and aqueous were clear as 
soon as the break was achieved. When the normal shake and break occurred, the tube had foam after shaking and both phases were slightly cloudy for $30 \mathrm{~min}$ to $2 \mathrm{~h}$ after break. No data was taken for break time during this trial. The gel-like formation is shown in the photos in Fig. 17 at various stages of phase separation.

The graduates were left as they were, and after five days in the graduates, the shakeouts were repeated. This time, both tubes were clear the first two shakes at $15{ }^{\circ} \mathrm{C}$, but on the third shake, the gel-like formation returned in the second tube, and it took about a minute to separate. At $20{ }^{\circ} \mathrm{C}$, no gel appeared in either tube. Then the temperature was increased to $35^{\circ} \mathrm{C}$, and shakeouts continued. On the second shake, gel-like formation occurred in the second tube. It took slightly longer to separate, but then on the third shake, both were normal again. At 30 and $25^{\circ} \mathrm{C}$, neither tube had the gel like formations on any shakeouts. The trigger for the gel-like formation is not known. Sometimes it occurred in one tube, then the other, and most times not at all. It could not be predicted when or at what temperature the material would behave this way and if it did, whether it would continue. All data are shown in Table 42 and Fig. 18.

\subsubsection{Scrubbing-Condition Dispersion-Number Determinations}

Solvent for the stripping dispersion number determinations was recovered from the single-batch extraction-condition equilibration and was determined to be $261.6 \mathrm{~mL}$. It was placed into a clean $500-\mathrm{mL}$ separatory funnel and a volume of scrub solution equal to one-fifth the solvent volume was added (52.32

$\mathrm{mL}$ ). The funnel was agitated vigorously for $20 \mathrm{~s}$, held for $10 \mathrm{~s}$, agitated for $20 \mathrm{~s}$, held for $10 \mathrm{~s}$, and agitated for $20 \mathrm{~s}$ again. The temperature of the dispersion was determined $\left(24.5^{\circ} \mathrm{C}\right)$ and the dispersion was allowed to separate. The solvent phase was collected and the aqueous solution was discarded. 


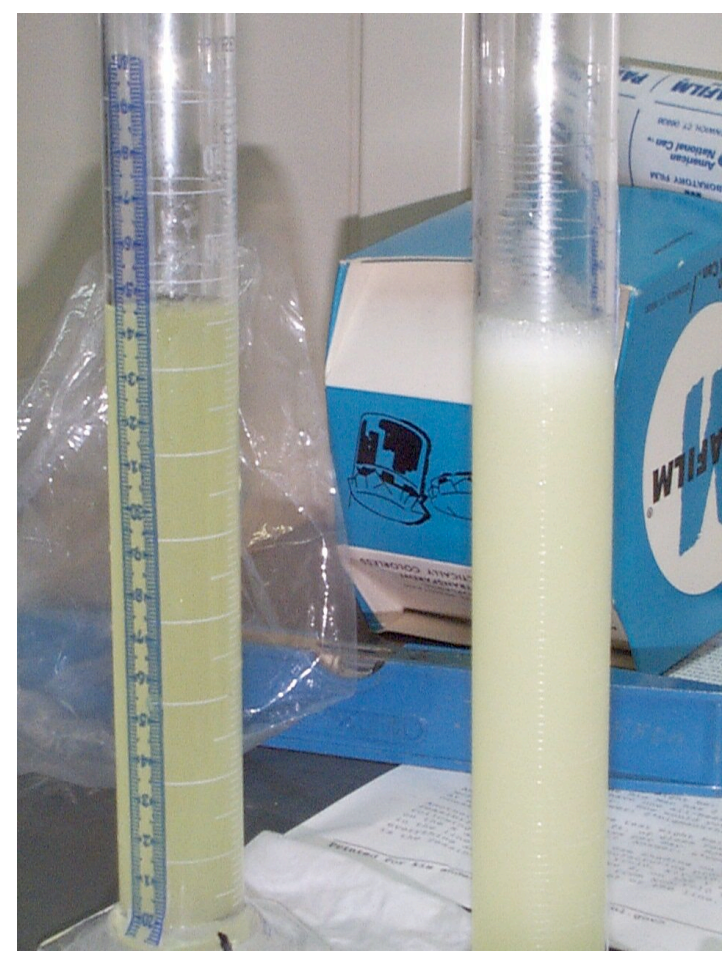

At the start of settling (gel on left)

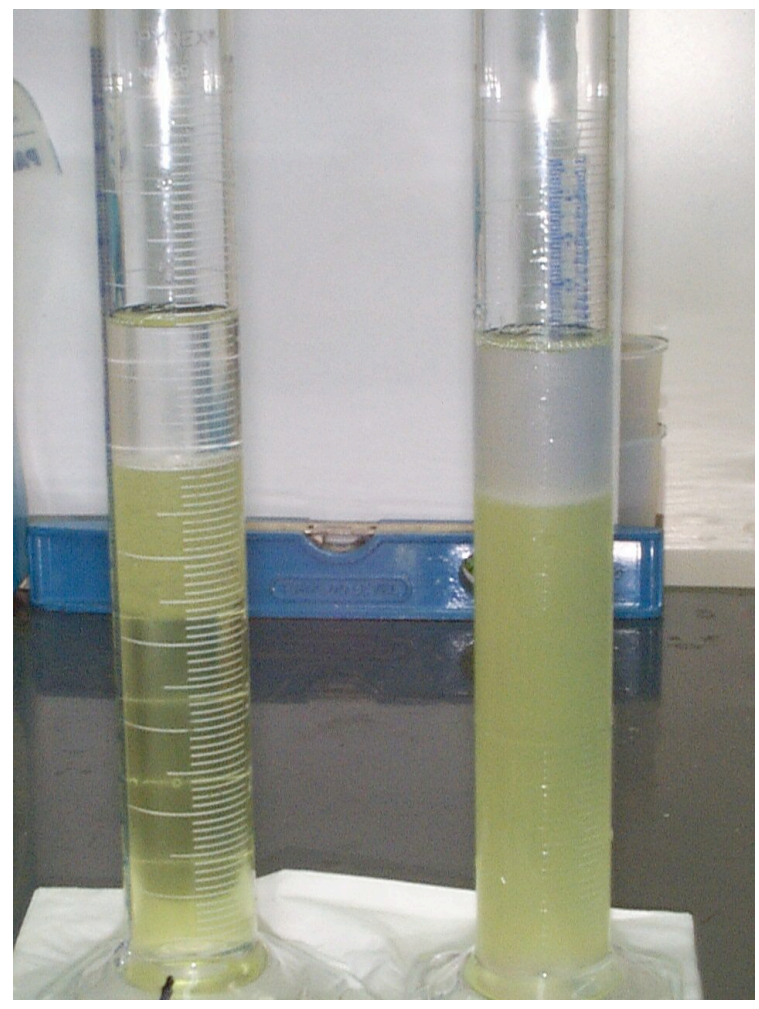

About 90\% complete settling.

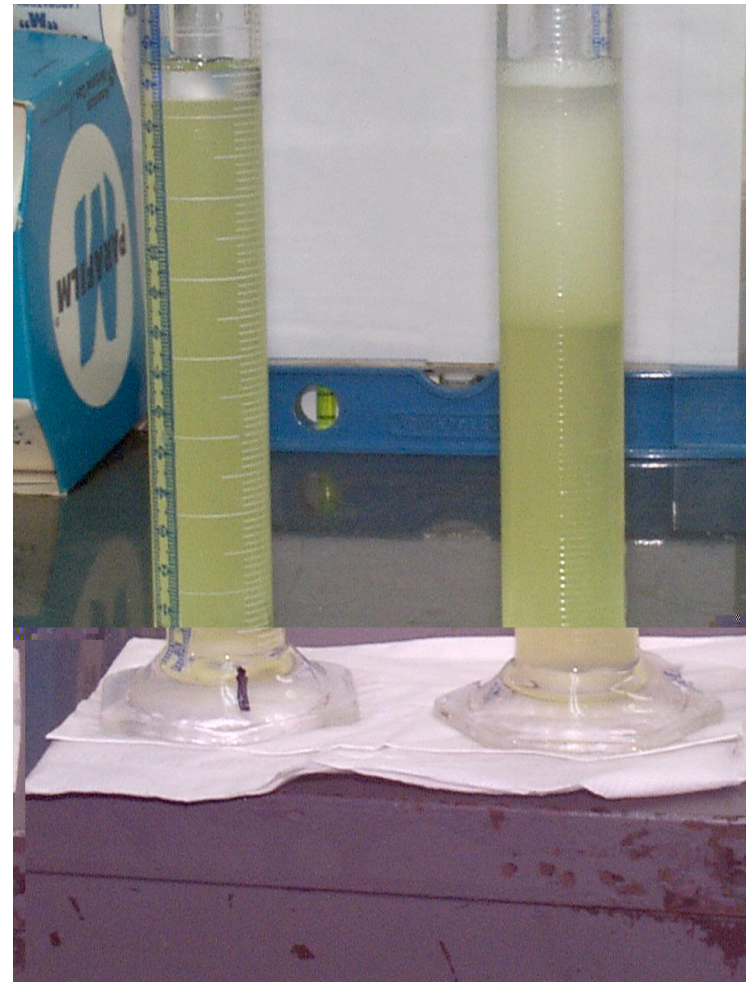

After about 1 minute

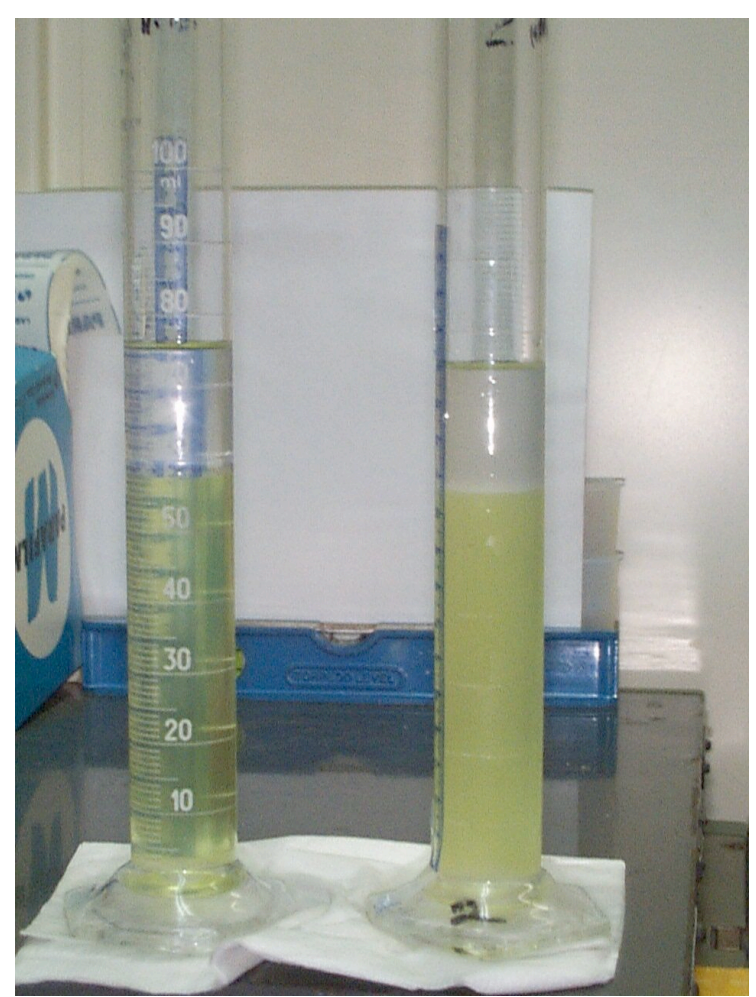

Completion of settling.

Fig. 17. Gel-like material formed during dispersion-number determinations. 
Table 42. Dispersion numbers for extraction with optimized CSSX solvent

\begin{tabular}{|c|c|c|c|}
\hline $\begin{array}{l}\text { Solvent } \\
\text { sample }\end{array}$ & $\begin{array}{l}\text { Dispersion height } \\
(\mathrm{cm})\end{array}$ & $\begin{array}{c}\text { Simulant/solvent } \\
\text { dispersion } \\
\text { number }\end{array}$ & $\begin{array}{c}\text { Determination } \\
\text { temperature } \\
\left({ }^{\circ} \mathrm{C}\right)\end{array}$ \\
\hline \multicolumn{4}{|c|}{ Trial 1} \\
\hline $15 \mathrm{C \# 1}$ & 13.3 & 0.001013 & 15.6 \\
\hline $15 \mathrm{C \# 2}$ & 13.75 & 0.000864 & 15.6 \\
\hline $20 \mathrm{C} \# 1$ & 13.3 & 0.001243 & 20.6 \\
\hline $20 \mathrm{C \# 2}$ & 13.75 & 0.001070 & 20.6 \\
\hline $25 \mathrm{C} \# 1$ & 13.3 & 0.001431 & 25.2 \\
\hline $25 \mathrm{C} \# 2$ & 13.75 & 0.001371 & 25.2 \\
\hline 30C\#1 & 13.3 & 0.001581 & 30.0 \\
\hline $30 \mathrm{C \# 2}$ & 13.75 & 0.001629 & 30.0 \\
\hline $35 \mathrm{C} \# 1$ & 13.3 & 0.001782 & 34.8 \\
\hline $35 \mathrm{C} \# 2$ & 13.75 & 0.001909 & 34.8 \\
\hline \multicolumn{4}{|c|}{ Trial 2} \\
\hline $15 \mathrm{C \# 1}$ & 14.0 & 0.000623 & 15.3 \\
\hline $15 \mathrm{CH} 2$ & 13.2 & 0.000680 & 15.3 \\
\hline $20 \mathrm{C} \# 1$ & 14.0 & 0.000872 & 20.2 \\
\hline $20 \mathrm{C \# 2}$ & 13.2 & 0.000893 & 20.2 \\
\hline $25 \mathrm{C} \# 1$ & 14.0 & 0.001001 & 25.2 \\
\hline $25 \mathrm{C} \# 2$ & 13.2 & 0.001212 & 25.2 \\
\hline $30 \mathrm{C \# 1}$ & 14.0 & 0.001107 & 30.0 \\
\hline $30 \mathrm{C \# 2}$ & 13.2 & 0.001338 & 30.0 \\
\hline $35 \mathrm{C} \# 1$ & 14.0 & 0.001226 & 34.9 \\
\hline $35 \mathrm{C} \# 2$ & 13.2 & 0.001591 & 34.9 \\
\hline \multicolumn{4}{|c|}{ Trial 3} \\
\hline $15 \mathrm{C} \# 1$ & 14.2 & 0.000451 & 15.2 \\
\hline $15 \mathrm{C} \# 2$ & 14.6 & 0.000436 & $\begin{array}{l}15.2 \text { (gel on one } \\
\text { shakeout) }\end{array}$ \\
\hline $20 \mathrm{CH} 1$ & 14.2 & 0.000424 & 20.1 \\
\hline $20 \mathrm{CH} 2$ & 14.6 & 0.000438 & 20.1 \\
\hline $25 \mathrm{C} \# 1$ & 14.2 & 0.000516 & 25.2 \\
\hline $25 \mathrm{CH} 2$ & 14.6 & 0.000485 & 25.2 \\
\hline $30 \mathrm{C \# 1}$ & 14.2 & 0.000632 & 30.0 \\
\hline $30 \mathrm{C \# 2}$ & 14.6 & 0.000569 & 30.0 \\
\hline $35 \mathrm{C \# 1}$ & 14.2 & 0.000813 & 35.0 \\
\hline $35 \mathrm{C} \# 2$ & 16.7 & 0.000664 & $\begin{array}{c}35.0 \text { (gel on one } \\
\text { shakeout) }\end{array}$ \\
\hline
\end{tabular}




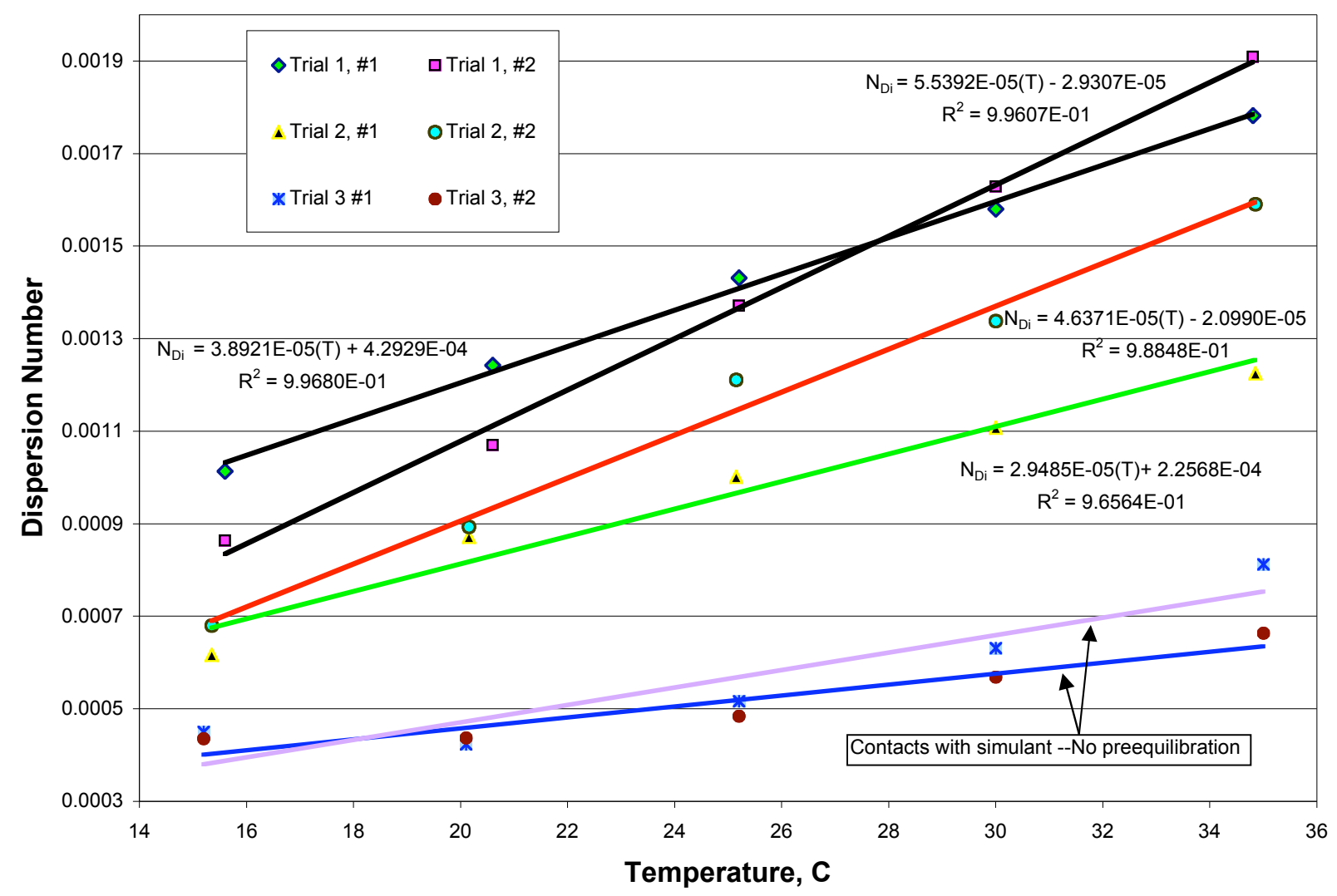

Fig. 18. Graph of CSSX solvent extraction equilibration dispersion numbers.

Then, $62.5 \mathrm{~mL}$ of recovered solvent was placed into each of two clean, $100 \mathrm{~mL}$ graduated cylinders and $12.5 \mathrm{~mL}$ of scrub solution $\left(0.05 \mathrm{M} \mathrm{HNO}_{3}\right)$ was added to each cylinder. The position of the stable interface between organic and aqueous phases and the height of the liquid column were measured. They were then placed in the water bath and equilibrated to the test temperature. After reaching the desired test temperature, the solution temperature was measured and each stoppered cylinder was removed from the bath and manually agitated for $20 \mathrm{~s}$, held still for $10 \mathrm{~s}$, agitated for another $20 \mathrm{~s}$, and then placed back into the water bath. The time from the cessation of agitation to the reestablishment of the interface was measured as the breaktime. Each equilibration was repeated two times, and then the temperature of the solution in the graduate was measured after the third equilibration. The temperature of the bath was then adjusted to the next test temperature and the equilibration process was repeated at $20,25,30$, and $35{ }^{\circ} \mathrm{C}$. The scrub-condition dispersion numbers results are shown in Fig. 19 and in Table 43.

\subsubsection{Stripping-Condition Dispersion-Number Determinations}

Solvent for the stripping determinations was recovered from the single-batch scrub-condition equilibration. A total of $130 \mathrm{~mL}$ solvent was placed into a clean $500-\mathrm{mL}$ separatory funnel. A volume of 
strip solution equal to one-fifth the solvent volume $(26 \mathrm{~mL})$ was added. The funnel was agitated vigorously for $20 \mathrm{~s}$, held for $10 \mathrm{~s}$, agitated for $20 \mathrm{~s}$, held for $10 \mathrm{~s}$, and agitated for $20 \mathrm{~s}$ again. The temperature of the dispersion was determined $\left(24.5^{\circ} \mathrm{C}\right)$ and the dispersion was allowed to separate. The solvent phase was collected and the aqueous solution was discarded.

Then, $62.5 \mathrm{~mL}$ of the recovered solvent was placed into each of two clean, $100-\mathrm{mL}$ graduated cylinders and $12.5 \mathrm{~mL}$ of strip solution $\left(0.001 \mathrm{M} \mathrm{HNO}_{3}\right)$ was added to each cylinder. The position of the stable interface between organic and aqueous phases and the height of the liquid column was measured. The cylinders were then placed in the water bath and equilibrated to the test temperature. After reaching the desired test temperature, the solution temperature was measured and each stoppered cylinder was removed from the bath and manually agitated for $20 \mathrm{~s}$, held still for $10 \mathrm{~s}$, agitated for another for another $20 \mathrm{~s}$, and then placed back into the water bath. The time from the cessation of agitation to the reestablishment of the interface was measured as the breaktime. Each equilibration was repeated two times, and then the temperature of the solution in the graduate was measured after the third equilibration. The temperature of the bath was then adjusted to the next test temperature and the equilibration process was repeated at $20,25,30$, and $35^{\circ} \mathrm{C}$. The stripping dispersion number results are shown in Fig. 20 and in Table 44.

Table 43. Dispersion numbers for scrub with optimized CSSX solvent

\begin{tabular}{cccc}
\hline $\begin{array}{c}\text { Solvent } \\
\text { sample }\end{array}$ & $\begin{array}{c}\text { Dispersion height } \\
(\mathrm{cm})\end{array}$ & $\begin{array}{c}\text { Scrub/solvent } \\
\text { Dispersion } \\
\text { number }\end{array}$ & $\begin{array}{c}\text { Determination } \\
\text { temperature } \\
\left({ }^{\circ} \mathrm{C}\right)\end{array}$ \\
\hline $15 \mathrm{C} \# 1$ & 14.5 & 0.000602 & 15.6 \\
$15 \mathrm{C} \# 2$ & 14.3 & 0.000623 & 15.6 \\
$20 \mathrm{C} \# 1$ & 14.4 & 0.000856 & 20.4 \\
$20 \mathrm{C} \# 2$ & 14.4 & 0.000828 & 20.4 \\
$25 \mathrm{C} \# 1$ & 14.6 & 0.001070 & 25.2 \\
$25 \mathrm{C} \# 2$ & 14.5 & 0.001045 & 25.2 \\
$30 \mathrm{C} \# 1$ & 14.6 & 0.001289 & 29.75 \\
$30 \mathrm{C} \# 2$ & 14.5 & 0.001254 & 29.75 \\
$35 \mathrm{C} \# 1$ & 14.6 & 0.001506 & 34.55 \\
$35 \mathrm{C} \# 2$ & 14.5 & 0.001453 & 34.55 \\
\hline
\end{tabular}




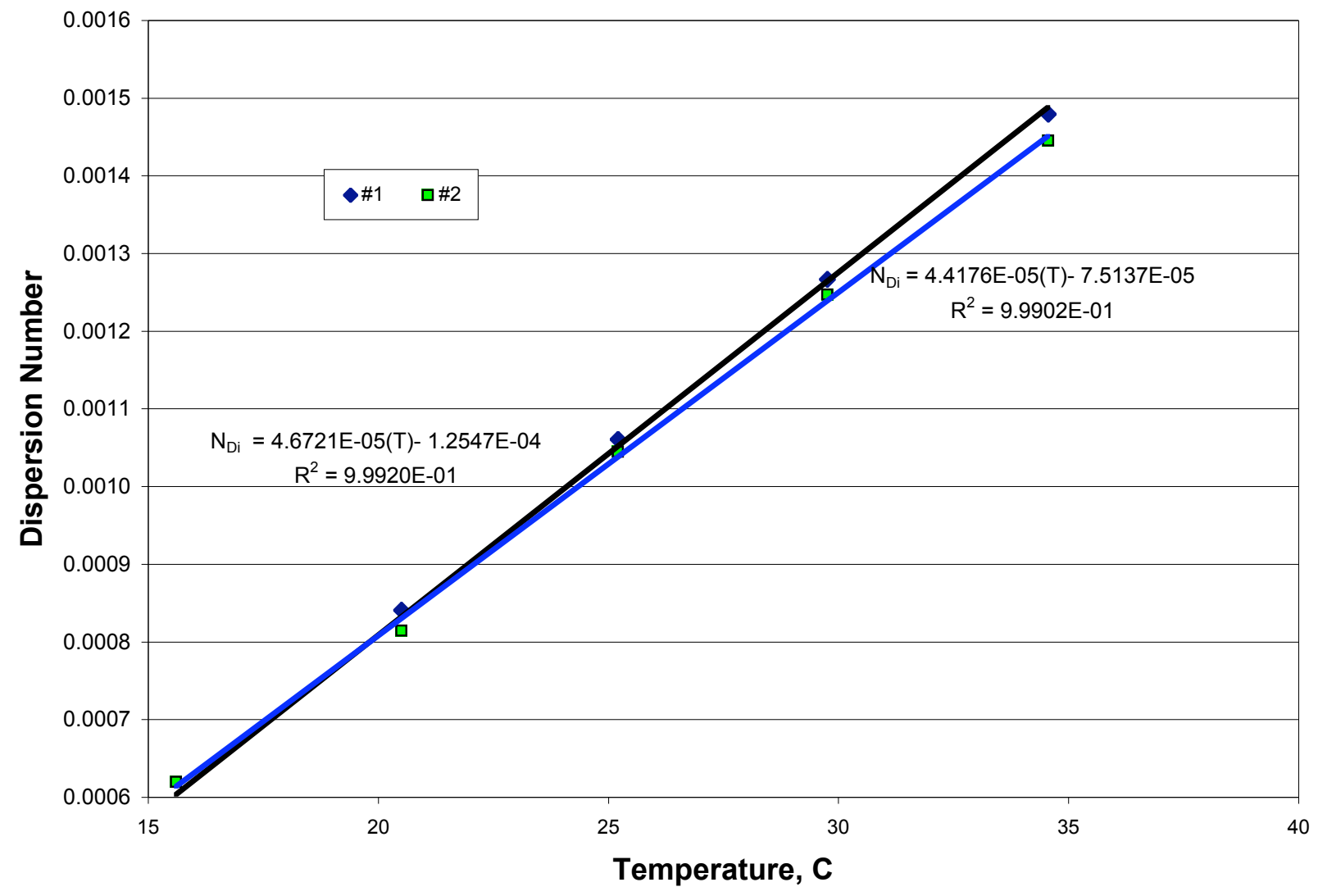

Fig. 19. Graph of CSSX solvent scrub equilibration dispersion numbers. 


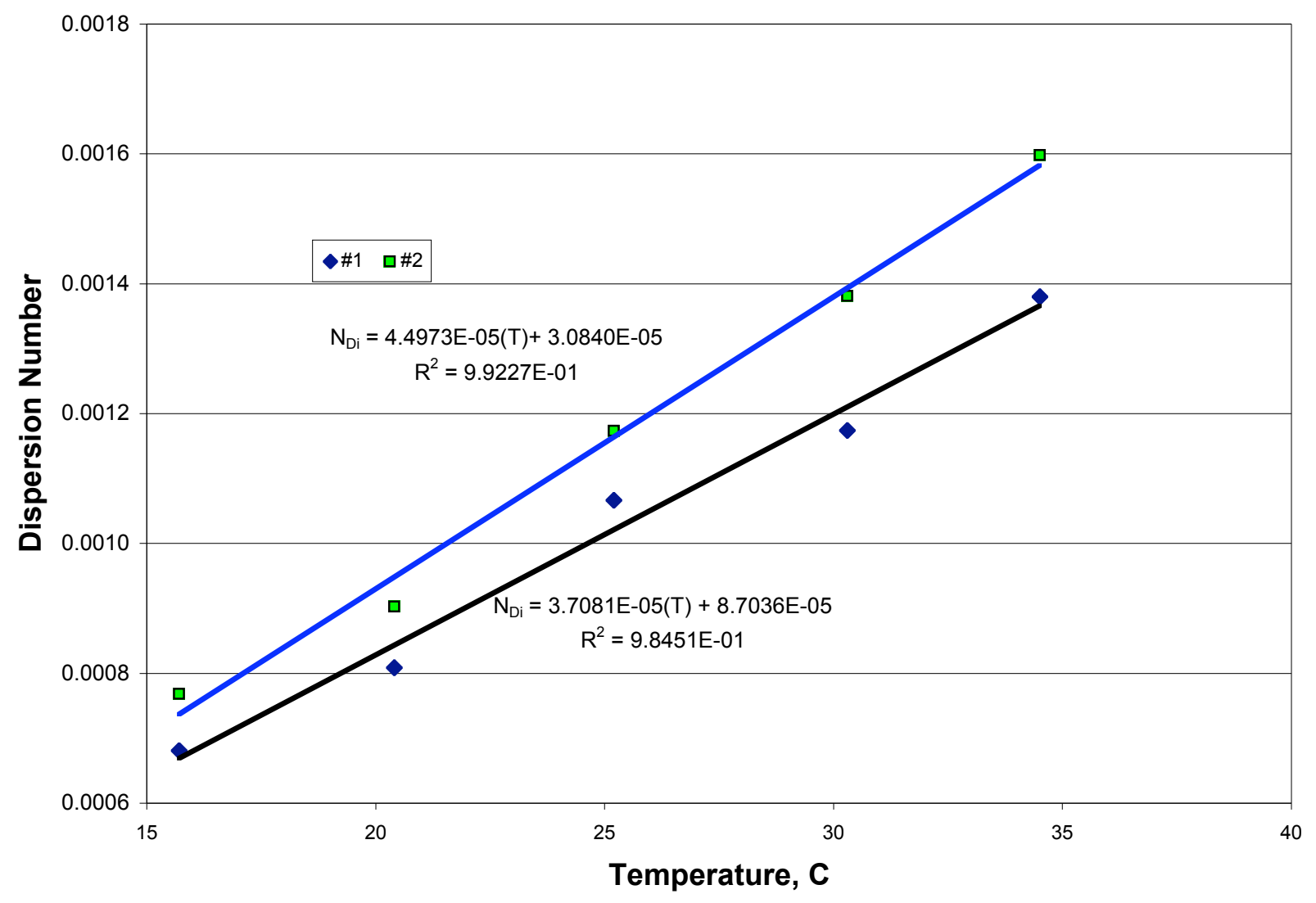

Fig. 20. Graph of CSSX solvent strip equilibration dispersion numbers. 
Table 44. Dispersion numbers for strip with optimized CSSX solvent

\begin{tabular}{cccc}
\hline $\begin{array}{c}\text { Solvent } \\
\text { sample }\end{array}$ & $\begin{array}{c}\text { Dispersion height } \\
(\mathrm{cm})\end{array}$ & $\begin{array}{c}\text { Scrub/solvent } \\
\text { dispersion } \\
\text { number }\end{array}$ & $\begin{array}{c}\text { Determination } \\
\text { temperature } \\
\left({ }^{\circ} \mathrm{C}\right)\end{array}$ \\
\hline $15 \mathrm{C \# 1}$ & 14.0 & 0.000686 & 15.7 \\
$15 \mathrm{C \# 2}$ & 14.9 & 0.000779 & 15.7 \\
$20 \mathrm{C \# 1}$ & 14.0 & 0.000813 & 20.4 \\
$20 \mathrm{C \# 2}$ & 14.9 & 0.000915 & 20.4 \\
$25 \mathrm{C \# 1}$ & 14.1 & 0.001080 & 25.2 \\
$25 \mathrm{C \# 2}$ & 14.8 & 0.001190 & 25.2 \\
$30 \mathrm{C \# 1}$ & 14.15 & 0.001189 & 30.3 \\
$30 \mathrm{C \# 2}$ & 14.9 & 0.001400 & 30.3 \\
$35 \mathrm{C \# 1}$ & 14.2 & 0.001398 & 34.5 \\
$35 \mathrm{C \# 2}$ & 14.95 & 0.001620 & 34.5 \\
\hline
\end{tabular}

\subsection{MEASUREMENT OF SOLVENT DENSITIES}

The solvent densities were measured using procedures described in Chapter 2. Each flask was filled using a 500-mL separatory funnel to just below the line and then adjusted to the line with a small transfer pipette after coming to temperature in the water bath. The actual volume of each flask was calculated from the weight of the water contained at $20^{\circ} \mathrm{C}$, and the volume at the other test temperatures was calculated according to ASTM E542. The density of water at each temperature was measured and then compared to the published data for water density at those temperatures. The calculated volume was used in subsequent density determinations of the solvent at each temperature. The results for the flask volume determinations are shown in Table 45.

For the solvent densities, the same volumetric flasks were emptied and rinsed twice with ethanol, twice with acetone, and allowed to air dry over night. They were weighed and then filled to the line with solvent using a separatory funnel. They were then placed in the water bath at $15{ }^{\circ} \mathrm{C}$ and allowed to come to bath temperature. After reaching bath temperature, the levels in each flask were adjusted by adding or removing (at higher temperatures) solvent using a small pipette. After adjustment of the levels, they remained in the bath for ten more minutes, then removed and the levels checked again and adjusted if needed. They were then dried and weighed. After weighing, they were returned to the bath and the temperature of the bath adjusted to the next test temperature. The results of the solvent density determinations are shown in Table 46 and Fig. 21. 
Table 45. Water-density determinations

\begin{tabular}{|c|c|c|c|c|c|}
\hline $\begin{array}{l}\text { Temperature } \\
\left({ }^{\circ} \mathrm{C}\right)\end{array}$ & & Flask 1 & Flask 2 & Flask 3 & $\begin{array}{c}\text { Actual water density at } \\
\text { temperature } \\
\left(\mathrm{g} / \mathrm{cm}^{3}\right)\end{array}$ \\
\hline \multirow{3}{*}{24.4} & Tare wt. & 60.1097 & 62.3954 & 61.1582 & \multirow{3}{*}{0.997197} \\
\hline & Gr. Wt. & 159.6757 & 161.9962 & 160.7973 & \\
\hline & Net Wt. & 99.5660 & 99.6008 & 99.6391 & \\
\hline \multirow{7}{*}{15.10} & density & 0.9966 & 0.9970 & 0.9968 & \multirow{8}{*}{0.999099} \\
\hline & deviation & 0.00059 & 0.00018 & 0.00036 & \\
\hline & Flask $\mathrm{Vol}_{24.4}=$ & 99.9046 & 99.8991 & 99.9548 & \\
\hline & Gr. Wt. & 159.9030 & 162.2013 & 161.0086 & \\
\hline & Net Wt. & 99.7933 & 99.8059 & 99.8504 & \\
\hline & density & 0.9990 & 0.9992 & 0.9990 & \\
\hline & deviation & 0.00012 & $-6.1 \mathrm{E}-05$ & $5.1 \mathrm{E}-05$ & \\
\hline \multirow{3}{*}{20.00} & Flask $\mathrm{Vol}_{15}=$ & 99.8953 & 99.8898 & 99.9455 & \\
\hline & Gr. Wt. & 159.8188 & 162.0990 & 160.9174 & \multirow{4}{*}{0.998204} \\
\hline & Net Wt. & 99.7091 & 99.7036 & 99.7592 & \\
\hline \multirow{7}{*}{30.00} & density & 0.9981 & 0.9981 & 0.9981 & \\
\hline & deviation & 0.00012 & 0.00012 & 0.00012 & \\
\hline & Flask $\mathrm{Vol}_{20}=$ & 99.9002 & 99.8947 & 99.9504 & \multirow{5}{*}{0.995647} \\
\hline & Gr. Wt. & 159.5551 & 161.8550 & 160.6975 & \\
\hline & Net Wt. & 99.4454 & 99.4595 & 99.5392 & \\
\hline & density & 0.9953 & 0.9955 & 0.9958 & \\
\hline & deviation & 0.00030 & 0.00010 & -0.00014 & \\
\hline \multirow{4}{*}{35.10} & Flask $\mathrm{Vol}_{30}=$ & 99.9102 & 99.9047 & 99.9604 & \multirow{5}{*}{0.993997} \\
\hline & Gr. Wt. & 159.4301 & 161.6880 & 160.5176 & \\
\hline & Net Wt. & 99.3204 & 99.2926 & 99.3594 & \\
\hline & density & 0.9940 & 0.9938 & 0.9939 & \\
\hline \multirow{7}{*}{40.15} & deviation & $-4.9 \mathrm{E}-05$ & 0.00017 & $6.0 \mathrm{E}-05$ & \\
\hline & Flask $\mathrm{Vol}_{35}=$ & 99.9153 & 99.9097 & 99.9655 & \multirow{6}{*}{0.992158} \\
\hline & Gr. Wt. & 159.2345 & 161.5226 & 160.3544 & \\
\hline & Net Wt. & 99.1248 & 99.1272 & 99.1962 & \\
\hline & density & 0.9920 & 0.9921 & 0.9923 & \\
\hline & deviation & 0.00012 & $4.1 \mathrm{E}-05$ & $-9.6 \mathrm{E}-05$ & \\
\hline & Flask $\mathrm{Vol}_{40}=$ & 99.9204 & 99.9148 & 99.9705 & \\
\hline
\end{tabular}


Table 46. Optimized-solvent density determinations ${ }^{a}$

\begin{tabular}{|c|c|c|c|c|c|c|c|}
\hline $\begin{array}{c}\text { Temperature } \\
\left({ }^{\circ} \mathrm{C}\right)\end{array}$ & & Flask 1 & Flask 2 & Flask 3 & $\begin{array}{c}\text { Average } \\
\text { density }\end{array}$ & $\begin{array}{l}\text { Standard } \\
\text { deviation }\end{array}$ & Variance \\
\hline \multirow{5}{*}{15.00} & Tare wt. & 60.1097 & 62.3954 & 61.1582 & \multirow{6}{*}{0.8595} & \multirow{6}{*}{0.0002} & \multirow{5}{*}{ 4.7E-08 } \\
\hline & Gr. Wt. & 145.9414 & 148.2582 & 147.0724 & & & \\
\hline & Net Wt. & 85.8317 & 85.8628 & 85.9142 & & & \\
\hline & density & 0.8592 & 0.8596 & 0.8596 & & & \\
\hline & $\mathrm{Vol}_{15}=$ & 99.8952 & 99.8897 & 99.9454 & & & \\
\hline \multirow[t]{4}{*}{20.05} & Gr. Wt. & 145.5436 & 147.8496 & 146.6507 & & & \\
\hline & Net Wt. & 85.4339 & 85.4542 & 85.4925 & \multirow{3}{*}{0.8553} & \multirow{3}{*}{0.0001} & \multirow{3}{*}{ 1.6E-08 } \\
\hline & density & 0.8552 & 0.8554 & 0.8553 & & & \\
\hline & $\mathrm{Vol}_{20}=$ & 99.9002 & 99.8947 & 99.9504 & & & \\
\hline \multirow[t]{4}{*}{25.00} & Gr. Wt. & 145.1693 & 147.4782 & 146.2873 & \multirow{5}{*}{0.8516} & \multirow{5}{*}{0.00028} & \multirow{4}{*}{$2.5 \mathrm{E}-08$} \\
\hline & Net Wt. & 85.0596 & 85.0828 & 85.1291 & & & \\
\hline & density & 0.8514 & 0.8517 & 0.8517 & & & \\
\hline & $\mathrm{Vol}_{25}=$ & 99.9052 & 99.8997 & 99.9554 & & & \\
\hline \multirow[t]{4}{*}{30.00} & Gr. Wt. & 144.7731 & 147.0728 & 145.893 & & & \\
\hline & Net Wt. & 84.6634 & 84.6774 & 84.7348 & \multirow{3}{*}{0.8476} & \multirow{3}{*}{0.0001} & \multirow{3}{*}{ 2.1E-08 } \\
\hline & density & 0.8474 & 0.8476 & 0.8477 & & & \\
\hline & $\mathrm{Vol}_{30}=$ & 99.9102 & 99.9047 & 99.9604 & & & \\
\hline \multirow[t]{4}{*}{35.00} & Gr. Wt. & 144.366 & 146.6559 & 145.496 & \multirow{4}{*}{0.8434} & \multirow{4}{*}{0.0002} & \multirow{4}{*}{ 4.2E-08 } \\
\hline & Net Wt. & 84.2563 & 84.2605 & 84.3378 & & & \\
\hline & density & 0.8433 & 0.8434 & 0.8437 & & & \\
\hline & $\mathrm{Vol}_{35}=$ & 99.9152 & 99.9096 & 99.9654 & & & \\
\hline \multirow[t]{4}{*}{40.15} & Gr. Wt. & 143.9722 & 146.2631 & 145.0803 & \multirow{4}{*}{0.8394} & \multirow{4}{*}{0.0001} & \multirow{4}{*}{ 7.7E-09 } \\
\hline & Net Wt. & 83.8625 & 83.8677 & 83.9221 & & & \\
\hline & density & 0.8393 & 0.8394 & 0.8395 & & & \\
\hline & $\mathrm{Vol}_{40}=$ & 99.9204 & 99.9148 & 99.9705 & & & \\
\hline
\end{tabular}

${ }^{a}$ Density results are bolded for easier reading. 


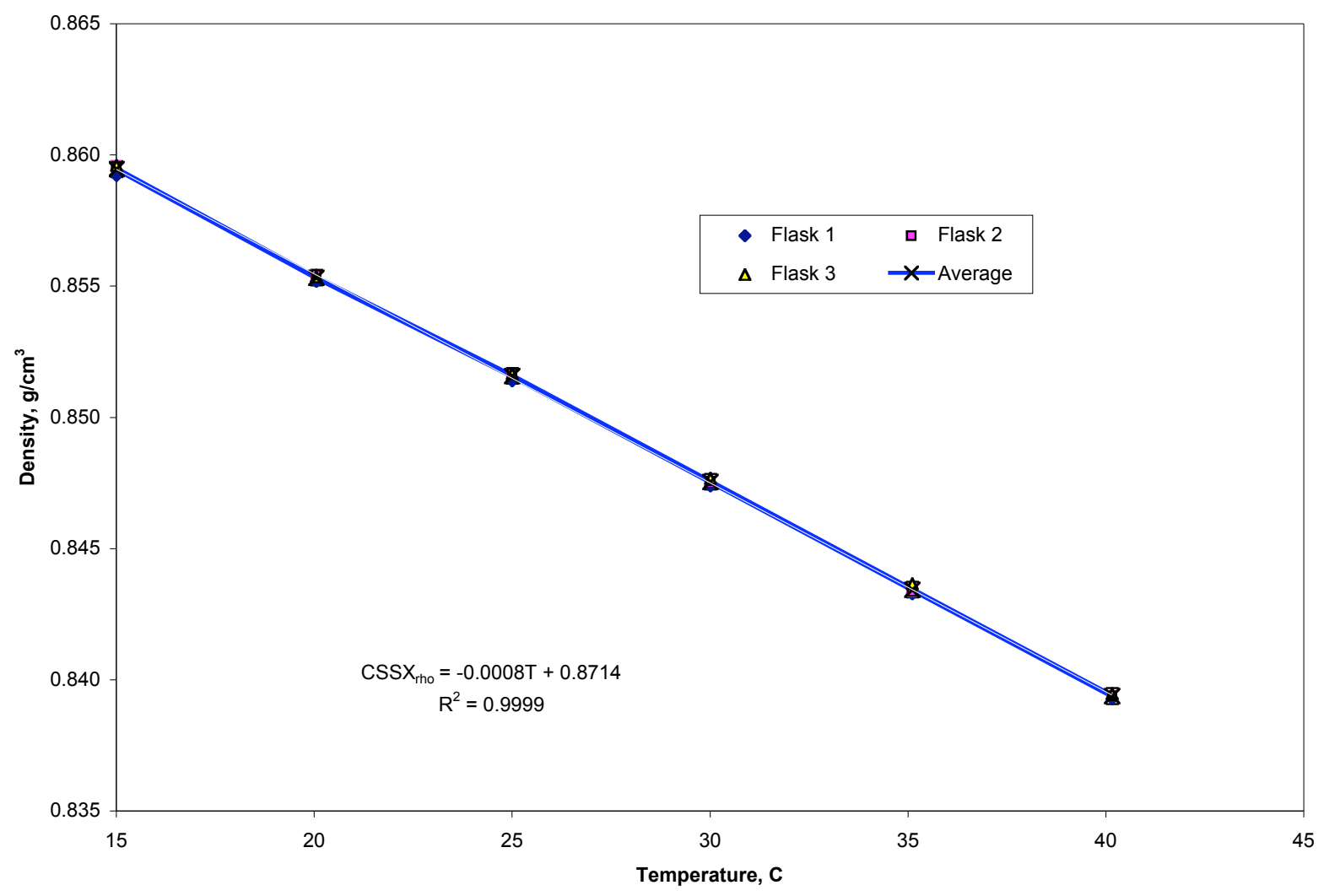

Fig. 21. Solvent density versus temperature.

\subsection{MEASUREMENT OF SOLVENT VISCOSITIES}

The viscosity of the new formulation of solvents was measured as described in Chapter 2. Each test was begun by adding $16 \mathrm{~mL}$ of the solvent to the UL adaptor, installing it on the viscometer, starting the spindle rotation at $60 \mathrm{rpm}$, and then setting the temperature bath to $15^{10} \mathrm{C}$. After the temperature had stabilized for several minutes, the viscosity of the sample was measured. The temperature bath was then adjusted to the next temperature and the system temperature allowed to stabilize before the next reading. The set of viscosity determinations were made three times. The second set was completed with fresh solvent, and the third set repeated the tests in reverse order with the same solvent after $30 \mathrm{~min}$ at $40{ }^{\circ} \mathrm{C}$. The results of three determinations of the solvent viscosity measurements are shown in Table 47 . The results are given for the percent torque, the viscosity, and the shear rate at each temperature. The results are also presented graphically in Figs. 22 and 23. Figure 22 is a plot of the viscosity versus temperature and Fig. 23 is a plot of the shear stress versus the temperature. The solvent's viscosity decreases with increasing temperature as expected for this type of liquid. 
Table 47. Solvent-viscosity determinations ${ }^{a}$

\begin{tabular}{lcccc}
\hline \multicolumn{1}{c}{ Solvent } & $\begin{array}{c}\text { Temperature } \\
\left({ }^{\circ} \mathrm{C}\right)\end{array}$ & $\begin{array}{c}\text { Torque } \\
(\%)\end{array}$ & $\begin{array}{c}\text { Viscosity } \\
(\mathrm{cP})\end{array}$ & $\begin{array}{c}\text { Shear Stress } \\
\left(\mathrm{dyn} / \mathrm{cm}^{2}\right)\end{array}$ \\
\hline Optimized & 15.05 & 48.2 & 4.83 & 3.53 \\
solvent & 20.10 & 40.9 & 4.09 & 2.99 \\
& 25.00 & 35.1 & 3.51 & 2.57 \\
& 30.00 & 30.5 & 3.07 & 2.23 \\
& 35.10 & 26.8 & 2.69 & 1.96 \\
& 40.10 & 23.8 & 2.38 & 1.73 \\
\hline Repeat & & & & \\
fresh solvent & 15.05 & 48.6 & 4.86 & 3.55 \\
& 20.10 & 41.2 & 4.12 & 3.01 \\
& 25.08 & 35.3 & 3.54 & 2.59 \\
& 30.05 & 30.6 & 3.07 & 2.24 \\
& 35.02 & 26.9 & 2.69 & 1.96 \\
& 40.10 & 24.0 & 2.39 & 1.74 \\
\hline Repeat & & & & \\
same solvent & 30.10 & 23.9 & 2.39 & 1.74 \\
starting at & 35.08 & 26.9 & 2.70 & 1.98 \\
$40{ }^{\circ} \mathrm{C}$ & 30.04 & 30.6 & 3.07 & 2.24 \\
& 25.10 & 35.1 & 3.52 & 2.57 \\
& 20.10 & 40.8 & 4.07 & 2.99 \\
& 15.05 & 48.4 & 4.84 & 3.54 \\
\hline
\end{tabular}

${ }^{a}$ Brookfield LVTDV-II (Serial Number D15869) UL Adapter with heating jacket was used. Precision of viscosity measurement is $\pm 0.1 \mathrm{cP}$. 


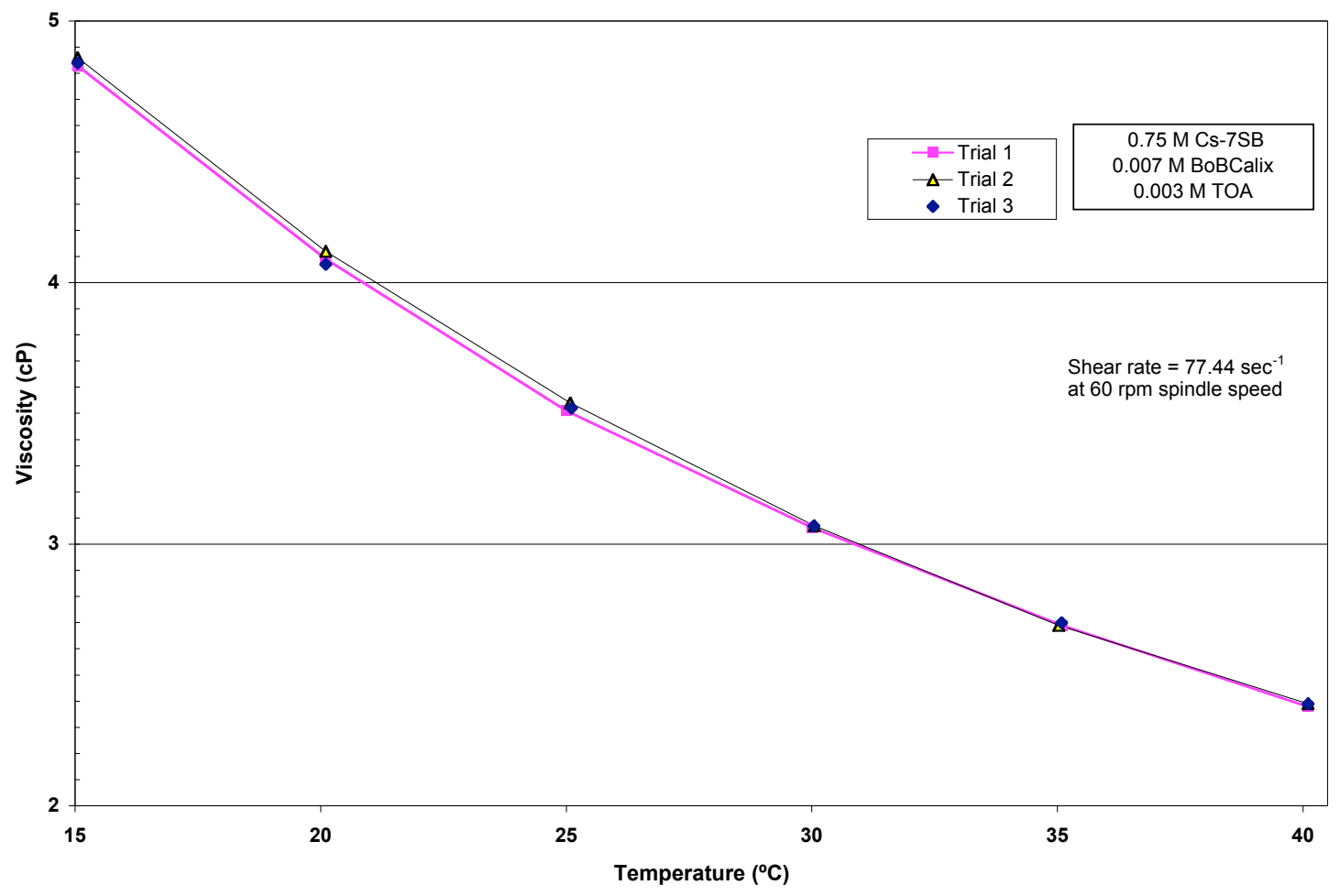

Fig. 22. Solvent viscosity versus temperature.

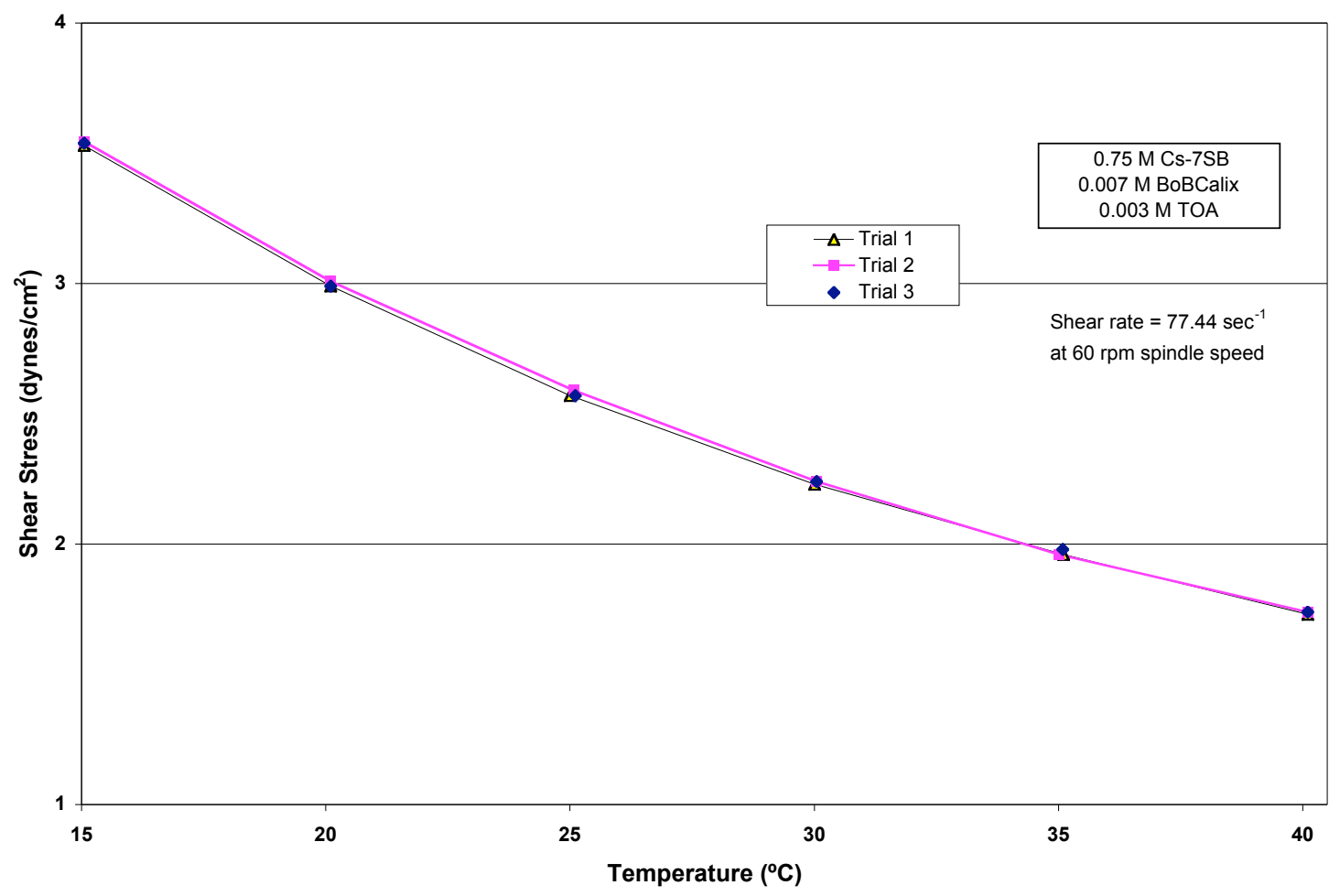

Fig 23. Solvent shear stress versus temperature. 


\subsection{DISCUSSION AND CONCLUSIONS}

\subsubsection{Dispersion Numbers}

The phase-coalescence behavior of the optimized CSSX solvent in contact with aqueous process solutions was characterized by dispersion numbers, as needed for centrifugal-contactors design. The criteria required the solvent dispersion number be greater than or equal to $4 \square 10^{-4}$ when contacted with the waste simulant, scrub, and strip solutions at the baseline flowsheet O:A ratios [20]. Table 48 summarizes the dispersion numbers obtained for optimized solvent contacted with waste simulant and scrub and strip solutions at $25^{\circ} \mathrm{C}$. It may be seen that these values all meet the criteria. Within the usual wide variability of such results, the values also compare favorably with the dispersion numbers obtained for the previous test solvents (portion of the table below the dashed line) taken at ambient laboratory temperature for solvent selection (see Chapter 2). For extraction contacts, the dispersion numbers covered the range of dispersion numbers obtained for all of the previous test solvents but were in the range of acceptability defined in the composition criteria. For the scrub and strip contacts, the optimized

Table 48. Dispersion numbers for CSSX solvent extraction, scrub, and stripping

\begin{tabular}{|c|c|c|c|}
\hline Solvent $^{a}$ & $\begin{array}{c}\text { Simulant/solvent } \\
\text { dispersion } \\
\text { number }\end{array}$ & $\begin{array}{l}\text { Scrub/solvent } \\
\text { dispersion } \\
\text { number }\end{array}$ & $\begin{array}{c}\text { Strip/solvent } \\
\text { dispersion } \\
\text { number }\end{array}$ \\
\hline Optimized solvent trial 1 (\#1) & 0.00143 & 0.00107 & 0.00108 \\
\hline Optimized solvent trial 1 (\#2) & 0.00137 & 0.00104 & 0.00119 \\
\hline Optimized solvent trial 2 (\#1) & 0.00100 & & \\
\hline Optimized solvent trial 2 (\#2) & 0.00121 & & \\
\hline Optimized solvent trial 3 (\#1) & 0.00052 & & \\
\hline Optimized solvent trial 3 (\#2) & 0.00048 & & \\
\hline Previous baseline solvent & 0.00149 & 0.00096 & 0.00115 \\
\hline B001107-3-1 & 0.00075 & 0.00102 & 0.00091 \\
\hline B001107-3-2 & 0.00056 & 0.00070 & 0.00078 \\
\hline B001107-3-3 & 0.00102 & 0.00052 & 0.00088 \\
\hline B001107-3-4 & 0.00102 & 0.00053 & 0.00094 \\
\hline B001107-3-5 & 0.00118 & 0.00050 & 0.00088 \\
\hline B001107-3-6 & 0.00105 & 0.00059 & 0.00075 \\
\hline B001107-3-7 & 0.00125 & 0.00058 & 0.00085 \\
\hline B001107-3-8 & 0.00120 & 0.00062 & 0.00054 \\
\hline B001107-3-9 & 0.00141 & 0.00041 & 0.00051 \\
\hline
\end{tabular}

${ }^{a}$ Optimized solvent was run at $25^{\circ} \mathrm{C}$. Data below the dashed line were collected at ambient laboratory temperature, as taken from Chapter 2 (Table 10). 
solvent gave comparable, if not better, dispersion numbers.

Earlier, a gel-like formation was described that occurred during the extraction contacts using the optimized solvent. The formation of the gel-like material was not predictable, and it occurred at least once at each test temperature and in either or both of the two tubes used. Attempts to cause the occurrence of the gel-like material were inconclusive; no specific triggering event or required condition was found.

\subsubsection{Solvent Density}

The density of the optimized solvent is $0.8516 \mathrm{~g} / \mathrm{cm}^{3}$ at $25{ }^{\circ} \mathrm{C}$ which is comparable to the density at $25.6{ }^{\circ} \mathrm{C}$ for the solvent compositions measured previously that are close in composition to the optimized solvent as shown below in Table 49. The Cs-7SB contributes the most to the changes in total solvent density among the different formulations and the three formulations with $0.75 \mathrm{M}$ Cs-7SB have densities very close to the optimized solvent, as expected.

Table 49. Comparison of CSSX solvent densities

\begin{tabular}{ccccc}
\hline Solvent & $\begin{array}{c}{[\text { BOBCalixC6 }]} \\
(\mathrm{M})\end{array}$ & $\begin{array}{c}{[\text { Cs-7SB }]} \\
(\mathrm{M})\end{array}$ & $\begin{array}{c}{[\mathrm{TOA}]} \\
(\mathrm{M})\end{array}$ & $\begin{array}{c}\text { Density at } 25^{\circ} \mathrm{C} \\
\left(\mathrm{g} / \mathrm{cm}^{3}\right)\end{array}$ \\
\hline Optimized solvent & 0.007 & 0.75 & 0.003 & 0.8516 \\
Original solvent & 0.010 & 0.50 & 0.001 & 0.8100 \\
B001107-3-1 & 0.010 & 0.65 & 0.001 & 0.8395 \\
B001107-3-2 & 0.008 & 0.65 & 0.001 & 0.8395 \\
B001107-3-3 & 0.010 & 0.75 & 0.001 & 0.8531 \\
B001107-3-4 & 0.008 & 0.75 & 0.001 & 0.8525 \\
B001107-3-5 & 0.006 & 0.75 & 0.001 & 0.8516 \\
B001107-3-6 & 0.008 & 0.85 & 0.001 & 0.8644 \\
B001107-3-7 & 0.006 & 0.85 & 0.001 & 0.8632 \\
B001107-3-8 & 0.008 & 1.00 & 0.001 & 0.8819 \\
B001107-3-9 & 0.006 & 1.00 & 0.001 & 0.8951 \\
\hline
\end{tabular}




\subsubsection{Solvent Viscosity}

The optimized solvent viscosity also compares well with the viscosities measured for the same test solvents listed above with similar Cs-7SB content as shown in Table 50.

Table 50. Comparison of CSSX solvent viscosities

\begin{tabular}{lcc}
\hline \multicolumn{1}{c}{ Solvent } & $\begin{array}{c}\text { Temperature } \\
\left({ }^{\circ} \mathrm{C}\right)\end{array}$ & $\begin{array}{c}\text { Viscosity } \\
(\mathrm{cP})\end{array}$ \\
\hline Optimized & 15.05 & 4.83 \\
solvent & 20.10 & 4.09 \\
& 25.00 & 3.51 \\
& 30.00 & 3.07 \\
B001107-3-3 & 35.10 & 2.69 \\
& 40.10 & 2.38 \\
& 20.00 & 4.31 \\
& 25.00 & 3.69 \\
B001107-3-4 & 30.02 & 3.19 \\
& 35.08 & 2.81 \\
& 40.00 & 2.49 \\
& 20.00 & 4.17 \\
& 25.00 & 3.61 \\
& 30.00 & 3.12 \\
& 35.00 & 2.74 \\
& 40.02 & 2.44 \\
& 20.00 & 4.12 \\
& 25.00 & 3.57 \\
& 30.00 & 3.11 \\
& 35.02 & 2.70 \\
& 40.02 & 2.40 \\
\hline
\end{tabular}




\section{CONCLUSIONS}

\subsection{OVERALL ASSESSMENT}

As necessitated by the supersaturation of the previous CSSX baseline solvent by the calixarene extractant, the purpose of this investigation was to optimize the solvent composition and to measure key chemical and physical properties related to its performance. This purpose has been fulfilled. Overall, it may be said that the optimization of the solvent composition has reduced the overall technical risk in meeting processing requirements using the CSSX process. Experimental results indicate that the changed solvent composition shifted various process performance measures incrementally, some with minor compromise and some with real improvement. A greater understanding of solvent properties and process performance has been obtained, and the precision with which performance can be predicted has been increased.

\subsection{EVALUATION OF RESULTS}

The optimization of the solvent composition specifically reduced technical risk by ensuring the integrity of the solvent with regard to crystallization of BOBCalixC6, to third-phase formation, and to the effects of impurities. Based on an established set of criteria [20], a matrix of trial concentrations of the baseline solvent components was examined toward the objective of a new, optimum solvent composition. No new constituents were added to the solvent; only the component concentrations were changed. The results led to a straightforward recommendation of a new baseline solvent having the following component concentrations in Isopar ${ }^{\circledR} \mathrm{L}$ diluent: $0.007 \mathrm{M}$ BOBCalixC6 extractant, $0.75 \mathrm{M}$ Cs-7SB modifier, and $0.003 \mathrm{M}$ TOA stripping aid. This composition met all of the criteria with regard to BOBCalixC6 solubility, third-phase formation, cesium batch distribution ratios, calculated flowsheet robustness, coalescence rate, and solvent density. Acceptable compromises were made in flowsheet robustness and solvent density, with no impact on process goals. Improved resistance to third-phase formation allows the process to operate at lower temperatures (as low as $11^{\circ} \mathrm{C}$ ) compared with the previous baseline solvent $\left(20^{\circ} \mathrm{C}\right)$, a significant advantage. In addition, the reduction of the concentration of the expensive BOBCalixC6 extractant implies a reduction in the total materials cost of the solvent by approximately $16 \%$. Finally, the higher TOA concentration decreases the risk that buildup of minor anionic species in the solvent could impact stripping performance.

Further data were collected to characterize the performance of the optimized solvent more thoroughly and to ensure that the optimization procedure did not unexpectedly produce unacceptable changes in process performance. Experiments specifically dealt with the temperature dependence of $D_{\mathrm{Cs}}$ in extraction, scrubbing, and stripping (ESS); ESS performance on recycle; partitioning of BOBCalixC6, Cs-7SB, and TOA to aqueous process solutions; partitioning of organic anions; distribution of metals; solvent phase separation at low temperatures; solvent stability to elevated temperatures; and solvent 
density and viscosity. In general, these system properties were changed only incrementally by solvent optimization, as judged from data presented earlier [11]. The temperature dependence of cesium distribution was found to exhibit approximately the same tendency toward decreasing extraction strength with increasing temperature as the former baseline solvent. This property may be used to advantage to increase extraction efficiency by cooling the extraction section and to increase stripping efficiency by warming the stripping section. New parameters were measured for quantifying the temperature dependence of cesium distribution in extraction, scrubbing, and stripping stages. Better measurements of the partitioning of the solvent components now allow a more confident assertion to be made that the solubility losses of solvent components to the aqueous phase are acceptable within the goal of a maximum of one solvent replacement per year. Some uncertainty remains with regard to the exact loss rate of the modifier, but loss of the expensive calixarene was shown to be definitely negligible. Thus, this conclusion has impact on methods for solvent recovery in that the major expected loss pathway is entrainment, which may be dealt with by mechanical methods. No changes in qualitative conclusions regarding the impacts of minor organic or metallic components on process performance have been found for the optimized solvent. Limited thermal-stability experiments again confirm earlier conclusions concerning the high stability of the solvent. A thermal-chemical stability of the solvent of more than 977 days at the maximum normal operating temperature of $35{ }^{\circ} \mathrm{C}$ is indicated by the data. A more focused examination of phase stability at low temperatures was necessitated by observation of unusual ESS behavior on batches of optimized CSSX solvent shipped to other laboratories. It was confirmed from earlier indications [11] that the solvent splits into two phases on storage at low temperatures, conditions expected during shipment or outside storage in the winter, necessitating warming to room temperature and remixing before use. Overall, solvent performance was found to be similar to that of the former baseline solvent, with no issues raised concerning unexpected phenomena.

\subsection{RECOMMENDATIONS FOR FUTURE WORK}

\subsubsection{Summary Remarks}

From the perspective of a year and a half since the previous assessment of needs for research and development in the area of CSSX chemistry [11], it is instructive to examine current needs. In particular, Chapter 9 of the previous report enumerated nine areas of possible investigation. These areas were listed under nine secondary headings similar to those given below. Additional information on potential needs may be found in FY 2002 program planning [18] and in documentation issued in connection with the solicitation for design, construction, and commissioning of the SRS Salt Waste Processing Facility [42].

\subsubsection{Solvent Composition}

The first need identified was for solvent optimization [11], which has now been fulfilled. Nevertheless, it may still be worthwhile to pursue additional measurements on BOBCalixC6 solubility 
with resolve to continue tests until true equilibrium is reached. The needed measurement time is perhaps a year or more. In addition, it would be valuable to understand if the solubility is impacted by variables such as TOA and aqueous-phase composition. Given the rate of diluent evaporation recently measured [43], possible questions on the environmental acceptability of hydrocarbon emissions or on the ease of process control could motivate consideration of the use of less volatile diluents. Finally, alternative calixarenes are being developed that behave similarly to BOBCalixC6 but have improved solubility [44]. A particularly promising example is calix[4]arene-bis(2-ethylhexylbenzo-crown-6), which has the same framework structure as BOBCalixC6, but with alternative alkyl groups.

\subsubsection{Actinide and Strontium Extraction}

It would be an obvious advantage toward an overall footprint reduction in the Salt Processing Facility if the CSSX process could also remove the traces of actinides and strontium from the waste. Based on current data, actinides are not significantly extracted by the CSSX solvent [11,40]. A project is under way to examine whether new solvent-extraction chemistry may be developed to remove actinides and strontium from alkaline high-level waste such as that stored at the SRS [45]. This might be accomplished by developing a new solvent and corresponding flowsheet to operate in tandem with the CSSX process. Or possibly the CSSX solvent chemistry may be augmented in a way that enables it to extract cesium, actinides, and strontium simultaneously.

\subsubsection{Radiation Stability}

Testing in FY 2001 on the previous baseline solvent indicated no significant technical risks due to radiation-induced degradation of the CSSX solvent components [11-14]. In support of this conclusion, an encouraging review of the literature [46] recently suggested that the rate of degradation of the solvent components should be no higher than $1 \%$ per year. Although these studies reduce the urgency for further examination of this issue, it remains desirable to pursue unanswered questions. That same literature review [46] also suggested that the aging of the solvent under process conditions should yield a complex mixture of possible organic degradation products that might not wash out. Only two key degradation products have so far been identified, dioctylamine and 4-sec-butylphenol [11-14], and these were fairly predictable. There remain the questions of how these products may further react and whether other, less obvious, products are also formed. An open issue exists as to the impact of slow degradation processes that occur after an initial irradiation period [11]. A further question pertains to whether the effects of irradiation differ between static batch tests and the dynamic flowsheet in which the solvent cycles between alkaline and acid conditions. The present report has provided no new data on radiation degradation, and little new data have become available in the past year. Although the risk from radiolysis effects appears low, further radiation experiments to provide data on the optimized solvent would be helpful, especially from the point of view of solvent aging and possible impurity buildup (see section 8.3.7 below). 


\subsubsection{Thermal Stability}

Static tests continue to show the high chemical and thermal stability of the CSSX, as verified herein and elsewhere [47] for the optimized solvent. As pointed out above, a recent review [46] suggests the solvent should have adequate chemical stability in terms of the rate of breakdown of the solvent components. Nevertheless, the same general questions remain as were identified above in the case of radiation stability. Such questions pertain to the reactions of dioctylamine and 4-sec-butylphenol, the formation of other as-yet unidentified degradation products, the difference between static and dynamic behavior, and the effects of solvent aging. In particular, it continues to be desirable to understand TOA degradation, particularly under acidic conditions. Earlier work showed that TOA is the most easily degraded solvent component, with deleterious consequences for stripping [11].

\subsubsection{Solvent Cleanup}

As previously recommended [11], it would be prudent to prepare for the possibility (see below) that strongly lipophilic anions accumulate in the solvent and eventually overcome the ability of TOA to suppress their harmful effect on stripping. In the work reported herein, limited data were collected to show that the effect of small amounts of dibutylphosphate and dodecanoate was negligible, as expected. Whereas dibutylphosphate is expected to be removed easily by a sodium hydroxide wash step, surfactants having more than 12 carbons are sufficiently lipophilic that their removal will be incomplete by washing [11]. Hence, alternative solvent cleanup methods, such as anion exchange, should be further developed as a ready solution to potential difficulties.

\subsubsection{Minor Species}

In simple batch contacting, it was found herein that minor organic and inorganic species pose no particular recognizable risks based on current knowledge of the waste composition, solvent breakdown products, the distribution behavior of minor species, and available solvent-cleanup methods. This limited conclusion agrees with the results of more extensive testing with the previous baseline solvent, including results from batch tests with waste simulant [11] and from contactor tests with simulant $[16,48]$ and with real waste [17,49] over a relatively small number of cycles. On the other hand, experience in solventextraction hydrometallurgy shows that long-term operation generally leads to buildup of species that can eventually impact the performance of a process [50]. Fortunately, the types of problems that may be encountered (e.g., poor phase disengagement, interfacial crud, or loss of extraction and stripping performance) generally yield to acceptable technical solutions. It may be expected that the impact to schedule and facility cost will decrease the earlier the problems are recognized and dealt with. Thus, the more that is known regarding the behavior of minor species prior to facility design, the lower the technical risk will be. Accordingly, contactor tests with long run times using real waste are especially recommended. Given that the solvent will be cycled approximately 3000 times in a year, tests running at least 300 cycles would start to be fruitful in revealing potential problems that may be encountered over 
the course of operating a plant for a full year. Thus far, flowsheet tests with real waste have been carried out for only $\sim 1 \%$ of the number of annual cycles. In addition, analysis of the wastes for lipophilic organic species should continue, as should study of the fate of surfactant species in the flowsheet. Certain metals such as technetium should be further studied to understand observed behavior in contactor testing. As pointed out above, it does not appear that actinides [40] nor any metals other than the alkali metals are extracted to a significant degree by the pristine CSSX solvent [11]. An unanswered question, though, is how minor waste components distribute when the solvent is aged from extended use and presumably accumulates organic species that do not wash out. For example, do degradation products or surfactant species that build up over a year begin to extract other metals? Such questions suggest the need for tests designed to simulate aging and to reveal how the aged solvent behaves, particularly with regard to the buildup of minor components and their effects.

\subsubsection{Fate of Trimethylamine}

Trimethylamine is a minor component expected at low concentrations in the waste feed. Its origin is thought to be the breakdown of strong-base anion-exchange resins in the waste. In previous tests, trimethylamine was shown to have the potential to build up in a loop between the extraction and scrub sections [11]. Although this species was not observed to cause any particular difficulties in batch tests, more evaluation is needed to definitely establish its fate in the flowsheet and its impacts on process performance.

\subsubsection{Role of Nitrite}

It has been recently established that impaired stripping associated with high nitrite concentrations in certain simulant testing [11] was caused by a surfactant added to the reagent sodium nitrite used to make the simulants [41]. The presence of nitrite as nitrous acid was also shown not to increase the already low risk of nitration of solvent components in scrubbing [47]. Hence, the effects of nitrite appear reasonably minimal. It should be noted, however, that nitrous acid is generated from co-extracted nitrite as the solvent moves from the extraction section into the scrubbing section. As nitrite is a reactive species [46,47], its continuous generation in the flowsheet could contribute to more rapid solvent aging effects than static tests indicate, as nitrous acid quickly dissipates in a static test [47].

\subsubsection{Modeling}

Progress has been made in modeling the CSSX process using the optimized solvent system, where it has been possible to predict with reasonable accuracy the cesium distribution ratios on variable aqueousfeed composition [39]. It is now desirable to factor in the effect of certain minor components, variation of the concentration of solvent components, and temperature variation. Data on the partitioning of Cs-7SB and TOA presented in this report together with data on diluent evaporation [42] reveal that variation of both the relative and absolute concentrations of the solvent components may be expected in normal process operation. It would therefore be helpful if the effects of such variation were easily predicted. 
Acid extraction by TOA needs to be studied and incorporated into the model, as this phenomenon affects how the cesium distribution ratio changes from stage to stage in scrubbing and stripping. In terms of making the model more accessible, a convenient user interface is needed, and the equilibrium model must be incorporated into a flowsheet model. 


\section{REFERENCES}

1. P. V. Bonnesen, L. H. Delmau, B. A. Moyer, and R. A. Leonard, "A Robust Alkaline-Side CSEX Solvent Suitable for Removing Cesium from Savannah River High Level Waste," Solvent Extr. Ion Exch. 18 (6), 1079-1107 (2000).

2. B. A. Moyer, P. V. Bonnesen, R. A. Sachleben, and D. J. Presley, "Solvent and Process for Extracting Cesium from Alkaline Waste Solutions,” U.S. Patent 6,174,503, January 16, 2001.

3. R. A. Dimenna et al., Bases, Assumptions, and Results of the Flow Sheet Calculations for the Decision Phase Salt Disposition Alternatives, WSRC-RP-99-00006, Rev. 3, Westinghouse Savannah River Company, Aiken, South Carolina, May 2001.

4. Savannah River Site Salt Processing Alternatives Final Supplemental Environmental Impact Statement (EIS), DOE/EIS-0082-S2D, U.S. Department of Energy, Aiken, South Carolina, July 20, 2001.

5. Federal Register, 66 (201), 52752-52756, October 17, 2001.

6. National Research Council, Committee on Radionuclide Separation Processes for High-Level Waste at the Savannah River Site, Research and Development on a Salt Processing Alternative for HighLevel Waste at the Savannah River Site, National Academy Press, Washington, D.C., 2001.

7. H. Harmon, S Schlahta, D. Wester, J. Walker, S. Fink, and M. Thompson, Tanks Focus Area Savannah River Site Salt Processing Project Research and Development Summary Report, TFA-0105, Pacific Northwest National Laboratory, Richland, Washington, May 2001.

8. J. T. Case, J. G. Burritt, J. L. Kovach, R. W. Kupp, R. P. Palluzi, L. L. Tavlarides, and R. F. Vance, Evaluation of Alternatives for Salt Waste Processing at the Savannah River Site, TAT Report, Rev. H., Savannah River Salt Processing Project Technical Advisory Team, U.S. Department of Energy, May 31, 2001.

9. K. Lang, W. F. Spader, K. Picha, and K. Gerdes, Final Report on the Salt Processing Project Technology Selection, Technical Working Group, U.S. Department of Energy, June 2001.

10. M. Frei, L. Erickson, B. Smith, C. Hansen, and T. Fryberger, Salt Processing Project Management Review Board Summary Report, U.S. Department of Energy, May 24, 2001.

11. B. A. Moyer, S. D. Alexandratos, P. V. Bonnesen, G. M. Brown, J. E. Caton, Jr., L. H. Delmau, C. R. Duchemin, T. J. Haverlock, T. G. Levitskaia, M. P. Maskarinec, F. V. Sloop, Jr., and C. L. Stine, "Caustic-Side Solvent Extraction Chemical and Physical Properties: Progress in FY 2000 and FY 2001," Report ORNL/TM-2001/285, Oak Ridge National Laboratory, Oak Ridge, Tennessee, February 2002. 
12. R. A. Peterson, T. L. White, S. Crump, and L. H. Delmau, Solvent Extraction External Radiation Stability Testing, WSRC-TR-2000-00413, Rev. 0, Westinghouse Savannah River Company, Aiken, South Carolina, November 20, 2000.

13. R. A. Peterson, T. L. White, and N. E. Gregory, Solvent Extraction External Irradiation Update, SRT-LWP-2000-00101, Westinghouse Savannah River Company, Aiken, South Carolina, June 16, 2000.

14. R. D. Spence, L. N. Klatt, L. H. Delmau, F. V. Sloop, Jr., P. V. Bonnesen, and B. A. Moyer, Batch-Equilibrium Hot-Cell Tests of Caustic-Side Solvent Extraction (CSSX) with SRS Simulant Waste and Internal ${ }^{137}$ Cs Irradiation, ORNL/TM-2001/49, Oak Ridge National Laboratory, Oak Ridge, Tennessee, September 2001.

15. J. F. Birdwell, Jr., and R. L. Cummings, Irradiation Effects on Phase-Separation Performance Using a Centrifugal Contactor in a Caustic-Side Solvent Extraction Process, ORNL/TM-2001/91, Oak Ridge National Laboratory, Oak Ridge, Tennessee, August 2001.

16. R. A. Leonard, S. B. Aase, H. A. Arafat, D. B. Chamberlain, C. Conner, M. C. Regalbuto, and G. F. Vandegrift, Multi-day Test of the Caustic-Side Solvent Extraction Flowsheet for Cesium Removal from a Simulated SRS Tank Waste, ANL-02/11, Argonne National Laboratory, Argonne, Illinois, January 15, 2002.

17. S. G. Campbell, M. W. Geeting, C. W. Kennell, J. D. Law, R. A. Leonard, M. A. Norato, R. A. Pierce, T. A. Todd, D. D. Walker, and W. R. Wilmarth, Demonstration of Caustic-Side Solvent Extraction with Savannah River Site-High-Level Waste, WSRC-TR-2001-00223, Rev. 0, Westinghouse Savannah River Company, Aiken, South Carolina, April 19, 2001.

18. H. Harmon, R. Leugemors, S. Schlahta, S. Fink, M. Thompson, and D. Walker, Savannah River Site Salt Processing Project: FY 2002 Research and Development Program Plan, PNNL-13707, Rev. 1, Pacific Northwest National Laboratory, Richland, Washington, December 2001.

19. H. Harmon, S. Schlahta, J. Walker, D. Wester, K. Rueter, and S. Fink, Tanks Focus Area, Savannah River Site Salt Processing Project, Research and Development Program Plan, PNNL-13253, Rev. 1, Pacific Northwest National Laboratory, Richland, Washington, November 2000.

20. L. N. Klatt, Criteria for Optimum Composition of the Caustic-Side Solvent Extraction (CSSX) Solvent, CERS/SR/SX/025, Rev. 0, Nuclear Science and Technology Division, Oak Ridge National Laboratory, Oak Ridge, Tennessee, August 2001. 
21. L. N. Klatt, J. F. Birdwell, Jr., P. V. Bonnesen, L. H. Delmau, L. J. Foote, D. D. Lee, R. A. Leonard, T. G. Leviskaia, M. P. Maskarinec, and B. A. Moyer, Caustic-Side Solvent Extraction SolventComposition Recommendation, CERS/SR/SX/026, Rev. 0, Nuclear Science and Technology Division, Oak Ridge National Laboratory, Oak Ridge, Tennessee, November 8, 2001.

22. L. N. Klatt, J. F. Birdwell, Jr., P. V. Bonnesen, L. H. Delmau, L. J. Foote, D. D. Lee, R. A. Leonard, T. G. Leviskaia, M. P. Maskarinec, and B. A. Moyer, Caustic-Side Solvent Extraction SolventComposition Recommendation, ORNL/TM-2001/258, Oak Ridge National Laboratory, Oak Ridge, Tennessee, January 2001.

23. R. A. Peterson, Preparation of Simulated Waste Solutions for Solvent Extraction Testing, WSRC-RP-2000-00361, Rev. 0, Westinghouse Savannah River Company, Aiken, South Carolina, May'2000.

24. R. A. Leonard, "Solvent Characterization Using The Dispersion Number," Sep. Sci. Technol. 30 (7-9), 1103-1122 (1995).

25. ASTM Standard D 891-95, "Standard Test Method for Specific Gravity, Apparent, of Liquid Industrial Chemicals," American Society for Testing and Materials, Philadelphia, 2000.

26. ASTM Standard D 1429-95, "Standard Test Methods for Specific Gravity of Water and Brine," American Society for Testing and Materials, Philadelphia, 2000.

27. ASTM Standard E 542-00, "Standard Practice for Calibration of Laboratory Volumetric Apparatus," American Society for Testing and Materials, Philadelphia, 2000.

28. ASTM Standard D 2196-99, "Standard Test Method for Rheological Properties of NonNewtonian Materials by Rotational (Brookfield type) Viscometer," American Society for Testing and Materials, Philadelphia, 1999.

29. "The Brookfield Digital Viscometer Model DV-II Operating Instructions," Manual No. M/85160-F, Brookfield Engineering Laboratories, Inc., Stoughton, Massachusetts, 1985.

30. ASTM Standard D 971-99a, "Standard Test Method for Interfacial Tension of Oil Against water by the Ring Method," American Society for Testing and Materials, Philadelphia, 1999.

31. ASTM Standard D 1331-89, "Standard Test Method for Surface and Interfacial Tension of Solutions of Surface-Active Agents," American Society for Testing and Materials, Philadelphia, 1989. 
32. CRC Handbook of Chemistry and Physics, $66^{\text {th }}$ ed., CRC Press, Boca Raton, Florida, 1985, p.'F-32.

33. R. A. Leonard and M. C. Regalbuto, "A Spreadsheet Algorithm for Stagewise Solvent Extraction," Solvent Extr. Ion Exch. 12 (5), 909-930 (1994).

34. J. F. Birdwell, Jr., and K. K. Anderson, Evaluation of 5-cm Centrifugal Contactor Hydraulic and Mass Transfer Performance for Caustic-Side Solvent Extraction of Cesium, ORNL/TM-2001/137, Oak Ridge National Laboratory, Oak Ridge, Tennessee, August 2001.

35. J. F. Birdwell, Jr., "Throughput Performance of a Fully-Pumping 5-cm Centrifugal Contactor with Vane Modifications," Tanks Focus Area (TFA) Plan of the Week (POW) Technical Discussion, Oak Ridge National Laboratory, Oak Ridge, Tennessee, November 5, 2001.

36. J. D. Law, R. D. Tillotson, and T. A. Todd, "Evaluation of the Hydraulic Performance and Mass Transfer Efficiency of the CSSX Process with the Optimized Solvent in a Single Stage of 5.5-cm Diameter Centrifugal Contactor," INEEL/EXT-02-01109, Idaho National Engineering and Environmental Laboratory, Idaho Falls, Idaho, September 2002.

37. L. H. Delmau, L. J. Foote, P. V. Bonnesen, H. Jennings, T. G. Levitskaia, M. P. Maskarinec, B. A. Moyer, D. D. Lee, K. K. Anderson, and L. N. Klatt, "Solvent Optimization," TFA POW Technical Discussion, Oak Ridge National Laboratory, Oak Ridge, Tennessee, October 29, 2001.

38. J. F. Birdwell, Jr., K. K. Anderson, and D. E. Hobson, Investigation of Emulsion Formation in Solvent Washing in the Caustic-Side Solvent Extraction (CSSX) Process, ORNL/TM-2002/126, Oak Ridge National Laboratory, Oak Ridge, Tennessee, June 2002.

39. L. H. Delmau, D. A. Bostick, T. J. Haverlock, and B. A. Moyer, Caustic-Side Solvent Extraction: Extended Equilibrium Modeling of Cesium and Potassium Distribution Behavior, ORNL/TM-2002/116, Oak Ridge National Laboratory, Oak Ridge, Tennessee, May 2002.

40. W. R. Wilmarth, V. H. Dukes, J. T. Mills, C. C. DiPrete, and D. P. DiPrete, Solvent Composition Impacts on the Extraction of Uranium and Plutonium in the Caustic Side Solvent Extraction Process, WSRC-TR-2002-00060, Westinghouse Savannah River Company, Aiken, South Carolina, January 18, 2002.

41. L. H. Delmau, T. J. Haverlock, and B. A. Moyer, Caustic-Side Solvent Extraction: Anti-Caking Surfactants Found to Be Cause of Apparent Effect of High Nitrite Concentration on Cesium Stripping, ORNL/TM-2002/104, Oak Ridge National Laboratory, Oak Ridge, Tennessee, May 2002. 
42. Design, Construction, and Commissioning of a Salt Waste Processing Facility, Request for Proposal No. DE-RP09-02SR22210, Amendment 002, U. S. Department of Energy, Savannah River Operations Office, Aiken, South Carolina, January 9, 2002.

43. D. D. Lee, J. F. Birdwell, Jr., P. V. Bonnesen, and B. A. Tomkins, Density Changes in the Optimized CSSX Solvent System, ORNL/TM-2002/204, Oak Ridge National Laboratory, Oak Ridge, Tennessee, October 2002.

44. B. A. Moyer, P. V. Bonnesen, J. C. Bryan, N. L. Engle, T. J. Keever, T. G. Levitskaia, R. A. Sachleben, R. A. Bartsch, V. S. Talanov, H. W. Gibson, J. W. Jones, and B. P. Hay, Next Generation Extractants for Cesium Separation from High-Level Waste: From Fundamental Concepts to Site Implementation, FY 2002 Annual Report, Environmental Management Science Program, August, 2002; posted on the EMSP web site http://emsp.em.doe.gov/.

45. L. H. Delmau, K. N. Raymond, and D. T. Hobbs, Combined Extraction of Cesium, Strontium, and Actinides from Alkaline Media: An Extension of the Caustic-Side Solvent Extraction (CSSX) Process Technology, FY 2002 Annual Report, Environmental Management Science Program, June, 2002; posted on the EMSP web site http://emsp.em.doe.gov/ .

46. L. M. Stock, D. M. Camaioni, D. W. Wester, and C. D. Gutsche, Decomposition Pathways for the Savannah River Site Caustic-Side Solvent Extraction System, PNNL-13935, Pacific Northwest National Laboratory, Richland, Washington, July 2002.

47. P. V. Bonnesen, F. V. Sloop, Jr., and N. L. Engle, Stability of the Caustic-Side Solvent Extraction (CSSX) Process Solvent: Effect of High Nitrite on Solvent Nitration, ORNL/TM-2002/115, Oak Ridge National Laboratory, Oak Ridge, Tennessee, July 2002.

48. M. P. Maskarinec, Analysis of a Sample of the Solvent Used in the Argonne National Laboratory Multiday Flowsheet Test, CERS/SR/SX/027, Rev. 0, Chemical Sciences Division and Nuclear Science and Technology Division, Oak Ridge National Laboratory, Oak Ridge, Tennessee, February 19, 2002.

49. S. L. Crump, M. A. Norato, R. A. Pierce, R. J. Ray, D. D. Walker, and T. L. White, Demonstration of Caustic-Side Solvent Extraction with Savannah River Site High-Level Waste: Results of Organic and Trace Component Analyses, WSRC-TR-2001-00372, Rev. 0, Westinghouse Savannah River Company, Aiken, South Carolina, December 7, 2001.

50. B. Grinbaum and L. Kogan, "Verification of a Process in a Demonstration Plant: How Long Does it Take to Find All the Problems?" Proc. Internat. Solvent Extraction Conf. (ISEC 2002), Cape Town, South Africa, Mar. 17-21, 2002, K. C. Sole P. M. Cole, J. S. Preston, D. J. Robinson, Eds., Chris van Rensburg Publications, Melville, South Africa, 2002; Vol. 2, pp. 1408-1413. 



\section{Appendix A}

PREDICTED $D_{\mathrm{Cs}}$ VALUES USING THE log VERSUS log RELATIONSHIPS BETWEEN $D_{\mathrm{Cs}}$ VALUES AND BOBCalixC6 AND Cs-7SB MODIFIER CONCENTRATIONS

Table A.1. Predicted $D_{\mathrm{Cs}}$ values

\begin{tabular}{|c|c|c|c|}
\hline \multirow[b]{2}{*}{ Process step } & \multicolumn{3}{|c|}{$D_{\mathrm{Cs}}$} \\
\hline & {$[\mathrm{Cs}-7 \mathrm{SB}]=0.70 \mathrm{M}$} & {$[\mathrm{Cs}-7 \mathrm{SB}]=0.75 \mathrm{M}$} & {$[\mathrm{Cs}-7 \mathrm{SB}]=0.80 \mathrm{M}$} \\
\hline & \multicolumn{3}{|c|}{$[$ BOBCalixC6] $=6.5 \mathrm{mM}$} \\
\hline Extraction & 12.76 & 13.08 & 13.40 \\
\hline Scrub no. 1 & 1.16 & 1.22 & 1.28 \\
\hline Scrub no. 2 & 1.21 & 1.26 & 1.31 \\
\hline Strip no. 1 & 0.91 & 0.096 & 0.101 \\
\hline Strip no. 2 & 0.054 & 0.057 & 0.059 \\
\hline Strip no. 3 & 0.043 & 0.045 & 0.047 \\
\hline \multirow[t]{2}{*}{ Strip no. 4} & 0.037 & 0.039 & 0.041 \\
\hline & \multicolumn{3}{|c|}{$[$ BOBCalixC6 $]=7.0 \mathrm{mM}$} \\
\hline Extraction & 13.77 & 14.13 & 14.48 \\
\hline Scrub no. 1 & 1.26 & 1.32 & 1.38 \\
\hline Scrub no. 2 & 1.30 & 1.35 & 1.40 \\
\hline Strip no. 1 & 0.099 & 0.104 & 0.109 \\
\hline Strip no. 2 & 0.059 & 0.062 & 0.065 \\
\hline Strip no. 3 & 0.047 & 0.049 & 0.051 \\
\hline \multirow[t]{2}{*}{ Strip no. 4} & 0.040 & 0.043 & 0.045 \\
\hline & \multicolumn{3}{|c|}{$[$ BOBCalixC6] $=7.5 \mathrm{mM}$} \\
\hline Extraction & 14.78 & 15.18 & 15.56 \\
\hline Scrub no. 1 & 1.35 & 1.42 & 1.49 \\
\hline Scrub no. 2 & 1.39 & 1.45 & 1.50 \\
\hline Strip no. 1 & 0.106 & 0.112 & 0.117 \\
\hline Strip no. 2 & 0.060 & 0.070 & 0.070 \\
\hline Strip no. 3 & 0.051 & 0.053 & 0.055 \\
\hline Strip no. 4 & 0.044 & 0.046 & 0.048 \\
\hline
\end{tabular}





\section{INTERNAL DISTRIBUTION}

1. J. F. Birdwell, Jr.

2. P. V. Bonnesen

3. J. L. Collins

4. R. L. Cummins

5-7. L. H. Delmau

8. R. D. Hunt

9-10. T. J. Keever

11. D. D. Lee

12. M. P. Maskarinec

13. A. J. Mattus

14. C. P. McGinnis

15-16. B. A. Moyer

17. F. V. Sloop, Jr.

18. R. D. Spence

19. J. F. Walker, Jr.

20. J. S. Watson

21. ORNL Central Research Library

22. Laboratory Records, RC

23. Laboratory Records, OSTI

\section{EXTERNAL DISTRIBUTION}

24. J. T. Carter, Westinghouse Savannah River Company, P.O. Box 616, Building 766-H, Aiken, SC 29808

25. D. Chamberlain, Argonne National Laboratory, Building 205, 9700 South Cass Avenue, Argonne, IL 60439

26. N. F. Chapman, Westinghouse Savannah River Company, P.O. Box 616, Building 704-3N, Aiken, SC 29808

27. W. D. Clark, U.S. Department of Energy, Savannah River Operations Office, Bldg. 704-3N, Aiken, SC 29808

28. C. Conner, Argonne National Laboratory, Building 205, 9700 South Cass Avenue, Argonne, IL 60439 
29. R. G. Edwards, Westinghouse Savannah River Company, P.O. Box 616, Building 704-3N, Aiken, SC 29808

30. S. D. Fink, Westinghouse Savannah River Company, P.O. Box 616, Building 773-A, Aiken, SC 29808

31. H. D. Harmon, Tank Focus Area Salt Processing Program, P.O. Box 616, Building 704-3N, Aiken, SC 29808

32. R. T. Jones, Westinghouse Savannah River Company, P.O. Box 616, Building 704-3N, Aiken, SC 29808

33. L. N. Klatt, 111 Carnegie Drive, Oak Ridge, TN 37830

34. R. A. Leonard, 224 Franklin Ave, River Forest, IL 60305

35. T. G. Levitskaia, Pacific Northwest National Laboratory, P.O. Box 999; MSIN P7-22, Richland, WA 99352

36. J. R. Noble-Dial, U.S. Department of Energy, Oak Ridge Operations Office, P.O. Box 2001, Oak Ridge, TN 37831-8620

37. M. Norato, Westinghouse Savannah River Company, P.O. Box 616, Building 773-A, Aiken, SC 29808

38. R. Pierce, Westinghouse Savannah River Company, P.O. Box 616, Building 773-A, Aiken, SC 29808

39. S. N. Schlahta, Battelle, Pacific Northwest National Lab, P.O. Box 999 / MS K9-14 Richland, WA 99352

40. P. C. Suggs, U.S. Department of Energy, Savannah River Operations Office, P.O. Box A, Building 704-3N, Aiken, SC 29808

41. W. L. Tamosaitis, Westinghouse Savannah River Company, P.O. Box 616, Building 773-A, Aiken, SC 29808

42. M. C. Thompson, Westinghouse Savannah River Company, P.O. Box 616, Building 773-A, Aiken, SC 29808 
43. T. A. Todd, Idaho National Engineering \& Environmental Laboratory, Building 637, MS-5218, Idaho Falls, ID 834415-5218

44. G. F. Vandegrift, Argonne National Laboratory, Building 205, 9700 South Cass Avenue, Argonne, IL 60439

45. D. D. Walker, Westinghouse Savannah River Company, P.O. Box 616, Building 773-A, Aiken, SC 29808

46. D. Wester, Battelle, Pacific Northwest National Lab, P.O. Box 999 / MS K8-93 Richland, WA 99352

47. Vickie Wheeler, U.S. Department of Energy, Savannah River Operations Office, P.O. Box A, Building 776-H, Aiken, SC 29808

48. W. R. Wilmarth, Westinghouse Savannah River Company, P.O. Box 616, Building 773-A, Aiken, SC 29808

49. Tanks Focus Area Technical Team, c/o B. J. Williams, Pacific Northwest National Laboratory, P.O. Box 999, MSIN K9-69, Richland, WA 99352

50. Tanks Focus Area Field Lead, c/o T. P. Pietrok, U.S. Department of Energy, Richland Operations Office, P.O. Box 550, K8-50, Richland, WA 99352

51. Tanks Focus Area Headquarters Program Manager, c/o K. D. Gerdes, DOE Office of Science and Technology, 19901 Germantown Rd., 1154 Cloverleaf Building, Germantown, MD 20874-1290

49. Nicole Simon and Jean-François Dozol, CEA Cadarache, DESD/SEP/LPTE, Bat.326, 13108 St Paul lez Durance Cedex, France

50. Charles Madic, CEA Valrhô-Marcoule, DCC, BP 171, 30207 Bagnols s/Ceze Cedex, France 